\title{
An Examination of Cardiovascular Health among Afro-Caribbean Immigrants in New York City
}

\author{
Sabena C Thomas
}

Follow this and additional works at: https://researchrepository.wvu.edu/etd

\section{Recommended Citation}

Thomas, Sabena C, "An Examination of Cardiovascular Health among Afro-Caribbean Immigrants in New York City" (2018). Graduate Theses, Dissertations, and Problem Reports. 7265.

https://researchrepository.wvu.edu/etd/7265

This Dissertation is protected by copyright and/or related rights. It has been brought to you by the The Research Repository @ WVU with permission from the rights-holder(s). You are free to use this Dissertation in any way that is permitted by the copyright and related rights legislation that applies to your use. For other uses you must obtain permission from the rights-holder(s) directly, unless additional rights are indicated by a Creative Commons license in the record and/ or on the work itself. This Dissertation has been accepted for inclusion in WVU Graduate Theses, Dissertations, and Problem Reports collection by an authorized administrator of The Research Repository @ WVU.

For more information, please contact researchrepository@mail.wvu.edu. 


\title{
An Examination of Cardiovascular Health among Afro-Caribbean Immigrants in New York City \\ Sabena C. Thomas
}

\author{
Submitted to \\ the School of Public Health \\ West Virginia University

\begin{abstract}
in partial fulfillment of the requirements for the degree of
Doctor of Philosophy in

Social and Behavioral Sciences
\end{abstract} \\ Christiaan Abildso Ph.D., MPH Chair \\ Tom Bias, Ph.D. \\ Danielle Davidov, Ph.D., MPH \\ Yvonne Commodore-Mensah, Ph.D. \\ Amna Umer, Ph.D. \\ Department of Social and Behavioral Sciences
}

Morgantown, West Virginia

2018

Keywords: cardiovascular health, Afro-Caribbean, immigrant health, acculturation Copyright 2018 Sabena C. Thomas 


\section{ABSTRACT \\ An Examination of Cardiovascular Health among Afro-Caribbean Immigrants in New
York City}

Sabena C. Thomas

Introduction: Non-Hispanic blacks (NHB) have the highest prevalence rates of cardiovascular disease (CVD) in the United States (U.S.). Afro-Caribbean (AC) immigrants represent the largest black immigrant group in the U.S. and often exhibit better health in comparison to U.S. born blacks. However, AC immigrants are underrepresented in cardiovascular health $(\mathrm{CVH})$ research. The limited research on AC immigrants tend to examine AC immigrants as a monolithic group. Country of birth differences is understudied. The purpose of this study is to conduct a population based examination of CVH among AC immigrants disaggregated by country of birth. The aims of this study were to 1) estimate and compare the prevalence of CVD risk factors among Guyanese, Haitian and Jamaican immigrants relative to U.S. born blacks 2) examine the relationship between acculturation (length of residence) and CVH among the Guyanese, Haitian and Jamaican immigrants and 3) assess the relationship between social determinants of health (education, employment, health access and health insurance) and CVH among the aforementioned AC immigrant sub-groups.

Methods: The study used cross-sectional data from the New York City Department of Health and Mental Hygiene Community Health Survey (NYC DOHMH CHS) combined years 2010-2014. The sampling frame included U.S. born blacks $(n=5,987)$ Guyanese $(n=369)$ Haitian $(n=291)$ and Jamaican $(n=1,031)$ black immigrants. The outcome variables for the first study included cardiovascular health (CVH) factors (diabetes mellitus [DM], hypercholesterolemia, hypertension and overweight/obesity). For the second and third study, a CVH score was created that incorporated seven health metrics (fasting glucose, total cholesterol, blood pressure, body mass index [BMI], physical activity, diet and smoking status) as per AHA's definition, but adapted based on CHS items. CVH scores were categorized into intermediate/poor CVH (0-3 components) or ideal CVH ( $\geq 4$ components). Multiple Logistic Regression (MLR) analyses were used to determine the associations between country of birth and CVH factors (DM, hypercholesterolemia, hypertension and overweight/obesity) for the first aim. MLR analysis were also used to determine the association between acculturation (length of residence in the U.S.), social determinants of health and $\mathrm{CVH}$ for the second and third aims, respectively.

Results: In regards to aim 1, relative to U.S. born blacks, Jamaican immigrants were more likely to selfreport diabetes $(\mathrm{OR}=1.45 ; 95 \% \mathrm{CI}=1.08-1.93)$ but less likely to be overweight/obese $(\mathrm{OR}=0.72 ; 95 \%$ $\mathrm{CI}=0.58-0.88)$. Guyanese immigrants were also less likely to be overweight/obese $(\mathrm{OR}=0.65 ; 95 \% \mathrm{CI}=$ 0.47-0.89) than U.S. born blacks. Haitian immigrants showed no significant differences from U.S. born blacks. Analyses for the second aim revealed that AC immigrants residing in the U.S. for $\geq 10$ years had greater odds of intermediate/poor CVH than those living in the U.S. for $<10$ years among Guyanese (OR $=3.51 ; 95 \% \mathrm{CI}=1.03-11.95)$ and Haitian immigrants $(\mathrm{OR}=8.02 ; 95 \% \mathrm{CI}=1.88-34.12)$. Among Jamaican immigrants, length of residence was not significantly associated with CVH. The findings of the third aim revealed education and employment were significantly associated with poor/intermediate CVH among Jamaican immigrants only. Significant association only remained for education after adjusting for relevant covariates $(\mathrm{OR}=1.69 ; 95 \% \mathrm{CI}=1.10-2.60)$. Education, employment, insurance and health care access were not associated with CVH among Guyanese and Haitian immigrants.

Conclusions: Ethnic heterogeneity in $\mathrm{CVH}$ was found among the three sub-groups examined in this study. In regards to risk factors for CVD, Jamaican immigrants had significantly greater risk of reporting diabetes than their U.S.-born counterparts. Length of stay in the U.S. was associated with CVH for 
Guyanese and Haitian immigrants only. Social determinants associated with poor/intermediate CVH were only found among Jamaicans. The study highlights the importance of examining country of birth differences in an immigrant population usually grouped together with other racial/ethnic or pan-regional groups. Health research efforts should include national surveillance that adds detail in oversampling racial/ethnic minority groups to correctly estimate their $\mathrm{CVH}$ outcomes. Future studies should replicate this study among nationally representative samples of AC immigrants. 


\section{DEDICATION}

This dissertation is dedicated my late grandmother, who passed away a few weeks before my departure to the United States to embark on my educational pursuits. Your physical and spiritual guidance enabled me to stand in the face of adversity. Your last message to me "God will take care of you" kept me throughout this whole journey. You inspire me more than you will ever know.

\section{ACKNOWLEDGEMENTS}

I would like to give thanks to God, my creator, the only constant in my life who has blessed me with every spiritual blessing in heavenly realms. Father, I thank you. You remained faithful to me throughout this process. I am in awe of your goodness over my life. Be exalted now and forever.

I would like to extend heartfelt gratitude to my immediate and extended family for all their love support, prayers and encouragements. I am most grateful for my sister Patricia, I would not have made it to this point without your love, support and guidance. It would have been very difficult for me to complete this task without the prayers and support of my best friends: Alicia, Antoinette, Diane and Jaydeen. Thank you all. I would also like to acknowledge the members of the Redeemed Christian Church of God (RCCG), Morgantown West Virginia. You all have been an immense blessing to me on this journey.

I am eternally thankful to my dissertation advisor Dr. Christiaan Abildso, I am grateful for your numerous professional advice, academic guidance and patience. I aspire to your level of patience and humility one day. Thank you for always providing detailed and timely feedback. I am grateful you came on this journey with me, and I would choose you all over again. Thank you for investing your time and supporting me throughout the best and worst moments of this journey. God bless you and yours.

I would like to convey my sincere gratitude to Dr. Yvonne Commodore-Mensah; I cannot thank you enough for being a part of this project. From our very first encounter, you have been nothing short of supportive. Thank you for extending yourself to assist me. Thanks for all the effort, time, guidance and feedback you have given me. You are an inspiration in so many ways. I would also like to thank my committee members Dr. Thomas Bias, Dr. Danielle Davidov and Dr. Amna Umer. Thank you for your time, support and guidance throughout this process. 
I would especially like to thank Dr. Michael Mann, who went beyond his call of duty to create an inclusive and supportive environment in the West Virginia University (WVU) where I felt welcomed and appreciated. Thank you for your mentorship. Special thanks to Dr. Romi Gomez and Dr. Alfgier Kristjansson, your support throughout my tenure at WVU means a lot to me. To my fellow doctoral colleagues that I met on this journey, your support was more than I could ask for. Thank you.

I would also like to thank the staff members of the New York City Department of Health and Mental Hygiene for providing the data for this project. Special mention goes to Nneka Lundy De La Cruz for conducting all the data checks. Dr. Amber Levanon Seligson thank you for your excellent and seamless service. Thank you for providing timely responses to all my queries, challenges and data concerns. I am grateful for the work done by you and your team; this dissertation would not be possible without you. Special thanks to the WVU information technology team. Thank you for all your assistance with the data storage. Finally, I would also like to thank the entire WVU School of Public Health faculty and staff for their support throughout my doctoral studies. I am eternally grateful. 


\section{Table of Contents}

\section{Table of Contents}

ABSTRACT

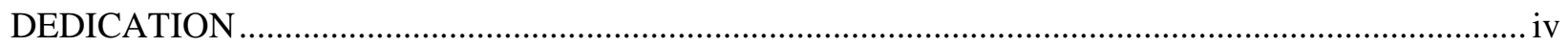

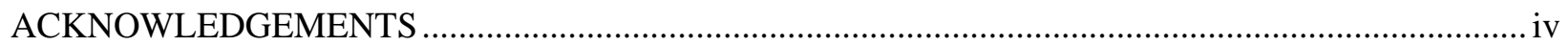

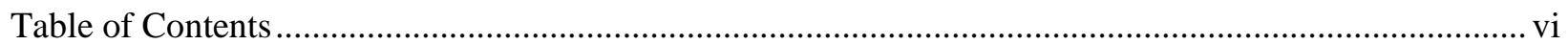

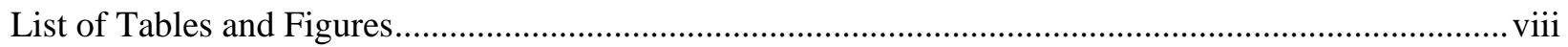

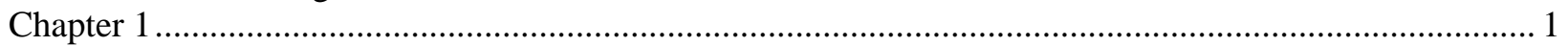

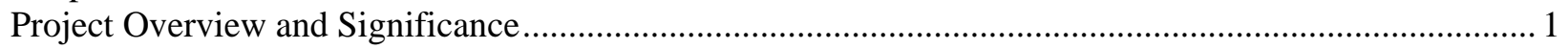

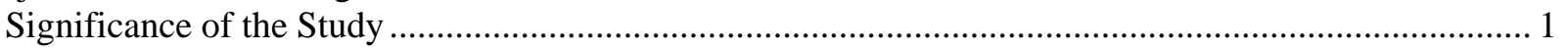

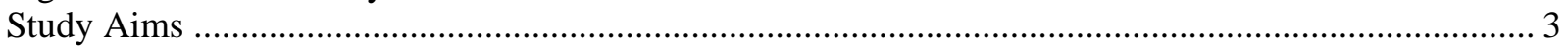

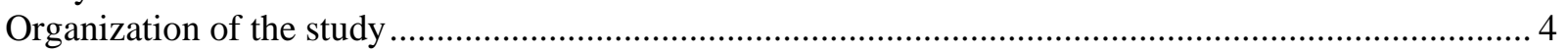

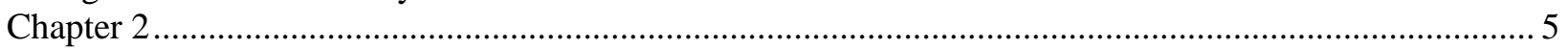

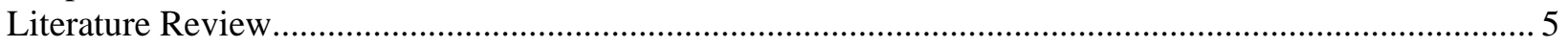

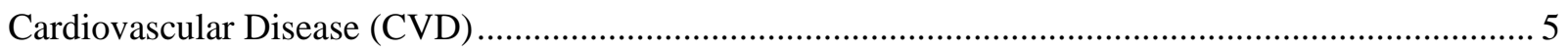

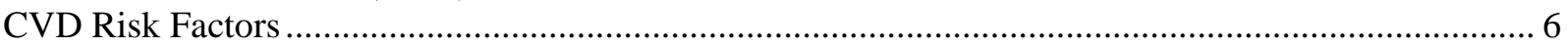

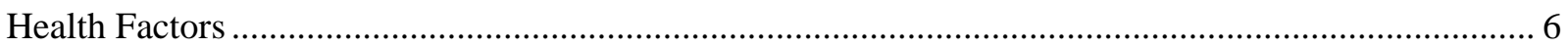

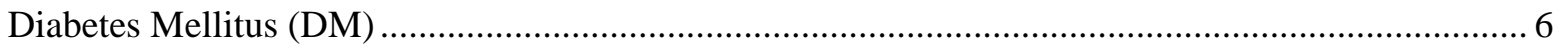

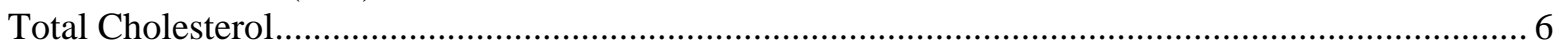

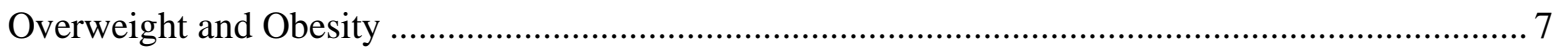

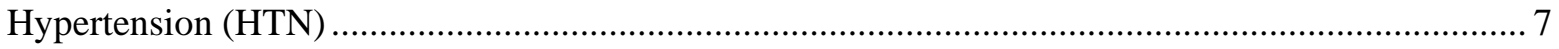

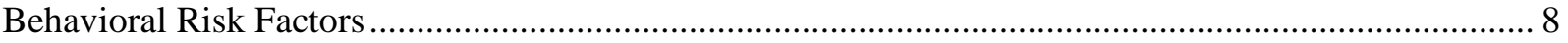

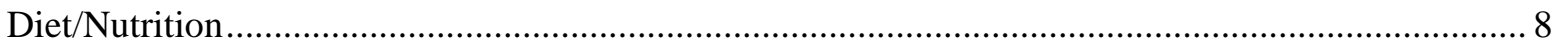

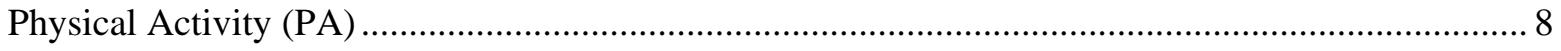

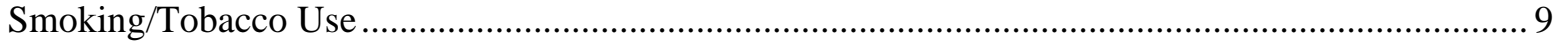

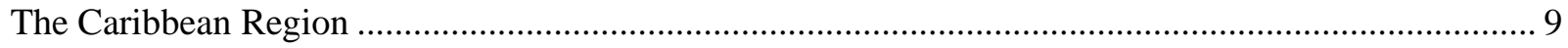

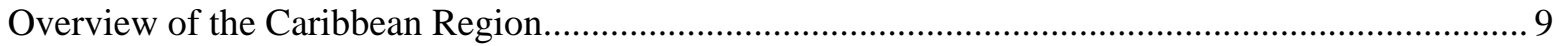

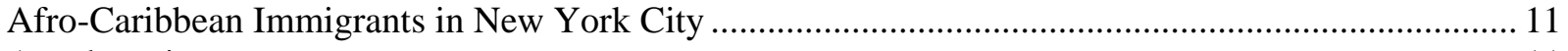

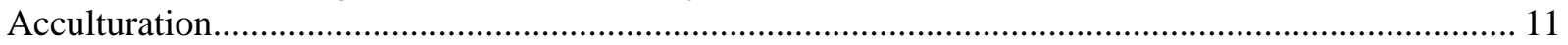

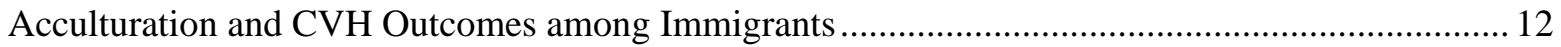

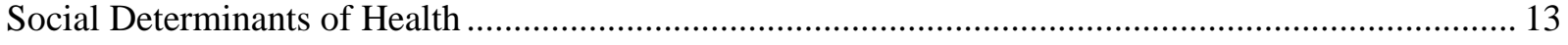

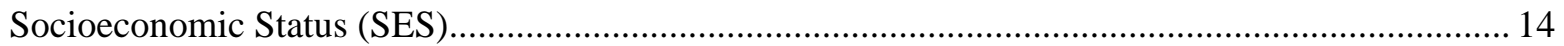

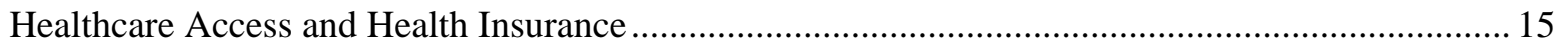

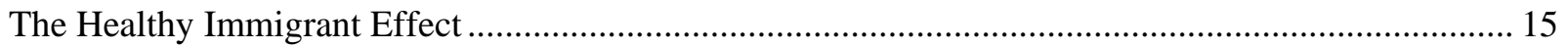

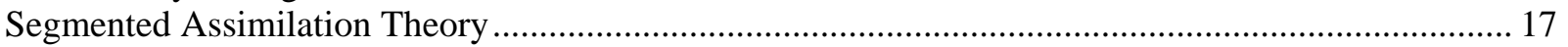

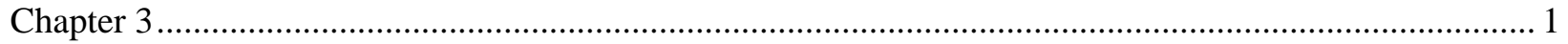

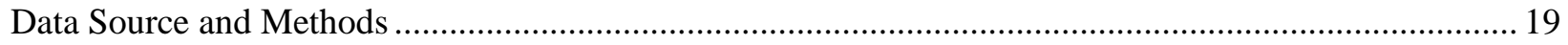

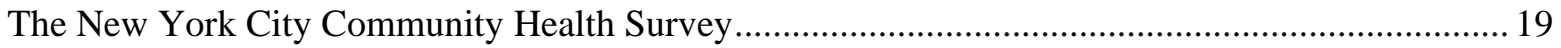

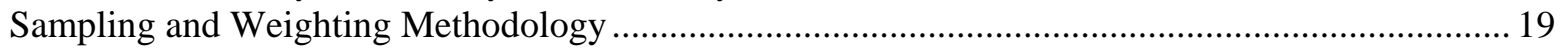

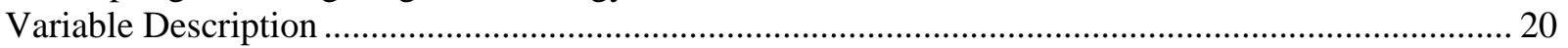

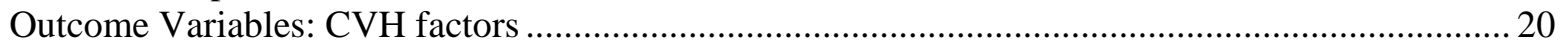

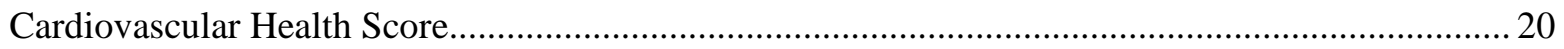

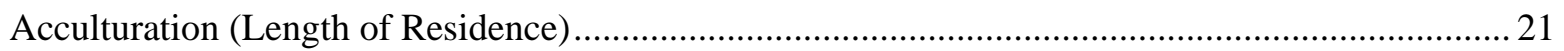

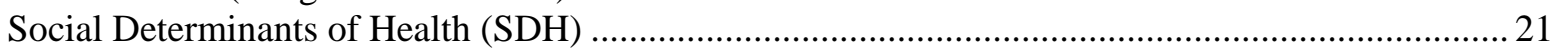

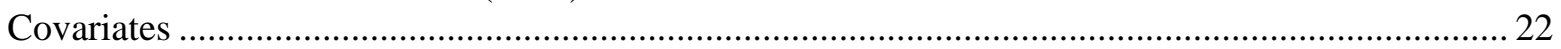

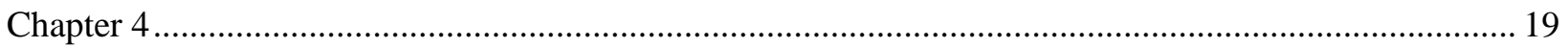

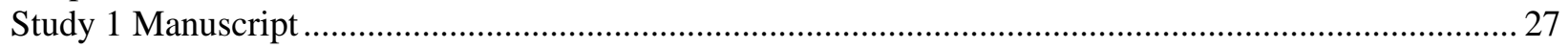




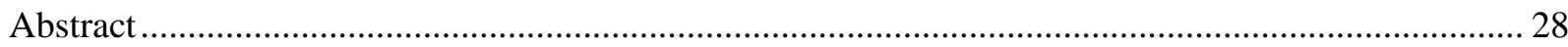

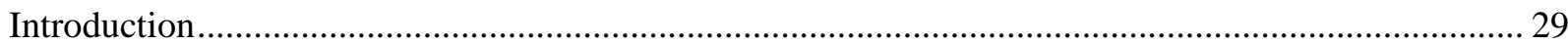

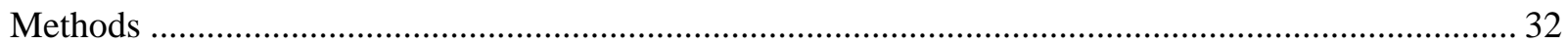

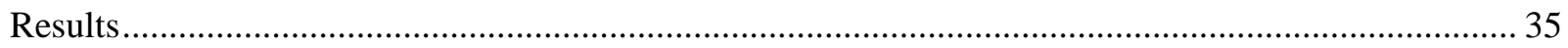

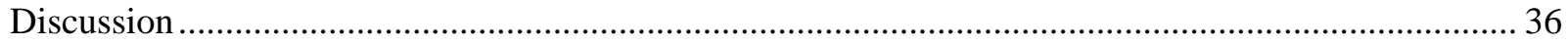

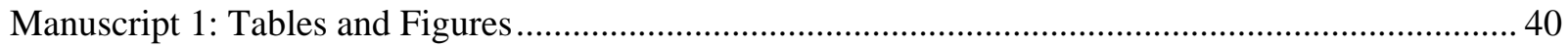

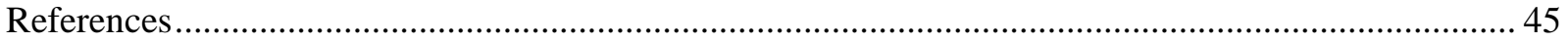

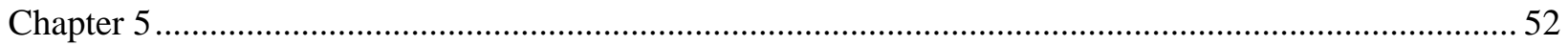

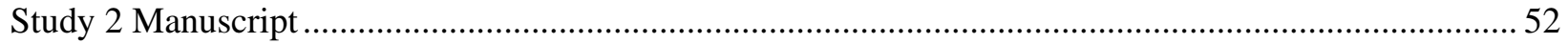

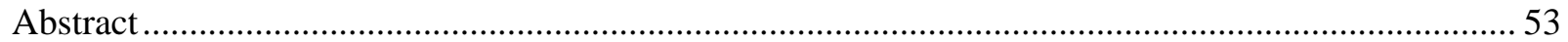

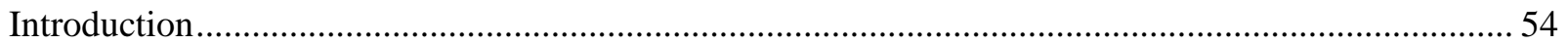

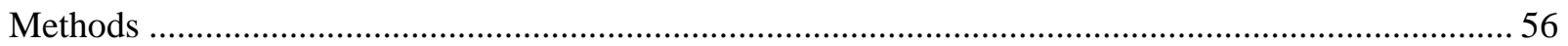

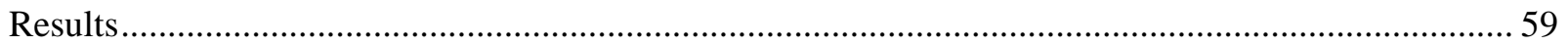

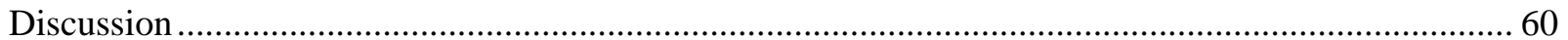

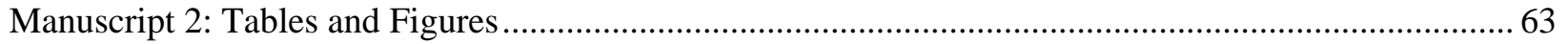

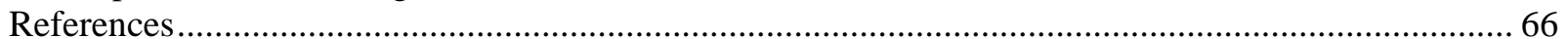

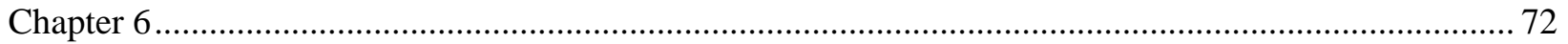

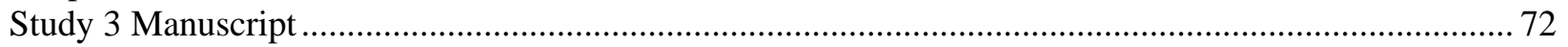

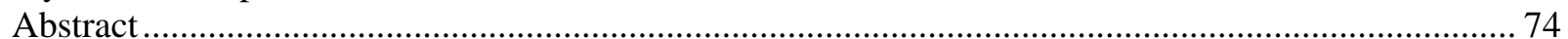

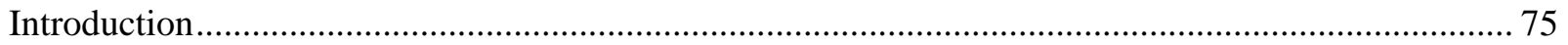

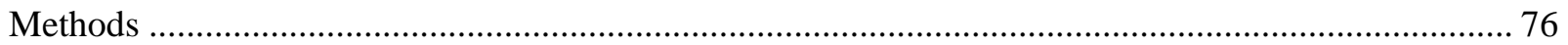

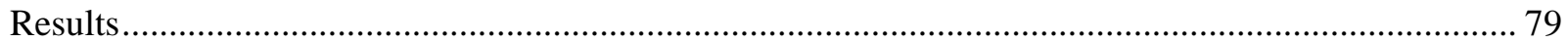

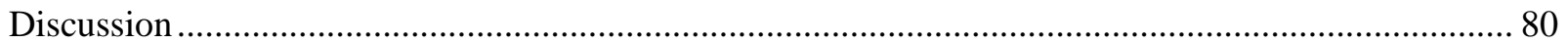

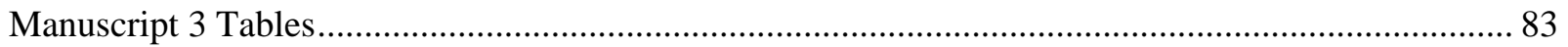

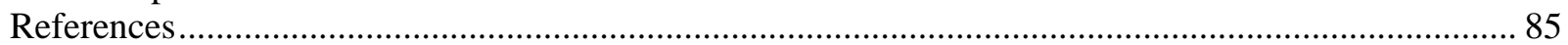

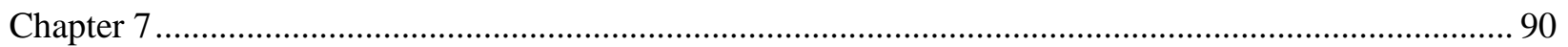

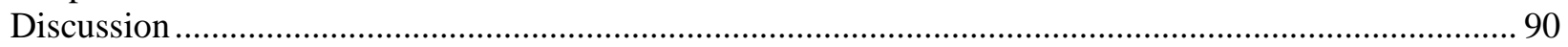

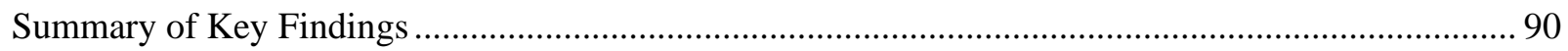

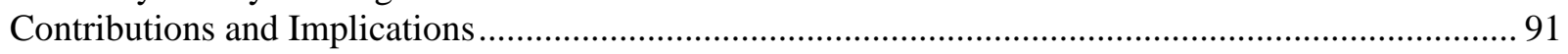

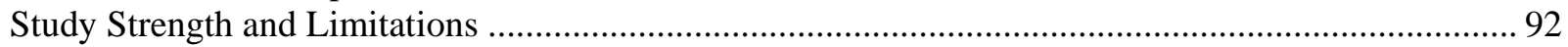

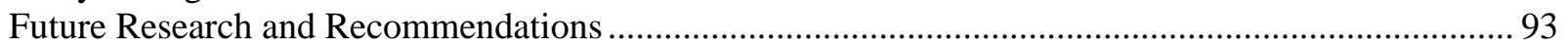

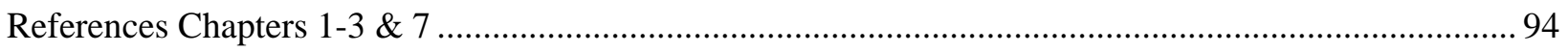




\section{List of Tables and Figures}

\section{Description}

Chapter 3.

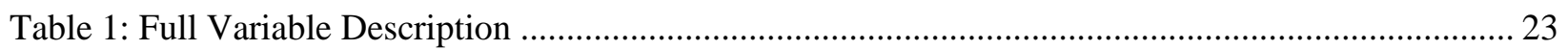

CHS 2010-2014 Questions and Definitions for classification of "Ideal" CVH for the Seven Metrics....... 26

Chapter 4: Manuscript 1

Table 1: Sample Characteristics by Country of Birth of non-Hispanic Blacks, New York City Community Health Survey, 2010-2014 .... 40

Table 2: Cardiovascular Health Factors for non-Hispanic Blacks by Country of Birth, New York City Community Health Survey, 2010-2014

Table 3: Unadjusted and Adjusted Odds Ratios (95\% CI) for CV Health Factors by Country of Birth, New York City Community Health Survey, 2010-2014.

Figure 1: Health Behaviors by Country of Birth for Non-Hispanic Blacks, New York City Community Health Survey, 2010-2014 ......

Chapter 5: Manuscript 2

Table 1. Descriptive Characteristics by Country of Birth among Afro-Caribbean Adult Immigrants, New York City Community Health Survey, 2010-2014. Weighted \% (95\% CI)

Table 2: Logistic Regression Analyses of the Association between Length of Residence and Poor/ Cardiovascular Health, among Afro-Caribbean Adult Immigrants, New York City Community Health Survey, 2010-2014

Figure 1: Prevalence of Ideal and Intermediate/Poor Cardiovascular Health Score by Country of Birth of Afro-Caribbean Adult Immigrants in New York City Community Health Survey, 2010-2014.

Chapter 6: Manuscript 3

Table 1: Descriptive characteristics of Afro-Caribbean Adult Immigrants by Country of Birth, New York City Community Health Survey, 2010-2014. Weighted\% (95\% CI).

Table 2: Association between Social Determinants of Health and Poor/Intermediate Cardiovascular Health by Country of Birth among Afro-Caribbean Adult Immigrants, New York City Community Health Survey, 2010-2014 ( $=1691)$ 


\section{Chapter 1}

\section{Project Overview and Significance}

Cardiovascular Diseases (CVDs) are the leading causes of death among adult populations globally and in the United States (U.S.) [1]. Racial/ethnic disparities in the prevalence of CVD exist; non-Hispanic blacks (NHB) have higher prevalence rates of CVDs than non-Hispanic whites [2]. The American Heart Association (AHA), as part of its 2020 Strategic Goals, is leading the effort to eliminate racial/ethnic disparities in CVD. In keeping with this goal, the AHA developed a comprehensive measure of cardiovascular health (CVH) that includes seven metrics: current smoking, Body mass index (BMI), physical activity, healthy diet score, total cholesterol, blood pressure and fasting plasma glucose (diabetes mellitus) [3]. Notably, NHBs have poorer CVH across almost all seven of these metrics compared to nonHispanic whites [2].

NHBs/African Americans (AAs) in the U.S. are a heterogeneous group consisting of U.S. born blacks, sub-Saharan Africans and African Caribbean immigrants (AC immigrants) [4]. Significant heterogeneities exist among AC immigrants and U.S. born blacks in regards to migratory patterns, beliefs, diet, linguistic, ethnic, cultural and national identities [5-7]. These factors are also likely to impact health [8]. AfroCaribbean migration to the U.S. is characterized by a new minority status ${ }^{1}$ that may induce additional stressors and barriers related to healthcare possibly influencing access to care and overall health [9-11]. Additionally, in comparison to AAs, AC immigrants may be more likely to adhere to deep cultural beliefs that may deny diagnosis or delay care. For example, many AC immigrants hold onto superstitions that dictate prayers, religion, traditional foods and medicine as an important part of healing and symptom relief [12-15]. There has been a growing body of work examining the health of U.S. born blacks separate from AC immigrants [11, 16-19].

\section{Significance of the Study}

\footnotetext{
${ }^{1}$ Afro-Caribbean immigrants migrate from societies with predominantly black populations upon migration they are considered minorities in the U.S.
} 
Researchers have identified that AC immigrants have relatively good physical health in comparison to U.S. born blacks [11, 18-20]. However, these studies examined AC immigrants as a uniform group rather than by country of birth and do not focus on CVH outcomes. AC immigrants comprise over fifty percent of the black immigrant population [21] but are not a monolithic group. They may differ substantially based on country of origin regarding language, political and social backgrounds, migration patterns and levels of assimilation and acculturation which may influence different health outcomes [8, 22, 23]. Although several studies have compared cardiovascular outcomes between Caribbean blacks and U.S. born blacks [16, 17, 24, 25], to the best of our knowledge, a comparison among AC immigrant subgroups by country of birth has not been conducted. Further, data used to conduct previous studies among AC immigrants are outdated and may no longer reflect the current state of CVH among AC immigrants in the U.S. [11, 16, 17, 19, 20, 24]. Additionally, evidence from the Caribbean indicates an increasing trend in CVD and risk factors in some countries [26, 27]. Research is therefore needed to provide insight into the current state of CVH among AC immigrants in the U.S.

Pertinent to immigrant health studies is the concept of acculturation. Broadly defined, "acculturation” is described as cultural changes that can occur when individuals of different cultures come into continuous first-hand contact $[28,29]$. A plethora of studies on immigrant health in the U.S. have found that acculturation influences immigrant health outcomes [30-36]. Acculturation has been shown to be a protective or risk factor for health outcomes depending on the immigrant group under study and the health outcomes. However, most studies conducted among racial/ethnic groups focus on Hispanic or Asian - and to a lesser extent African - immigrants [31, 37-41]. Given that social factors such as assimilation and health selection may vary across immigrant groups, the effects of acculturation may also vary. Therefore, examining how social factors such as acculturation impact AC immigrant health is critical in understanding the health trajectories of blacks in the U.S.

The AHA has emphasized the role of social determinants in eliminating CVH disparities [42]. Social determinants of health (SDH) such as education, employment, health insurance and healthcare access are 
underexplored among AC immigrants. As described prior, AC immigrants may differ in regard to social experiences based on country of origin that may be exacerbated by "positive selection" in the immigration process on social factors that may benefit health [43]. The segmented assimilation theory also contends that immigrant groups display different social and human capital that allows diverging paths of assimilation in the U.S. society, hence providing a potential explanation to differential health outcomes. These potential explanatory theories are fully discussed in Chapter 2. Given the heterogeneity that exists among AC immigrants regarding social experiences from different regions of origin [8, 22], a separate analysis of SDH by country of birth is warranted.

\section{Study Aims}

In light of the research gaps identified above the following aims will be explored in this dissertation:

Aim 1: Estimate and compare the prevalence of CVH factors between three prominent AC sub-groups (Guyanese, Haitian and Jamaican immigrants) relative to U.S. born blacks in NYC.

Aim 2: Examine the relationship between acculturation (length of residence in the U.S.) and CVH among Guyanese, Haitian and Jamaican AC immigrants in NYC.

Hypothesis (Aim 2): It is hypothesized that AC immigrants with greater length of residence ( $\geq 10$ years) will have a higher prevalence of intermediate/poor CVH than those who have resided in the U.S. for a shorter duration ( $<10$ years).

Aim 3: Examine the social determinants (education, employment, health insurance and healthcare access) associated with CVH among AC immigrants (Guyanese, Haitian and Jamaican) in NYC.

Hypothesis (Aim 3): It is hypothesized that AC immigrants with lower levels of education and employment will have a higher prevalence of intermediate/poor CVH. Also AC immigrants without health insurance and healthcare access are expected to have a higher prevalence of intermediate/poor CVH. 


\section{Organization of the study}

The following sections of this dissertation include: Chapter 2- a review of related concepts and literature;

Chapter 3- a full description of the methods; Chapters 4, 5 and 6 which include manuscripts 1-3,

respectively and Chapter 7- a summary of overall findings, discussion and future research and recommendations. 


\section{Chapter 2}

\section{Cardiovascular Disease (CVD)}

\section{Literature Review}

Cardiovascular diseases (CVDs) are vascular disorders affecting the heart, brain and diseases of the blood vessels; these include coronary heart disease, cerebrovascular and rheumatic heart diseases [44]. CVDs are the leading causes of death worldwide, accounting for 32\% (17.3 million) of all deaths globally in 2013 - an increase from 12.3 million in 1999 [1]. In the United States (U.S.), approximately one in every three deaths is attributable to CVDs [2]. In 2015, there were an estimated 102.7 million adults (41.5\%) with at least one form of CVD [45]. It is also projected that by 2035, approximately half of the U.S. population will have some form of CVD, increasing the estimated economic burden of CVDs from $\$ 555$ billion (direct and indirect cost) in 2016 to $\$ 1.1$ trillion (direct and indirect costs) in 2035 [45]. In the U.S., racial and ethnic minority groups are disproportionately affected by CVDs and known risk factors. More specifically, non-Hispanic blacks or African Americans (AAs) have the highest rates of hypertension, stroke and diabetes compared to all other ethnic groups [46]. By 2035, it is projected that non-Hispanic blacks will have the highest rates of CVDs in relation to other races [45].

According to the American Heart Association (AHA) ideal cardiovascular health is defined as a combination of four favorable health factors and three favorable health behaviors [3].

The four favorable health factors:

1. absence of diabetes mellitus

2. untreated total cholesterol $<200 \mathrm{mg} / \mathrm{dl}$

3. ideal body mass index (BMI; $<25 \mathrm{~kg} / \mathrm{m}^{2}$ )

4. untreated high blood pressure $<120 /<80 \mathrm{~mm} \mathrm{Hg}$ 
The three favorable health behaviors include:

1. consumption of a dietary pattern that promotes $\mathrm{CVH}$

2. physical activity at goal

3. abstinence from smoking/tobacco use within the last year

\section{CVD Risk Factors}

\section{Health Factors}

The following is a summary of the cardiovascular risk factors established by the AHA. These risk factors and disparities experienced by non-Hispanic blacks in the U.S. will be the focus of this dissertation.

\section{Diabetes Mellitus (DM)}

Diabetes is a group of metabolic diseases caused by an abnormally high blood glucose level resulting from insufficient insulin secretion [47]. Diabetes mellitus is clinically defined as having a fasting glucose level of $\geq 126 \mathrm{mg} / \mathrm{dl}$ or hemoglobin A1C levels of $\geq 6.5 \%[3,47]$. Diabetes may result in vital organ failure such as: heart, eyes, kidneys and blood vessels [47]. The known risk factors for diabetes complications are smoking, overweight and obesity, physical inactivity, high blood pressure, high cholesterol and hyperglycemia (high blood glucose) [48]. Diabetes is the seventh leading cause of death in the U.S. In 2015, there was an estimated 30.3 million or $9.4 \%$ of the population affected by diabetes [47]. The cost (direct and indirect) of diagnosed diabetes in the 2012 was $\$ 245$ billion [49]. Non-Hispanic

blacks have a prevalence rate of $13.4 \%$, the highest among all racial/ethnic groups, followed by Hispanics and non-Hispanic Asians [48].

Total Cholesterol 
Total cholesterol is comprised of good cholesterol (high-density lipoprotein; HDL) and bad cholesterol (low-density lipoprotein; LDL). High total cholesterol is defined as having $\geq 190 \mathrm{mg} / \mathrm{dl}$ or $\geq 5.0 \mathrm{mmol} / \mathrm{L}$ of LDL which may lead to atherosclerosis and other forms of heart diseases [50]. From 2011-2014, prevalence rates for total cholesterol was approximately 94.6 million (39.7\%) for adults $\geq 20$ years [2]. Total cholesterol levels have shown a significant decrease in trend from $126.2 \mathrm{mg} / \mathrm{dl}$ from 1999-2000 to 111.3 mg/dl in 2013-2014 [2]. Among racial/ethnic groups Mexican Americans have the highest mean serum total cholesterol levels (196 mg/dl) and non-Hispanic blacks have the lowest (189 mg/dl) [2].

\section{Overweight and Obesity}

Body Mass Index (BMI) is one of the most common ways to assess overweight and obesity; it is defined by an individual's weight in kilograms relative to height in meters squared. In adults, overweight is classified as $25.0 \leq \mathrm{BMI}<30.0 \mathrm{~kg} / \mathrm{m}^{2}$, and obese is classified as BMI $\geq 30.0 \mathrm{~kg} / \mathrm{m}^{2}$ [51]. In adults, obesity is associated with conditions such as hypertension, high-cholesterol, diabetes mellitus, stroke and coronary heart disease [52]. According to National Center for Health Statistics (NCHS) data from 20112014, the prevalence of overweight among adults and youth was approximately 36.5\% from 2011-2014 [53]. Healthcare expenditure attributable to obesity was estimated at a mean annual per capita cost of $\$ 1,160$ for males and $\$ 1,525$ for females [53]. The highest rates of obesity were observed among nonHispanic blacks (48.1\%) [53].

\section{Hypertension (HTN)}

Hypertension (HTN) is characterized by the presence of consistent elevated blood pressure causing strain on the heart, weakening blood vessels and increased risk of cardiovascular diseases [54]. The AHA informed by results from the Systolic Blood Pressure Intervention Trial (SPRINT) noted that HTN is clinically defined as a systolic reading of $\leq 120 \mathrm{~mm} \mathrm{Hg}$ and a diastolic reading of $\geq 80 \mathrm{~mm} \mathrm{Hg}$ [2]. However, recent data from the said study support high blood pressure treatment in some individuals at $\leq 130 / 80 \mathrm{~mm} \mathrm{Hg}$ [55]. There were approximately 52.8\% of Americans $\geq 20$ years old affected by 
hypertension in 2014 [56], and 73,345 deaths attributable to hypertension [57]. The estimated direct and indirect cost of hypertension has increased from \$46 billion in 2011 [58] to \$51.2 billion in 2013 [2]. Among racial/ethnic groups, the prevalence rate among non-Hispanic blacks in the U.S. was among the highest in the world at $41.2 \%$ [59].

\section{Behavioral Risk Factors}

\section{Diet/Nutrition}

The AHA recognized several factors pertinent to an overall healthy dietary pattern; these include but are not limited to:

- Sugar-sweetened beverages: $\leq 450$ kilocals (kcals) (36 oz) per week

- sodium: $1500 \mathrm{mg}$ per day

- fruits and vegetables: $\geq 4.5$ cups per day

- fish: $\geq$ two $3.5 \mathrm{oz}$ serving per week [3]

Unhealthy diets can contribute to problems such as unhealthy weight, obesity, diabetes mellitus and cardiovascular diseases [60]. The proportion of adults achieving the AHA guidelines for total serving of fruits and vegetables remained between 4.9\% and 5.1\% from 2003-2012 [61]. The required sodium intake was exceeded for all racial/ethnic groups [62]. Non-Hispanic blacks and Mexican Americans had the lowest percentage of individuals meeting the recommended intake for fruits and vegetables and sugarsweetened beverages [2].

Physical Activity (PA)

Among the factors for ideal cardiovascular health is physical activity at goal. Physical activity encompasses four dimensions: mode, frequency, duration and intensity [2]. According to the 2008 PA Guidelines for Americans, the proportion of individuals meeting the PA guideline $(\geq 150$ minutes of moderate PA or 75 minutes of vigorous PA or an equivalent combination each week) was approximately 49.8\% [63]. PA reduces the risk of cardiovascular diseases, greater health benefits are expected to occur with increased frequency and duration of PA [3]. Approximately $30.4 \%$ of adults do not engage in any 
leisure time PA [2]. For racial/ethnic groups, non-Hispanic blacks and Hispanics have the highest rates of physical inactivity (39\% and 38\%, respectively) compared to non-Hispanic whites (27\%) [2].

\section{Smoking/Tobacco Use}

Tobacco use is a major risk factor for CVD. One of the seven components of ideal cardiovascular health for adults is never smoked or quit smoking within the last 12 months [3]. In 2015, the overall prevalence of smoking was $15.2 \%$ among adults in U.S., 13.7\% among women and 16.7\% among men [2]. Smoking was the second leading cause of death in 2010; consequently, deaths rates for smokers are three times higher than non-smokers $[63,64]$. Direct medical cost attributable to smoking was between $\$ 133-\$ 175$ billion and \$151 billion lost to productivity relating to premature death for the years 2005-2009 [65]. Racial/ethnic minority groups have the highest prevalence rates, more specifically American Indians (males: 25.8\%, females: 24.8\%) and non-Hispanic black males (20.9\%) [65].

As described prior, non-Hispanic blacks/AAs experience significant disparities relating to CVD risk factors. It is important to note that the racial category of black/AA is used in the U.S. to identify people of African descent, including American born blacks, Sub-Saharan Africans (except Sudanese and Cape Verdean) and AC immigrants [4]. AC immigrants are the largest black immigrant population in the U.S. and comprise about $54 \%$ of the total black immigrant population [21]. The term AC immigrant refers to individuals of African descent who migrated from their native Caribbean islands or West Indies [5]. The majority of Afro-Caribbean blacks are from non-Hispanic origins such as the Francophone (e.g., Guadeloupe, Martinique, Haiti) and Anglophone Caribbean (e.g., Barbados, Jamaica,Trinidad and Tobago). Conversely, the majority of Hispanic Caribbean blacks (e.g., Puerto Rico, Cuba, Dominican Republic) may not self-identify as blacks [66].

\section{The Caribbean Region}

Overview of the Caribbean Region 
Geographically, the Caribbean islands extend from the tip of Florida and encompass Cuba, Dominican Republic, Haiti, Jamaica and Puerto Rico. It also expands to the eastern islands of Trinidad and Tobago, Barbados, Grenada, St Vincent and the Grenadines, Dominica, Antigua and Barbuda. Guyana and Surinam are considered a part of the Caribbean because of their history, although geographically located in South America [5]. The Caribbean region has a rich racial/ethnic and cultural diversity. This racial/ethnic diversity of the Caribbean stems from the settlement of European colonialists (French, Spanish, Dutch and British) in the island nations, African enslaved peoples who came to the colonies and East Indian and Chinese indentured workers who came to the islands to work after the abolition of slavery [67].

ACs are a heterogeneous group made up of individuals from several Caribbean nations. These sub-groups may possess different languages, socio-economic backgrounds, levels of acculturation, racial contexts of origin and patterns of migration. They also possess differing socioeconomic, political and health structures in home countries, all of which may impact their health outcomes [8, 13, 22, 23]. For example, in the late twentieth Century, Haitian immigration to the U.S. was propelled by political unrest, poverty, economic depression and crime in their home country. Haitian immigrants to the U.S. were mainly political asylees and refugees $[68,69]$, suggesting that Haitian immigrants may not be positively selected on health. Positive selection is a process where better educated and skilled immigrants gain entry; in addition, immigration policies by host countries may subject immigrants to health screening which further improves the chances that these individuals are also better in health [70, 71]. Other major AC immigrant groups migrated in search of better economic opportunities, however, their migration patterns were mainly attributed to the 1986 Immigration Reform Control Act (IRCA) and family ties rather than refugees and political asylees [5, 21]. The 1986 IRCA provided legal residence to undocumented immigrants in the U.S.; Caribbean immigrants benefited largely from this venture [5]. These differences in migratory patterns may grant some AC immigrants greater assimilation and opportunities for employment and consequently impact different health outcomes in the AC sub-populations [5]. 


\section{Afro-Caribbean Immigrants in New York City}

New York City is home to one of the largest AC immigrant populations in the U.S. In New York City approximately 600,000 AC immigrants reside in communities such as Kings, Bronx and Queens Counties [72]. Jamaica, Guyana and Haiti have the largest AC immigrant sub-populations accounting for the $3^{\text {rd }}, 4^{\text {th }}$

and $8^{\text {th }}$ largest immigrant groups overall. Community needs assessments identified diabetes, hypertension, heart disease and obesity as top health needs for the years 2013-2016 [72]. Compared to other counties in New York state, Bronx and Kings Counties have the highest percentage of their residents living in poverty [73]. The cultural and ethnic diversity of these counties may also pose barriers to healthcare access such as unfamiliarity with U.S. health care system, immigration status, work related stress, linguistic and assimilation challenges [74]. It is well known that socio-economic factors may influence CVH outcomes [42]. Given this geographical and socio-economic context in which AC immigrants reside in NYC, they may be at increased risk for adverse CVH outcomes.

The following describes important concepts and theories that are pertinent to immigrant health studies and may explain the health trajectory of AC immigrants in the U.S.

\section{Acculturation}

Pertinent to studies on health outcomes among immigrant groups is the concept of acculturation. The term acculturation is defined as psychological and cultural changes that occur as a result of persistent first-hand contact with two or more cultural groups and their members $[28,75]$. It may encompass the adoption of values, ideas, norms and behaviors of a dominant foreign culture [29, 75, 76]. Acculturation has gained increased prominence in immigrant health research and several scales and proxy measures have been used including length of residence, birthplace and language proficiency [77-79]. Particularly in population based studies unidimensional proxy measures for acculturation are commonly used to avoid lengthy scales that may increase participant burden [77]. Approximately 54\% of immigrant research studies in the U.S. utilize a unidimensional proxy scale [80]. Length of residence is a commonly used proxy scale for 
acculturation. The assumption is that greater length of residence is associated with greater acculturation and translates to the adoption of American (potentially unhealthy) lifestyles, and loss of health behaviors associated with immigrants' home countries [32].

While acculturation has been associated with adverse health among immigrants in the U.S. [32, 33, 37]; immigrant groups may experience acculturation differently due to factors such as language, reasons for migration, socio-economic backgrounds and social environment [38]. Acculturation may be seen as a protective or risk factor depending on the health outcome and immigrant group under examination [33, 39, 81]. As previously mentioned, some AC immigrants may not be positively selected on health prior to migration to the U.S. Therefore, a contextual approach to evaluating acculturation might be needed to advance our understanding of its impact on health. Additionally, previous racial/ethnic studies on acculturation and CVH outcomes mainly focus on Hispanic, Asian and to lesser extent African immigrants [31, 37-41]. To my knowledge, there are no published studies examining acculturation among AC immigrant sub-groups by country of birth.

\section{Acculturation and CVH Outcomes among Immigrants}

Research on acculturation and its association with CVD risk factors among U.S. immigrants provides mixed results. Using the proxy measure length of residence, studies have shown an increase in CVD risk factors with more years of residence in the U.S. compared to those with less years of residence [32, 34, 37, 77]. For example, Commodore-Mensah and colleagues using data from 2010-2014 National Health Interview Surveys (NHIS), found that immigrants (Hispanics, Caribbean, Central American and South American) residing in the U.S. for $\geq 10$ years were more likely to be overweight/obese, have diabetes mellitus and hypertension as compared to their counterparts whose length of stay was < 10 years [77]. Similarly immigrants from different pan-regional groups (Central America \& the Caribbean, South America, Europe, Middle East, Southeast and Central Asia) with $\geq 15$ years of residence in the U.S. were found to have greater odds of diabetes [82], obesity [35] and high cholesterol [35] prevalence compared 
to those residing for less years. Additionally, among Hispanics, obesity rates increased among more acculturated immigrants ( $\geq 15$ years length of stay) compared to less acculturated $(<5$ years length of stay) [32]. Another study among Ghanaian and Nigerian immigrants found that residing in the U.S. for $\geq$ 10 years was associated with greater odds of hypertension and obesity among females and males respectively [37] in comparison to their counterparts with less years of residence in the U.S.

On the other hand, acculturation has shown to have no association or may suggest better CVH outcomes among more acculturated immigrants. Wong et al. in a community-based study assessed anthropometric measures for Chinese immigrants in New York City and found no association between length of stay and CVD risk factors except systolic blood pressure [40]. Using the 2009 California Health Interview Survey (CHIS) data, Nguyen found no support for an association of length of residence and obesity; although further sub-group analysis found that Vietnamese immigrants were less likely to obese with increased length of stay in the U.S. [83].

Acculturation has been shown to be a protective factor particularly for physical inactivity. For instance, among a diverse sample of U.S. immigrants, physical activity levels were shown to increase among immigrants who resided in the U.S. $\geq 15$ years relative to those who resided in the U.S. for $<10$ years [35]. Bharmal et al used data from the 2005, 2007 and 2009 CHIS, and found that South Asians who resided in the U.S. for 10 to $<15$ years had greater odds of being sedentary compared to those who resided for 15 years or more [31]. Similarly, Abraido-Lanza et al. found that leisure-time physical activity was lower among low acculturated ( $>5$ but $<15$ years in the U.S.) Latina women [36].

\section{Social Determinants of Health}

According to the American Heart Association (AHA), social factors pose an important influence on CVD incidences and outcomes. Consequently, exploring the role of social determinants related to CVH are critical to achieving the AHA's impact goals [42]. Broadly defined, social determinants of health (SDH) are "the circumstances in which people are born, grow, live, work and age, and the systems put in place to 
deal with illness” [84]. SDH can encompass a wide range of factors. The AHA places special emphasis on socio-economic status, race/ethnicity, social support, culture, access to medical care and residential environments and their relationship to cardiovascular outcomes in the U.S. [42]

The following describes the SDH that will be the focus of this dissertation.

Socioeconomic Status (SES)

SES is a theoretical construct that describes the social and economic factors that influence the positions people occupy within the order of a society [85]. The most common indicator measures of SES used in health research includes: education, employment/occupation status and income [86]. The association of one SES indicator measure to CVH outcomes may not equate to the association of another, hence studies may employ one or all of the indicator measures in CVH studies [87]. Generally, despite the indicator measure used, scientific literature has consistently shown an inverse relationship between CVH outcomes and SES [87-89].

Education is the most frequently used indicator measure of SES [85]. Education signifies the acquisition of skills needed to attain social, psychological and economic resources [88]. Regardless of ethnicity, lower educational status has been shown to be associated with higher burden of CVD and related risk factors [88, 90]. Occupational status/employment, another indicator measure most often used in health research studies is conceptualized differently in some studies. However, several studies identify an inverse relationship with occupational status and CVH outcomes [88, 89, 91]. A more complex indicator measure of SES is income. Income provides access to social amenities necessary to combat illness. Lower income may influence poorer CVH [92].

SES, regardless of indicator measure used has proven to be one of the most salient contributors to CVH. In the U.S. CVD incidence is more common among low SES and ethnic minorities [93]. Immigrants in the U.S. vary in SES due to different countries of origin, generational status, migration patterns, language ability, education and skills [94]. AC immigrants come from diverse socio-cultural backgrounds with 
differences in language, education assimilation and migration patterns [8, 23, 95]. For example, despite their level of education, employment opportunities and healthcare access may be restricted for some AC immigrants with limited English proficiency [96]. These differences in SES may drive differential outcomes in CVH.

Due to data limitations, the SES measures that will be examined in this dissertation are education and employment.

\section{Healthcare Access and Health Insurance}

Healthcare access involves "the timely use of personal health services to achieve the best health outcomes”[97]. Measuring healthcare access encompasses having resources such as usual source of care or health insurance, accessibility and utilization [98]. Healthcare access may have an impact on CVH outcomes. For example, CVD risk factors are more treated and controlled among the insured compared to the uninsured [99], and being insured is associated with higher rates of CVD diagnosis [100]. Lack of usual source of care is also linked to suboptimal screening for CVD risk factors [101].

Immigrants face more barriers to healthcare access than their U.S. born citizens [102]. Factors such as immigration status, language proficiency, residential location, discrimination, stigma and marginalization impair healthcare access among immigrants $[102,103]$. Black immigrants may face increased vulnerabilities to adequate healthcare access because of their double minority status (i.e. being black and immigrants). Access to care has been shown to increase odds of CVD prevention among Latino immigrants [104]. There is a paucity of literature on the impact of healthcare access on CVH outcomes among black immigrants in the U.S.

The following describes two important concepts/theories that provide possible explanations for differential health outcomes among immigrants and may be applicable to AC immigrants in the U.S.

\section{The Healthy Immigrant Effect}


Pertinent to the study of immigrant health in the U.S. is the concept of the healthy immigrant effect. The healthy immigrant effect articulates that the health of immigrants supersedes that of their U.S. born counterparts. However, as time passes in the host country the health of immigrants deteriorates to resemble that of their native-born counterparts [105]. There are several explanations for the healthy immigrant effect: 1) positive selection factors enforced by migration policies in receiving countries; 2) positive selection on social determinants of health such as economic resources, health and education; 3) salmon bias and 4) cultural buffering associated with home countries. Positive selection of immigrants is emphasized through screening policies implemented by host countries that require immigrants to undergo medical screening to ensure that immigrants are free from certain diseases prior to migration [106]. Positive selection theory also contends that only the most educated, healthiest and motivated individuals choose to migrate [43]. In addition, there is the reverse migration categorized by the return of older, less healthy individuals to their home countries also known as salmon bias [107, 108]. The healthy immigrant effect can also be attributed to cultural buffering; immigrants tend to have better diets and other positive health behaviors associated with immigrants' home countries. Social networks, close family and religious ties in countries of origin also provide a cultural buffer against adverse health outcomes [109].

The healthy immigrant effect may vary. Positive selection may not apply to all categories of immigrants. Lax immigration policies geared towards welcoming immigrants such as refugees and political asylees might attract immigrants with compromised health [110]. Individuals admitted for employment and spouses of U.S. citizens were found to report better health than spouses of permanent residents [111]. The healthy immigrant effect may also vary based on the health status measure used to classify immigrant health upon arrival [112, 113].

Although extensively used to describe the overall health of immigrants to the United States; not all immigrants adhere to the positive selection theory or cultural buffering. Host country immigration policies may accept immigrants that are negatively selected on socio-economic characteristics and health. Also, with social factors such as globalization and epidemiological changes in sending regions such as the 
Caribbean, it can no longer be assumed that immigrants will maintain their "cultural buffers” against unhealthy behaviors prior to migration. It is plausible that while some immigrants are healthier upon arrival and may experience health deterioration overtime, other classes of immigrants may not exhibit the same health advantage. These alternative explanations reinforce the theory that the healthy immigrant effect may not be evenly distributed across all immigrant groups.

\section{Segmented Assimilation Theory}

Segmented assimilation theory describes immigrant trajectories into mainstream U.S. society and asserts that assimilation is largely dependent on immigrant socio-economic characteristics and the social context of the host country [114]. Segmented assimilation theory proposes that immigrants may take three possible paths to assimilation: 1) assimilation into an urban underclass or "downward assimilation”, 2) assimilation into a middle class or "straight line assimilation" and 3) maintaining ethnic/national cultural values from immigrant's community also known as “selective assimilation” [114, 115]. In addition to the varying social and human capital brought by different classes of immigrants, the U.S. society is also highly stratified and immigrants assimilate into different strata of the U.S. society [114]. For AC immigrants their different national/ethnic identities may account for different assimilation trajectories. Segmented assimilation, therefore, may explain differential health outcomes of AC immigrants.

Immigrants that integrate into an urban underclass characterize downward assimilation. In this social context, the urban underclass experience several vulnerabilities that may promote adverse health outcomes. For example, immigrants are highly concentrated in economically disadvantaged neighborhoods in gateway cities such as New York, Boston and Chicago [116]. Some of these neighborhoods are adversely affected by persistent poverty and poor health outcomes [72, 73]. Immigrants residing in economically disadvantaged neighborhoods may encounter lack of neighborhood resources such as adequate housing, healthcare services and limited upward social mobility [117].

Additionally, broader societal issues such as racism and discrimination may also influence negative health 
outcomes $[118,119]$. In this social context immigrants are in daily contact with the poor, native minorities and other immigrants, hence making it difficult to assimilate into other areas of society [115].

Assimilation into the middle class or straight-line assimilation assumes that some immigrant groups that possess high levels of human capital and are favorably incorporated into the host society. In this context immigrants may be quickly driven on a path of upward socioeconomic mobility and integration into American mainstream society [114]. Immigrants may therefore reside in affluent middle-class suburbs and economic advancement is seamless into the normative structures of middle-class America [115]. Straight-line assimilation toward middle-class American society is expected to produce more favorable health outcomes among immigrants [120].

The third variant to segmented assimilation theory is selective assimilation. Much like straight-line assimilation, selective assimilation may propel immigrants into middle-class America rather than an “underclass” society. This middle class status is attained through maintaining traditional cultural immigrant values, education and strong sense of community that exist in ethnic communities [114]. The most salient characteristic of this society is that immigrants and their children are offered a social safety net that includes access to moral and material resources that safeguard against downward assimilation [114]. 


\section{Chapter 3}

\section{Data Source and Methods}

The New York City Community Health Survey

Data for this project are from the New York City Department of Health and Mental Hygiene Community Health Survey (CHS). The CHS is a cross-sectional telephone survey conducted each year by the Department of Health and Mental Hygiene, Division of Epidemiology, Bureau of Epidemiology Services. The CHS is conducted annually and includes approximately 9,000 NYC non-institutionalized residents ages $\geq 18$ years. The CHS captures data on the health of individuals from all five boroughs of NYC (Manhattan, Brooklyn, Queens, Bronx and Staten Island), including neighborhood and citywide estimates of a variety of chronic diseases and behavioral risk factors. CHS is based upon the National Behavioral Risk Factor Surveillance System (BRFSS), conducted by the Centers for Disease Control and Prevention. CHS dataset was used rather than data from BRFSS because of the ability of the CHS data to disaggregate respondents by country of birth for the different AC immigrant sub-groups. Data collected for the CHS survey utilized a computer assisted telephone interviewing (CATI) system, and interviews were done in five different languages: English, Spanish, Russian, Mandarin and Cantonese. Starting in 2009 CHS included respondents with cell phones in addition to landlines. All data collected are selfreport. Analyses for this project were conducted utilizing 2010-2014 administrations of the NYC CHS [121].

Sampling and Weighting Methodology

A stratified random sampling technique is employed to produce citywide and neighborhood estimates. The sampling frame was constructed from a list of telephone numbers provided by a commercial vendor. One adult is randomly selected from the household to complete the survey then consent to participate is received. The 2010-2014 combined years' analyses are weighted to the NYC adult residential population as per Census 2010 and the 2011- 2013 American Community Survey. The CHS uses weights so that over or under-represented groups in the survey sample better represent the actual proportions of the target 
population. The weightings also take into account probability of participant selection and non-response bias. Weightings for the CHS are created using the "raking” or "iterative proportional fitting” so demographic characteristics such age, sex and race/ethnicity are accurately represented in the survey. During this process, as each demographic characteristic is included, the weights are fitted until population representativeness is achieved. The full methodology of the CHS is available elsewhere [122].

\section{Variable Description}

All variables from the CHS that will be used in this project are extensively described in Table 1.

\section{Outcome Variables: CVH factors}

The main outcomes for study 1 are CVH factors: DM, hyperlipidemia, hypertension and overweight/obese which are based on respondents' self-report.

\section{Cardiovascular Health Score}

The main outcome for study 2 and 3 is overall cardiovascular health score based on AHA's definition using methodology from previous studies [20, 123, 124] but adapted based on CHS items. The adaptation to CHS items is outlined in Table 2. The cardiovascular health score incorporated seven metrics (fasting plasma glucose, total cholesterol, blood pressure, body mass index (BMI), physical activity, diet and smoking status). Blood glucose (diabetes), high cholesterol and high blood pressure were self-reported as a "yes" or "no" on the CHS survey and were categorized as "not ideal" = 0 or "ideal" =1, respectively. The survey responses from the CHS did not capture information on "intermediate" category for each health factor. Hence, each behavioral factor and BMI were also categorized as "ideal” or "not ideal” as adapted from previous studies [123, 125]. For BMI, underweight/normal weight was “ideal” whereas overweight/obese was “not ideal”. For physical activity, “ideal” or "not ideal” was determined from a self-reported “yes” or “no” respectively on CHS survey question: “during the past 30 days, other than your regular job, did you participate in any physical activities or exercises such as running, calisthenics, 
golf, gardening, or walking for exercise?” Regarding diet, respondents who reported having consumed $\geq$ 5 servings of fruit and or vegetable yesterday were classified were classified as "ideal”. Respondents who reported $<5$ servings were classified as “not ideal”. For smoking status, respondents who reported never having smoked at least 100 cigarettes in their lifetime were considered "ideal” and those who reported to be current or former smokers were considered "not ideal”. The seven metrics were summed together and could range from 0-7.

The overall CVH score was further grouped into three categories: "ideal” where the overall CVH score was $\geq 4$; "intermediate" where the overall CVH score ranged from 2-3; and "poor" where the overall CVH score ranged from 0-1 [124]. After conducting cross tabulations of the three categories (ideal, intermediate and poor) by each county of birth, there was a paucity of individuals in the poor category. Therefore, intermediate and poor categories were combined into a single group for more stable estimates for each country of birth group. This CVH variable was analyzed as a dichotomous variable coded as 0 for “ideal” CVH and 1 for "poor/intermediate” CVH.

\section{Acculturation (Length of Residence)}

Acculturation was measured by the proxy length of residence in the U.S., determined from the question “how long have you lived in this country?” Responses are categorized as $<5$ years, 5-9 years or $\geq 10$ years. This variable was dichotomized into $<10$ years and $\geq 10$ years based on prior literature examining length of residence and CVD risk factors among U.S. immigrants [37, 126].

\section{Social Determinants of Health (SDH)}

Education: Education status was ascertained from the question "What is the highest grade or year of school you completed?” Responses were coded as < high school, high school graduate, some college, or college graduate.

Employment: The CHS categorized employment status as employed, unemployed, or not in labor force. 
Health Insurance Status: Health insurance was assessed from the question "Do you have any kind of health insurance coverage?” Response categories were “yes”, “no”, “don’t know”, “refused” and “missing”. This variable was recoded as yes or no; other responses were coded as missing.

Healthcare Access: Healthcare access was derived from the question "Was there a time in the past 12 months when you needed medical care but did not get it?” Responses were dichotomized into yes or no. Responses were reversed coded for the variable to represent having healthcare access or not.

\section{Covariates}

Covariates for this study included participant's age (18-24, 25-44, 45-64 and 65+ years) and sex (male, female).

Table 1: Full Variable Description from the NYC CHS

\begin{tabular}{|l|l|l|}
\hline \multicolumn{3}{|c|}{ Table 1: Full Variable Description from the NYC CHS } \\
\hline Variable & Question & Response Categories \\
\hline Guyana & Where are you born? Please tell me & $0=$ no \\
& the country. & $1=$ yes \\
\hline Haiti & Where are you born? Please tell me & $0=$ no \\
& the country. & $1=$ yes \\
\hline Jamaica & Where are you born? Please tell me & $0=$ no \\
& the country. & $1=$ yes \\
\hline USmainblack & Non-Hispanic black /African & $1=$ Born in the U.S. mainland \\
& Americans born in the U.S. &.$=$ missing \\
& mainland. & $1=$ yes \\
\hline Diabetes & Ever been told by a doctor, nurse or & $0=$ no \\
& other health professional” that you & had diabetes? \\
\hline
\end{tabular}




\begin{tabular}{|c|c|c|}
\hline High cholesterol & $\begin{array}{l}\text { Ever been told by a doctor, nurse or } \\
\text { other health professional” that you } \\
\text { had high cholesterol? }\end{array}$ & $\begin{array}{l}0=\text { no } \\
1=\text { yes }\end{array}$ \\
\hline Hypertension & $\begin{array}{l}\text { Ever been told by a doctor, nurse or } \\
\text { other health professional” that you } \\
\text { had hypertension? }\end{array}$ & $\begin{array}{l}0=\text { no } \\
1=\text { yes }\end{array}$ \\
\hline Obesity & $\begin{array}{l}\text { Calculated from self-reported } \\
\text { height and weight }\end{array}$ & $\begin{array}{l}\text { Underweight } \\
\text { Overweight } \\
\text { Obese }\end{array}$ \\
\hline Age & What is your age? & $\begin{array}{l}1=18-24 \text { yrs } \\
2=25-44 \text { yrs } \\
3=45-64 \text { yrs } \\
4=65+\text { yrs } \\
. d=\text { Don't know } \\
. r=\text { Refused }\end{array}$ \\
\hline Education & $\begin{array}{l}\text { What is the highest grade or year of } \\
\text { school you completed? }\end{array}$ & $\begin{array}{l}\text { 1=2=High school grad } \\
3=\text { Some college } \\
4=\text { College graduate } \\
. d=\text { Don't know Less than HS }\end{array}$ \\
\hline Sex & Are you male or female? & $\begin{array}{l}\text { 1=Male } \\
2=\text { Female }\end{array}$ \\
\hline Employment & Employment status & $\begin{array}{l}\text { 1=Employed } \\
2=\text { Unemployed } \\
3=\text { Not in labor force } \\
\text {.d=Don't know }\end{array}$ \\
\hline
\end{tabular}




\begin{tabular}{|c|c|c|}
\hline & & $. r=$ Refused \\
\hline $\begin{array}{l}\text { Length of stay in the U.S. } \\
\text { (acculturation) }\end{array}$ & $\begin{array}{l}\text { How long have you lived in this } \\
\text { country? }\end{array}$ & $\begin{array}{l}1=<5 \text { yrs } \\
2=5-9 \text { yrs } \\
3=10+\text { yrs } \\
. d=\text { Don't know } \\
. r=\text { Refused } \\
.=\text { Missing/Not asked }\end{array}$ \\
\hline Health insurance & $\begin{array}{l}\text { Was there a time in the past } 12 \\
\text { months when you needed medical } \\
\text { care but did NOT get it? }\end{array}$ & $\begin{array}{l}1=\text { Yes } \\
2=\text { No } \\
. d=\text { Don't know } \\
. r=\text { Refused }\end{array}$ \\
\hline Health access & $\begin{array}{l}\text { Was there a time in the past } 12 \\
\text { months when you needed medical } \\
\text { care but did NOT get it? }\end{array}$ & $\begin{array}{l}1=\text { Yes } \\
2=\text { No } \\
. d=\text { Don't know }\end{array}$ \\
\hline Physical activity & $\begin{array}{l}\text { During the past } 30 \text { days, other than } \\
\text { your regular job, did you participate } \\
\text { in any physical activities or } \\
\text { exercises such as running, } \\
\text { calisthenics, golf, gardening, or } \\
\text { walking for exercise? }\end{array}$ & $\begin{array}{l}1=\text { Yes } \\
2=\text { No } \\
. d=\text { Don't know } \\
. r=\text { Refused }\end{array}$ \\
\hline Diet/Nutrition & $\begin{array}{l}\text { How many total servings of fruit } \\
\text { and/or vegetables did you eat } \\
\text { yesterday? }\end{array}$ & $\begin{array}{l}1=\text { None } \\
2=1-4 \text { servings } \\
3=\geq 5 \text { servings } \\
. d=\text { Don't know } \\
. r=\text { Refused }\end{array}$ \\
\hline Diet/Nutrition & Drink two or more sodas per day & $1=\geq 2$ sodas \\
\hline
\end{tabular}




\begin{tabular}{|c|c|c|}
\hline & & $\begin{array}{l}2=<2 \text { sodas } \\
. d=\text { Don't know } \\
. r=\text { Refused } \\
.=\text { Missing }\end{array}$ \\
\hline Smoking & $\begin{array}{l}\text { Have you smoked at least } 100 \\
\text { cigarettes in your entire life? } \\
\text { Do you now smoke cigarettes: } \\
\text { everyday, some days or not at all? }\end{array}$ & $\begin{array}{l}1=\text { Never } \\
2=\text { Current } \\
3=\text { Former } \\
. d=\text { Don't know } \\
. r=\text { Refused }\end{array}$ \\
\hline
\end{tabular}

CHS 2010-2014 Questions and Definitions for classification of "Ideal" CVH for the Seven Metrics

\begin{tabular}{|l|l|l|}
\hline \multicolumn{3}{|c|}{ Table 2. CHS 2010-2014 Questions and Definitions for classification of "Ideal" CVH for the } \\
\hline CVH Component & CHS Question & Definition for Ideal Cardiovascular Health \\
\hline Blood glucose & $\begin{array}{l}\text { Have you ever been told by a } \\
\text { doctor, nurse or other health } \\
\text { professional that you have } \\
\text { diabetes? }\end{array}$ & Participant answered "no" \\
\hline Cholesterol & $\begin{array}{l}\text { Have you ever been told by a } \\
\text { doctor, nurse or other health } \\
\text { professional that your blood } \\
\text { cholesterol is high? }\end{array}$ & Participant answered "no" \\
\hline Blood pressure & $\begin{array}{l}\text { Have you ever been told by a } \\
\text { doctor, nurse or other health } \\
\text { professional that you have } \\
\text { hypertension, also called high } \\
\text { blood pressure? }\end{array}$ & Participant answered "no" \\
\hline BMI & $\begin{array}{l}\text { About how much do you weigh } \\
\text { without your shoes? About how } \\
\text { tall are you without your shoes? }\end{array}$ & BMI was between 18.5-24.5 \\
\hline Physical activity & $\begin{array}{l}\text { During the past 30 days, other } \\
\text { than your regular job, did you } \\
\text { participate in any physical } \\
\text { activities or exercises such as } \\
\text { running, calisthenics, golf, } \\
\text { gardening, or walking for } \\
\text { exercise? }\end{array}$ & Participant answered "yes" \\
\hline $\begin{array}{l}\text { Thinking about nutrition...how } \\
\text { many total servings of fruit and/or } \\
\text { vegetables, did you eat yesterday? }\end{array}$ & $\begin{array}{l}\text { Participant consumed 5 or more servings of } \\
\text { fruits and vegetables per day }\end{array}$ \\
\hline Diet & \begin{tabular}{l}
$\mid l$ \\
\hline
\end{tabular}
\end{tabular}




\begin{tabular}{|l|l|l|}
\hline & $\begin{array}{l}\text { A serving would equal one } \\
\text { medium apple, a handful of } \\
\text { broccoli, or a cup of carrots. }\end{array}$ & \\
\hline Smoking status & $\begin{array}{l}\text { Have you smoked at least 100 } \\
\text { cigarettes in your entire life? Do } \\
\text { you now smoke cigarettes: } \\
\text { everyday, some days, or not at } \\
\text { all? }\end{array}$ & $\begin{array}{l}\text { Participant reported never having smoked at } \\
\text { least } 100 \text { cigarettes in their lifetime }\end{array}$ \\
\hline
\end{tabular}




\title{
Chapter 4
}

\section{Study 1 Manuscript}

Title: The Cardiovascular Health of Afro-Caribbean Immigrants in New York City-A descriptive epidemiology study.

\section{Authors Names and Affiliations}

\author{
Sabena C. Thomas \\ West Virginia University School of Public Health \\ Department of Social and Behavioral Sciences \\ 1 Medical Center Drive \\ P.O. Box 9190 \\ Morgantown West Virginia 26506-9190. U.S.A. \\ sbthomas@mix.wvu.edu \\ Amna Umer \\ West Virginia University School of Medicine \\ Department of Pediatrics \\ West Virginia University \\ 1 Medical Center Drive \\ Morgantown West Virginia 26506. U.S.A. \\ amumer@hsc.wvu.edu \\ Yvonne Commodore-Mensah \\ Community-Public Health Nursing \\ John's Hopkins School of Nursing Room \#419 \\ Baltimore, Maryland 21205 \\ ycommod1@jhu.edu \\ Sumaira Khalid \\ West Virginia School of Public Health \\ Department of Epidemiology \\ West Virginia University \\ P.O. Box 9190 \\ Morgantown, WV 26506 \\ Email:sk0055@mix.wvu.edu \\ West Virginia University School of Public Health \\ Department of Social and Behavioral Sciences \\ 1 Medical Center Drive \\ P.O. Box 9190 \\ Morgantown West Virginia 26506-9190. U.S.A \\ cgabildso@hsc.wvu.edu
}

Corresponding author: Christiaan G. Abildso 


\begin{abstract}
Afro-Caribbean (AC) immigrants display better physical health than United States (U.S.) born blacks. Cardiovascular (CV) health disparities among AC sub-groups are poorly understood. We examined the prevalence of CV health among AC immigrants (Guyanese, Haitian and Jamaican) relative to U.S. born blacks residing in New York City. We employed a descriptive epidemiological design using pooled data from 2010-2014 New York City Community Health Survey administrations to estimate the prevalence of CV health and differences among AC immigrant sub-groups. Results showed that in comparison to U.S. Born blacks, non-Hispanic black (NHB) Jamaican immigrants were more likely to self-report diabetes but were less likely to be overweight/obese. NHB Guyanese immigrants were also less likely to be overweight/obese than U.S. born blacks. There were no significant differences between NHB Haitian immigrants and U.S. born blacks for CV health factors. Future efforts to disaggregate the AC immigrant population to effectively identify health disparities are warranted.
\end{abstract}

\title{
Key Words
}

Afro-Caribbean immigrants, race/ethnicity, cardiovascular health, disparities 


\section{Introduction}

Cardiovascular diseases (CVDs) are the leading causes of death worldwide, accounting for 32\% (17.3 million) of all deaths globally [1] and approximately one in every three deaths in the United States (U.S.) [2]. Estimated prevalence rates of total CVDs using 2010-2014 data [2] indicate that non-Hispanic blacks (NHB) far outpace non-Hispanic whites in CVD prevalence (46.0\% vs 37.7\% among males, $47.7 \%$ vs 35.1\% among females). The American Heart Association (AHA) in its effort to improve cardiovascular (CV) health of Americans developed a metric for ideal CV health using seven key indicators. Included in this metric are CV health factors (i.e., diabetes mellitus (DM), hyperlipidemia, hypertension, healthy body mass index (BMI)) and CV health behaviors (i.e., smoking, physical activity, diet) [3]. In accordance with higher CVD prevalence, NHB adults have significantly lower prevalence (10.8\%) of achieving at least five of these seven factors than other races/ethnicities [2].

Similar to the racial/ethnic category of NHB used in health data described prior, the category of Black/African American (AA) used by the U.S. Census Bureau is a heterogeneous group that may mask important ethnic health differences. The AA racial category and NHB health data categories similarly include people of African descent, specifically including American born blacks, African immigrants and Afro-Caribbeans (hereafter AC immigrants) [4]. AC immigrants are the largest black immigrant population in the U.S., making up approximately 54\% of the total black (Hispanic and non-Hispanic) immigrant population [5]. AC immigrant refers to individuals of African descent who migrated from their native Caribbean islands or West Indies [6]. The majority of AC immigrants are from the Francophone (e.g., Haiti) and Anglophone Caribbean (e.g., Jamaica, Barbados) whereas the majority of Hispanic Caribbean blacks are from Cuba, Dominica Republic and Puerto Rico but may ethnically self-identify as Hispanics rather than blacks [6-8]. Thus, a focus on non-Hispanic AC immigrant population is warranted. 
New York City (NYC) is one of the most ethnically and culturally diverse cities in the United States and hosts the largest concentration of AC immigrants in the U.S. [8, 9]. Approximately 600,000 AC immigrants of non-Hispanic origins reside in Bronx, Kings and Queens counties [9, 10]. The majority of AC immigrants in these counties are from Guyana, Haiti, Jamaica or Trinidad and Tobago [10]. In comparison to other counties in NYC, these counties have higher prevalence rates of cardiovascular risk factors such as: diabetes, hypertension obesity and smoking [11, 12]. Additionally, Bronx and Kings Counties have the highest percentage of their residents living below the poverty line in comparison to all counties in the state of New York [13]. Consequently in King's county, the highest number of hospital admissions for CVD, hypertension and diabetes are concentrated in low income neighborhoods [12]. The cultural and ethnic diversity of these counties may also pose barriers to healthcare access such as unfamiliarity with U.S. health care system, immigration status, work related stress, linguistic and assimilation challenges [12]. It is well known that socio-economic factors may influence CVH outcomes [14]. Given this geographical and socio-economic context in which AC immigrants reside in NYC, they may be at increased risk for adverse $\mathrm{CVH}$ outcomes.

Little is known about the health of this large population of AC immigrants, especially CV health. The limited epidemiological studies that have been undertaken in the Caribbean region to gather CVD and risk factor data are limited by the use of different surveillance strategies, methodologies, definitions of CVD and the risk factors across countries, making regional estimations of prevalence and trends difficult [1522]. Despite these limitations, the nation-specific data that have been collected suggest that many Caribbean nations have been experiencing an increase in non-communicable diseases (NCDs), including the CV health factors. For example, a comparison of nationally representative data from the Jamaica Health Lifestyle Surveys for the years 2000-01 and 2007-08 identified an increase in DM, hypertension and hyperlipidemia prevalence over time [18]. In Guyana, deaths due to CVD risk factors have shown one of the highest percentage increases in all-cause mortality from 2005-2016 [23]. 
In the U.S., there has been increasing attention in the literature to the variations in health status among AC immigrants and U.S. born blacks [24-32]. However, several gaps exist within these studies, including: 1) examination of limited health outcomes, 2) methodological/data concerns and 3) lack of insights into country of birth differences. Firstly, examinations of ethnic variation among AC immigrants and U.S. born blacks tend to focus on limited health outcomes, specifically self-rated general physical health or psychological health outcomes [24, 25, 27, 33, 34].

Secondly, the data used for previous population-based AC immigrant samples analyzed in these studies are outdated [25-28, 35, 36]. Most notably, data from the National Survey of American Life, (NSAL) are used in several studies examining ethnic differences in cardiovascular health among blacks in the United States $[28,35]$. Although the NSAL survey provides data on a nationally-representative sample of AC immigrants, this survey was conducted from 2001 to 2003[37]. Fang and colleagues analyzed differences in mortality rates from cardiovascular causes based on NYC mortality records from 1988 through 1992 [27]. Read et al. also examined health disparities among black Americans and included a sample of West Indian blacks [26], but the data were from the 2000-2001 National Health Interview Survey (NHIS). While most of these studies serve as seminal works and were contextually applicable at the time of publication, they may provide little insight into the current state of AC immigrant health in the U.S.

Lastly, country of birth differences is understudied. AC immigrants are a heterogeneous group made up of individual Caribbean nations with different languages, socio-economic backgrounds, levels of acculturation, racial context of origin and immigrant selectivity. They also possess differing political and health structures in their home countries, all of which may influence health outcomes [33, 38-40]. Few studies have examined CV health factors among AC immigrant populations and AAs [27-29, 32]. Among these studies, most compared first and second-generation AC immigrants and have limited sample sizes, making the disaggregation of the data by country of birth impossible [27-29, 39]. In 2007, Davis and Huffman highlighted the need for further research to investigate and compare risk factors for heart diseases in different Caribbean sub-groups and make comparison with U.S. born blacks [39]. Although 
several studies have compared cardiovascular outcomes between Caribbean blacks and U.S.-born blacks $[28,35,36,41]$; to our knowledge, a country of birth comparison is yet to be conducted.

Given the epidemiological transition that is underway in Caribbean countries, it is plausible that the current generation of AC immigrants may have a higher risk for CVDs than their predecessors. Further, the lack of subgroup analysis within the NHB health data and other limitations described above, underscore the importance of examining cardiovascular health of AC immigrants relative to U.S. born blacks. This study will estimate and compare the prevalence of CV health factors between three prominent AC sub-groups: Guyanese-, Haitian- and Jamaican born AC immigrants, relative to U.S. born blacks in NYC.

\section{Methods}

\section{Data Source}

The study used data from the New York City Department of Health and Mental Hygiene Community Health Survey (NYC DOHMH CHS). The full methodology of the CHS is published elsewhere [42]. Briefly, the CHS is a cross-sectional telephone survey conducted each year by the Department of Health and Mental Hygiene, Division of Epidemiology, Bureau of Epidemiology Services. The CHS includes approximately 9,000 NYC non-institutionalized residents ages $\geq 18$ years, capturing data on the health of individuals from all five boroughs of NYC, including neighborhood and citywide estimates of a variety of chronic diseases and behavioral risk factors. The CHS survey utilized a computer-assisted telephone interviewing system (CATI), and interviews were conducted in five different languages: English, Spanish, Russian, Mandarin and Cantonese. One adult is randomly selected from the household to complete the survey then consent information is received [43].

The CHS uses weights so that over- or under-represented groups in the survey sample better represent the actual proportions of the target population. The 2010-2014 combined years' analyses are weighted to the NYC adult residential population as per Census 2010 and 2011-2013 American Community Survey. 
Weightings for the CHS are created using the "raking” or "iterative proportional fitting” with certain demographic characteristics. During this process, as each demographic characteristic is included, the weights are fitted until population representativeness is achieved [42]. Analysis for the study utilized pooled data collected during the 2010-2014 administrations. Institutional Review Board was not required for this study as the data were de-identified and provided under a data use agreement.

\section{Study Population}

Respondents who reported their race as NHB and place of birth as the U.S. mainland (U.S. born blacks), or Guyana, Haiti, or Jamaica (AC immigrants) were included in our study. Respondents’ place of birth was ascertained from the question "Where were you born? Please tell me the country" in the CHS.

\section{Variable Description}

The main independent variable was determined by country of birth for NHBs. A single variable country of birth (COB) was created with four levels: U.S. born blacks (referent), Guyana, Haiti, or Jamaica.

The main outcomes for this study are CV health factors: DM, hypercholesterolemia, hypertension and overweight/obesity. DM status was determined from the question "Have you ever been told by a doctor, nurse, or other health professional that you have diabetes?” Women who had diabetes only while pregnant were included in the 'no' category. Hypercholesterolemia was determined from the question "Have you ever been told by a doctor, nurse or other health professional that your blood cholesterol is high?” Hypertension was determined from the question "Have you ever been told by a doctor, nurse or other health professional that you have hypertension, also called high blood pressure?” Responses were coded as binary yes/no. Responses to any questions coded as “don’t know”, “refused” or “missing” were categorized as missing. Body mass index (BMI) was calculated from self-reported height and weight [43], and dichotomized as either underweight/normal $\left(\mathrm{BMI}<25 \mathrm{~kg} / \mathrm{m}^{2}\right)$ or overweight/obese (BMI $\geq 25$ $\left.\mathrm{kg} / \mathrm{m}^{2}\right)$. 
Covariates included demographic variables (i.e., age, sex, education, employment, health insurance, health care access) and CV health behavior variables (i.e., smoking, diet/nutrition, physical activity). Age was categorized as 18-24, 25-44, 45-64 and 65+ years, and sex as male or female. Education status was ascertained from the question "What is the highest grade or year of school you completed?” Responses were recorded as < high school, high school graduate, some college, or college graduate. Employment status was categorized as employed, unemployed, or not in labor force. Health insurance was assessed from the question “Do you have any kind of health insurance coverage?” Response categories were “yes”, “no”, “don’t know” “refused” and “missing”. All responses were coded as binary yes/no; other responses were coded as missing. Healthcare access was determined from the question "Was there a time in the past 12 months when you needed medical care but did not get it?” Responses were dichotomized into yes or no. Responses were reversed coded to satisfy having healthcare access or not.

Smoking was determined from the question "Have you smoked at least 100 cigarettes in your entire life?" Response categories included never, former, or current. This variable was dichotomized into never former/current). Diet/nutrition was determined from asking the questions "How many total servings of fruit and/or vegetables did you eat yesterday?” and “drink two or more sodas per day?” Responses included none, 1-4 servings, or $>5$ servings of fruits and/or vegetables, and $\geq 2$ sodas or $<2$ sodas, respectively. Physical activity was ascertained from the question "During the past 30 days, other than your regular job, did you participate in any physical activities or exercises such as running, calisthenics, golf, gardening, or walking for exercise?” Responses were categorized as yes or no.

\section{Analysis}

Frequency analysis of responses for all covariates and outcomes was performed for the entire sample and for each COB group. Logistic regression was used to determine significant differences between COB groups in unadjusted models. To examine the association between country of birth and CV health factors, we adjusted the models for significant covariates using the following stepwise process. For each outcome of interest, covariates that were significantly associated with the outcome variable $(p<.05)$ were included 
in a multivariable logistic regression model. Using backward sequential selection, the non-significant covariates were deleted from the model one at a time removing the covariate with the highest p-value each time. If COB was not associated with the outcome variable, no additional analyses was performed. Odds ratios and 95\% confidence intervals are presented for logistic regression analyses. All analyses included survey weights and were conducted in SAS Enterprise version 5.1 [44]. All analyses and coding were double checked for accuracy by the New York City Department of Mental Health and Hygiene.

\section{Results}

The sample characteristics are shown in table 1. Prevalence of CV health and behavioral factors by COB are shown in table 2 and figure 1 respectively.

\section{$\underline{\text { Diabetes Mellitus }}$}

The overall prevalence of DM for NHBs in the sample was 12.6\% (Table 2). NHB immigrants from Guyana (17.3\%) and Jamaica (15.9\%) reported significantly higher rates of DM compared to U.S. born black blacks (11.8\%). NHB Guyanese immigrants were 57\% more likely to report DM than U.S. born blacks (OR =1.57; 95\% CI = 1.04-2.36) however, this association was not statistically significant after adjusting for age and employment. NHB Jamaican immigrants were 42\% more likely to report having DM compared to U.S. born blacks ( $\mathrm{OR}=1.42 ; 95 \% \mathrm{CI}=1.10-1.83)$. This association remained significant even after adjusting for age and employment $(\mathrm{OR}=1.45$; 95\% CI = 1.08-1.93).

\section{Hyperlipidemia}

The overall prevalence of hyperlipidemia for the sample was 26.2\% (Table 2) with no significant differences in the odds of reporting hyperlipidemia among NHB immigrant sub-groups compared to U.S born blacks.

\section{Hypertension}


The overall prevalence of hypertension for the sample was 35.5\%. NHB Haitians had significantly lower odds (31\%) of reporting hypertension than U.S born blacks (OR $=0.69 ; 95 \% \mathrm{CI}=0.48-1.00)$ but this association was not significant $(\mathrm{OR}=0.69 ; 95 \% \mathrm{CI}=0.45-1.04)$ after adjusting for age, sex, education, employment and physical activity.

\section{Overweight/Obese}

The overall sample prevalence rates for overweight and obesity were 67.4\% (Table 2). Both NHB Guyanese $(\mathrm{OR}=0.72 ; 95 \% \mathrm{CI}=0.58-0.88)$ and Jamaican immigrants $(\mathrm{OR}=0.65 ; 95 \% \mathrm{CI}=0.47-0.89)$ were less likely to overweight/obese in comparison to U.S. born blacks when adjusting for age, sex and health insurance (Table 3). NHB Haitians displayed no significant differences in prevalence rates for overweight/obesity from U.S. born blacks.

\section{Discussion}

Previous studies have consistently highlighted that Caribbean born blacks tend to fair better than U.S. born blacks on several indicators of health [24, 33, 45]. Our study provides evidence that there is a mixture of CVD health advantages and disadvantages among NHB Caribbean sub-groups in comparison to U.S. born blacks. Some researchers attribute health advantages to "immigrant selectivity" and "cultural buffering”. Respectively, these theories propose that more educated, healthier immigrants are more motivated to migrate; and cultural factors cause immigrants low tendency to partake in smoking, alcohol consumption or to have negative health outcomes [46].

Our analyses depict "immigrant selectivity” and “cultural buffering” in interestingly opposite ways among NHB Haitian immigrants. Prior to 2015, the majority (98\%) of Haitian immigrants to the U.S. received lawful permanent residency status through family ties, and as refugee or asylum seekers [47]. Due to their reasons for migration, it may be argued that these immigrants might be less than positively selected on factors such as health and education. 
However, upon arrival in the U.S., their new status may have granted them opportunities to seek employment and higher education in the U.S. Our data depict higher education, greater employment and lower prevalence of CV health factors for NHB Haitians in comparison to their Jamaican and Guyanese counterparts, but lower prevalence of health insurance and access to health care. Consistent with previous literature, Haitian immigrants in our sample experience greater healthcare access challenges, likely resulting from linguistic barriers, lack of insurance and cultural practices and beliefs that favor traditional over western medicine [48-51]. Evidently, the “cultural buffer” that supports positive behaviors may also limit health seeking behaviors. These barriers to health care access may present fewer opportunities for diagnosis of CV health factors relative to their NHB Jamaican and Guyanese counterparts.

NHB Jamaican immigrants had a significantly greater risk of reporting DM - and Guyanese immigrants, a nearly significant greater risk - than U.S. born blacks when controlling for age and employment. This may be partly explained by the acculturation process. Acculturation is defined as changes that occur as a result of contact with a dissimilar group of people and social influences [52]. Acculturation implies adoption of foreign cultures, beliefs, behaviors and lifestyles (potentially unhealthy), and resultant association with poorer health outcomes [53]. Acculturation may explain these results in two ways. First, in comparison to Haiti, Jamaica and Guyana have more stable economies that may facilitate cultural contact and adoption of the U.S. lifestyle through globalization prior to migration. Consequently, their cultural "buffer" may have eroded prior to migration making them more susceptible to negative effects of acculturation. Secondly, Guyanese and Jamaican immigrants may have better English proficiency and consequently experience acculturation more rapidly upon migration in comparison to their French speaking Haitian counterparts. Additionally, data from Jamaica and Guyana show that prevalence of chronic diseases have been increasing rapidly over the last $15-20$ years [18, 23] among Caribbean residents prior to departure for the U.S.

Despite these patterns of higher prevalence of DM among Guyanese and Jamaican immigrants, the contrary was observed in rates of overweight and obesity, where a health advantage was found. When 
controlling for age, sex and health insurance, NHB Guyanese and Jamaican immigrants were less likely to be overweight/obese in comparison to U.S born blacks. The reasons for this transposition in health outcomes among the AC sub-groups is unclear. Behavioral (e.g., salt, sugar consumption), genetic, or social factors not assessed or acculturation may play a role in these country of birth differences exhibited for overweight/obesity among the AC sub-groups.

These findings should be interpreted in light of some limitations. The prevalence of CV health factors was self-reported, which may have resulted in underestimated prevalence rates particularly in those individuals who are undiagnosed. There were smaller samples of NHB immigrants from Guyana, Haiti and Jamaica in comparison to U.S born blacks, which may have affected the precision of the estimates. Finally, survey items were not an exact representation of established guidelines by the AHA. The unique ability of CHS to delineate the sub-populations of interest and provide reliable population estimates far outweigh these limitations.

\section{New Contribution to the Literature}

To our knowledge, this is the first study to examine CV health factors among AC immigrant subgroups disaggregated by country of birth. Our study highlights the value in disaggregating the AC immigrant sub-groupings that may conceal critical health disparities. Our findings imply that specific sub-groups of AC immigrants are more vulnerable to certain CV health factors than others, providing information about the most at-risk populations for disease-specific programmatic and/or policy intervention. In addition, this study marks an initial step in delineating a population that has been understudied in immigrant health research.

To further identify reasons for health disparities among the AC immigrant populations, an exploration of ethnic heterogeneity is warranted. Ethnic background (country of birth) may be as crucial as racial group in understanding immigrant health disparities. Further analyses into country of birth differences should be replicated in nationally representative surveillance in the U.S., incorporating assessments of social 
determinants of health such as acculturation, length of residency and perceived discrimination that may explain the differences in health outcomes among AC immigrant subgroups. 


\section{Manuscript 1: Tables and Figures}

Table 1: Sample Characteristics by Country of Birth of non-Hispanic Blacks, New York City Community Health Survey, 2010-2014.

\begin{tabular}{|c|c|c|c|c|c|}
\hline & $\begin{array}{l}\text { Guyana } \\
(\mathrm{n}=369)\end{array}$ & $\begin{array}{l}\text { Haiti } \\
(n=291)\end{array}$ & $\begin{array}{l}\text { Jamaica } \\
(\mathrm{n}=1031)\end{array}$ & $\begin{array}{l}\text { U.S. } \\
(n=5987)\end{array}$ & $\begin{array}{l}\text { Total } \\
(\mathrm{n}=7678)\end{array}$ \\
\hline $\begin{array}{l}\text { Age Group } \\
18-24\end{array}$ & $9.3^{*}(4.16-14.48)$ & $13.1^{*}(6.47-19.79)$ & $10.0(6.96-13.08)$ & 19.4 (17.63-21.25) & $17.0(15.55-18.54)$ \\
\hline $25-44$ & $35.6(28.75-42.50)$ & $47.3(39.12-55.52)$ & $37.3(33.17-41.51)$ & 37.5 (35.56-39.38) & 37.8 (36.18-39.49) \\
\hline $45-64$ & $39.3(32.30-46.26)$ & $30.9(23.76-38.02)$ & $38.2(34.24-42.14)$ & 29.4 (27.73-30.97) & $31.4(29.94-32.86)$ \\
\hline $65^{+}$ & $15.8(10.71-20.84)$ & $8.7^{*}(4.77-12.57)$ & $14.4(11.75-17.15)$ & 13.7 (12.67-14.81) & $13.7(12.75-14.68)$ \\
\hline Female & $56.6(49.44-63.73)$ & $55.6(47.36-63.81)$ & $61.5(57.44-65.60)$ & 57.4 (55.46-59.36) & $58.0(56.22-59.57)$ \\
\hline $\begin{array}{l}\text { Education } \\
\text { Less than High } \\
\text { School }\end{array}$ & $13.5^{*}(8.56-18.36)$ & $6.1^{*}(2.35-9.93)$ & $21.1(17.66-24.59)$ & 13.1 (11.77-14.39) & $14.0(12.84-15.16)$ \\
\hline High School Graduate & 43.7 (36.39-50.96) & $37.1(29.68-45.62)$ & $34.9(30.87-38.97)$ & 33.8 (31.97-35.72) & $34.8(33.14-36.41)$ \\
\hline Some College & $19.2(13.44-24.88)$ & 31.3 (23.78-38.74) & $26.1(22.28-29.92)$ & 34.0 (32.10-35.81) & 31.7 (31.13-33.29) \\
\hline College Graduate & $23.7(18.07-29.31)$ & $25.5(19.00-31.90)$ & $17.9(14.86-20.86)$ & 19.1 (17.74-20.50) & $19.5(18.31-20.72)$ \\
\hline $\begin{array}{l}\text { Employment } \\
\text { Employed }\end{array}$ & $61.8(54.79-68.79)$ & $57.6(49.3-65.99)$ & $63.4(59.32-67.48)$ & $52.6(50.68-54.54)$ & $55.1(53.42-56.75)$ \\
\hline Unemployed & $11.5^{*}(7.07-15.92)$ & $16.1^{*}(8.95-23.27)$ & $13.4(10.37-16.45)$ & 13.3 (11.85-14.72) & $13.3(12.10-14.58)$ \\
\hline Not in Labor Force & 26.7 (20.29-33.15) & 26.2 (18.91-33.59) & $23.2(19.69-26.68)$ & 34.1 (32.33-35.87) & $31.6(30.06-33.08)$ \\
\hline
\end{tabular}

Insurance 


$\begin{array}{llll}\text { Uninsured } \quad 23.4(15.66-31.24) & 24.7(21.01-28.42) & 13.6(12.15-15.12) & 16.2(14.88-17.57)\end{array}$

Health Access

$$
\text { No }
$$

8.1* (4.12-12.17)

$16.7^{*}(10.27-23.22) \quad 10.0(7.48-12.54) \quad 10.4(9.13-11.64)$

$10.5(9.42-11.59)$ *Estimate should be interpreted with caution Estimate's Relative Standard Error (a measure of estimate precision) is greater than $30 \%$, or
the $95 \%$ Confidence Interval half-width is greater than 10 or the sample size is too small, making the estimate potentially unreliable. 
Table 2: Cardiovascular Health Factors for non-Hispanic Blacks by Country of Birth, New York City Community Health Survey, $2010-2014$.

\begin{tabular}{|c|c|c|c|c|c|}
\hline & $\begin{array}{l}\text { Guyana } \\
\mathrm{n}=369\end{array}$ & $\begin{array}{l}\text { Haiti } \\
n=291\end{array}$ & $\begin{array}{l}\text { Jamaica } \\
\mathrm{n}=1031\end{array}$ & $\begin{array}{l}\text { U.S. Black } \\
\mathrm{n}=5987\end{array}$ & $\begin{array}{l}\text { Total } \\
\mathrm{n}=7678\end{array}$ \\
\hline Diabetes & $17.3(77.04-88.35)$ & $8.7^{*}(4.70-12.70)$ & 15.9 (12.84-18.99) & $11.8(10.68-12.85)$ & $12.6(11.57-13.60)$ \\
\hline Hyperlipidemia & $28.3(22.01-34.67)$ & $23.3(16.45-30.12)$ & $28.6(25.00-32.20)$ & 25.7 (24.14-27.32) & $26.2(24.81-27.60)$ \\
\hline Hypertension & $38.2(31.31-45.10)$ & $27.3(20.26-34.42)$ & $38.9(34.90-42.92)$ & 35.2 (33.40-36.92) & 35.5 (33.98-37.06) \\
\hline Overweight/obese & $62.2(55.10-69.30)$ & 73.8 (66.65-80.91) & 63.7 (59.58-67.90) & $68.2(66.35-70.10)$ & $67.4(65.82-69.07)$ \\
\hline
\end{tabular}

*Estimate should be interpreted with caution Estimate's Relative Standard Error (a measure of estimate precision) is greater than 30\% or 95\% Confidence Interval half-width is greater than 10 or the sample size is too small, making the estimate potentially unreliable. 
Table 3: Unadjusted and Adjusted Odds Ratios (95\% CI) for CV Health Factors by Country of Birth, New York City Community Health Survey, 2010-2014.

Table 3: Unadjusted and Adjusted Odds Ratios (95\%CI) for CV Health Factors by Country of Birth, New York City Community Health Survey, 2010-2014.

\begin{tabular}{|c|c|c|}
\hline Diabetes & Unadjusted Model (OR(95\%CI) & $\begin{array}{c}\text { Adjusted Model a }^{a} \\
\text { (OR(95\%CI) }\end{array}$ \\
\hline U.S. Black (referent) & 1.00 & 1.00 \\
\hline Guyana & $1.57(1.04-2.36)$ & $1.48(0.96-2.28)$ \\
\hline Haiti & $0.71(0.43-1.20)$ & $0.83(0.50-1.36)$ \\
\hline Jamaica & $1.42(1.10-1.83)$ & $1.45(1.08-1.93)$ \\
\hline Hyperlipidemia & Unadjusted Model & Adjusted Model \\
\hline U.S. Black (referent) & 1.00 & - \\
\hline Guyana & $1.14(0.83-1.58)$ & - \\
\hline Haiti & $0.88(0.59-1.30)$ & - \\
\hline Jamaica & $1.16(0.95-1.41)$ & - \\
\hline Hypertension & Unadjusted Model & Adjusted Model ${ }^{\mathrm{b}}$ \\
\hline U.S. Black (referent) & 1.00 & 1.00 \\
\hline Guyana & $1.14(0.84-1.54)$ & $0.88(0.63-1.23)$ \\
\hline Haiti & $0.69(0.48-1.00)$ & $0.69(0.45-1.04)$ \\
\hline Jamaica & $1.17(0.98-1.41)$ & $0.97(0.78-1.20)$ \\
\hline Overweight/Obese & Unadjusted Model & Adjusted Model $^{c}$ \\
\hline U.S. Black (referent) & 1.00 & 1.00 \\
\hline Guyana & $0.77(0.56-1.05)$ & $0.65(0.47-0.89)$ \\
\hline Haiti & $1.31(0.90-1.91)$ & $1.30(0.87-1.93)$ \\
\hline Jamaica & $0.82(0.67-1.00)$ & $0.72(0.58-0.88)$ \\
\hline
\end{tabular}


Figure 1: Health Behaviors by Country of Birth for Non-Hispanic Blacks, New York City Community Health Survey, 2010-2014.

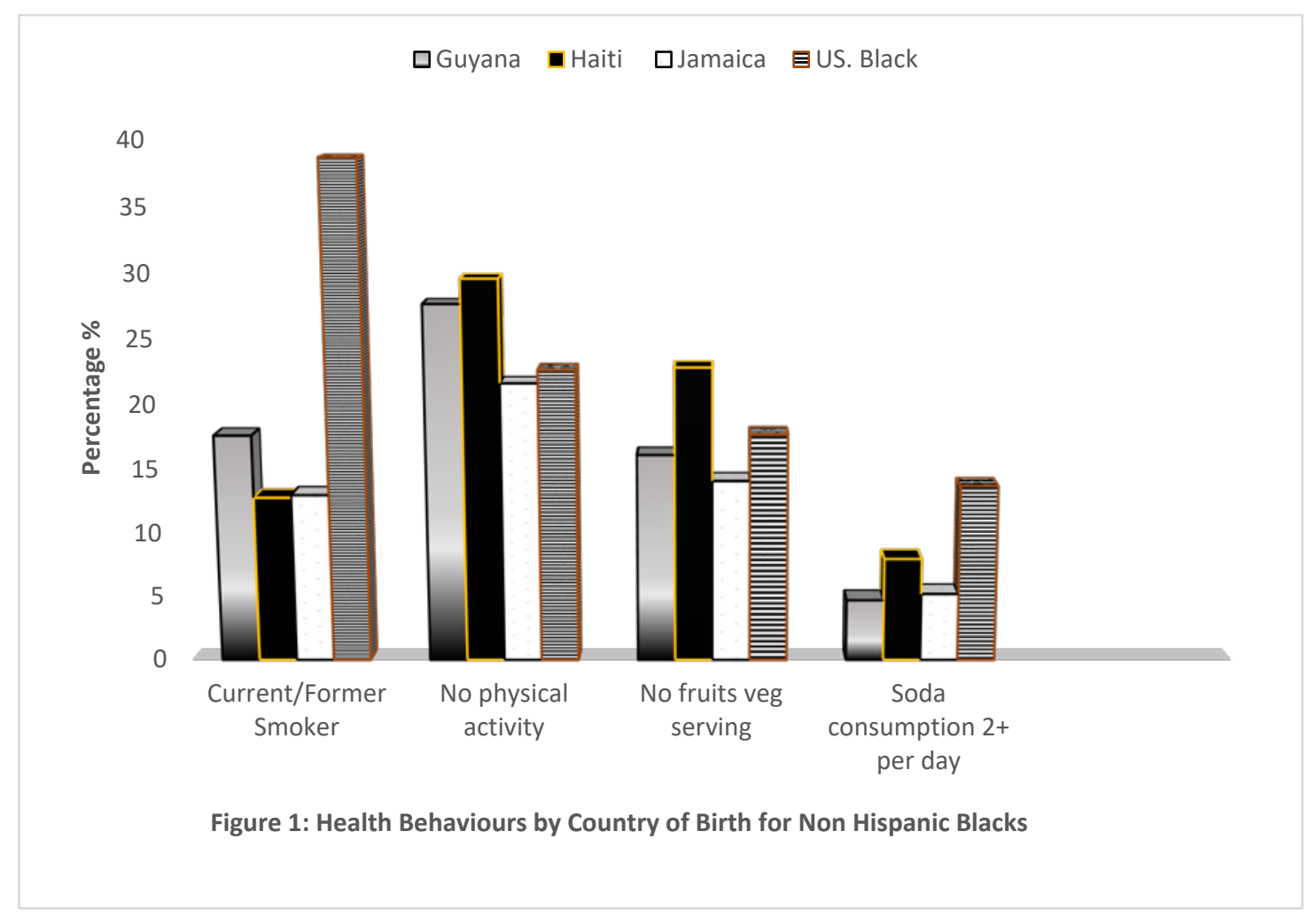

a. Note: Prevalence estimates for current/former smokers (Haiti), no fruit/vegetable consumption (Guyana) and 2+ soda consumption (Guyana, Haiti, Jamaica) should be interpreted with caution due to small sample sizes, making the estimate potentially unreliable. 


\section{References}

1. Roth GA, Huffman MD, Moran AE, et al: Global and regional patterns in cardiovascular mortality from 1990 to 2013. Circulation. 2015;132(17):1667-1678.

2. Benjamin EJ, Blaha MJ, Chiuve SE, et al: Heart disease and stroke statistics-2017 update: a report from the American Heart Association. Circulation. 2017;135(10): e146-e603.

3. Lloyd-Jones DM, Hong Y, Labarthe D, et al: Defining and setting national goals for cardiovascular health promotion and disease reduction: the American Heart Association's strategic impact goal through 2020 and beyond. Circulation. 2010;121(4):586-613.

4. Rastogi SJ, Hoeffel E, Drewery MP: The black Population 2010. 2010 Census Briefs. Washington, DC: US Department of Commerce, Economics and Statistics Administration. U.S. Census Bureau, 2010. Available at: https://www.census.gov/prod/cen2010/briefs/c2010br-06.pdf. Accessed October 30, 2017.

5. Thomas KA: A demographic profile of black Caribbean Immigrants in the United States. Migration Policy Institute; 2012. Available at: https://www.migrationpolicy.org/research/CBIdemographic-profile-black-caribbean-immigrants. Accessed October 27, 2017

6. Shaw-Taylor Y, Tuch SA: The Other African Americans: Contemporary African and Caribbean Immigrants in the United States. Maryland: Rowman \& Littlefield; 2007.

7. Kent M: Immigration and America's black population. Washington, DC: Population Reference Bureau; 2007. Available at: http://www.prb.org/pdf07/62.4immigration.pdf. Accessed November 25, 2017.

8. Zong J, Batalova J: Caribbean Immigrants in the United States. 2016. Available at https://www.migrationpolicy.org/article/caribbean-immigrants-united-states. Accessed January 8, 2018. 
9. Lobo AP, Salvo JJ: The Newest New Yorkers, 2000: Immigrant New York in the New Millenium. New York NY: Department of City Planning; 2004. Available at https://www1.nyc.gov/assets/planning/download/pdf/data-maps/nycpopulation/nny2000/newest_new_yorkers_2000.pdf. Accessed June 19, 2018.

10. United States Census Bureau: American fact finder. Selected profile in the United States: 2016 American Community Survey 1-Year Estimates. Available at https://factfinder.census.gov/faces/tableservices/jsf/pages/productview.xhtml?pid=ACS 16 1YR S0201\&prodType=table. Accessed June 19, 2018.

11. Dragan KL, King L, Hitherland K, et al. Community health profiles atlas 2015; The New York City Department of Health and Mental Hygiene. Available at https://www1.nyc.gov/assets/doh/downloads/pdf/data/2015_CHP_Atlas.pdf. Accessed June 19, 2018.

12. New York Academy of Medicine: New York City health provider partnership Brooklyn needs assessment. Available at https://www.health.ny.gov/health_care/medicaid/redesign/dsrip/pps_applications/docs/maimonid es medical center/3.8 maimonides cna.pdf. Accessed June 19, 2018.

13. The City of New York Department of Youth and Community Development: 2017 Community needs assessment. Retrieved from https://www1.nyc.gov/assets/dycd/downloads/pdf/CNA/CNA_Report-4-19-17.pdf. Accessed June 18, 2018

14. Havranek EP, Mahasin MS, Barr DA, et al: Social determinants of risk and outcomes for cardiovascular disease: a scientific statement from the American Heart Association. Circulation, 2015. 132(9): p. 873-98. 
15. Oladele C, Thompson TA, Zhang ER, Nunez-Smith M: Population-Based surveillance for cardiovascular disease in the Caribbean: challenges and opportunities for regional approaches. Current Cardiovascular Risk Report. 2017;11(4).

16. Bennett NR, Francis DK, Ferguson TS, et al: Disparities in diabetes mellitus among Caribbean populations: a scoping review. International Journal of Health Equity. 2015; 14:23.

17. Ferguson TS, Tulloch-Reid M: Cardiovascular disease risk factors in blacks living in the Caribbean. Current Cardiovascular Risk Reports. 2010;4(1):76-82.

18. Ferguson TS, Francis DK, Tulloch-Reid MK, Younger NO, McFarlane SR, Wilks RJ: An update on the burden of cardiovascular disease risk factors in Jamaica: findings from the Jamaica Health and Lifestyle Survey 2007-2008. West Indian Med J. 2011;60(4):422-428.

19. Sargeant LA, Wilks RJ, Forrester TE: Chronic diseases--facing a public health challenge. West Indian Med J. 2001;50 Suppl 4:27-31.

20. Boyne MS: Diabetes in the Caribbean. In Diabetes Mellitus in Developing Countries and Underserved Communities. Springer International Publishing; 2017.

21. Hennis A, Suh-Wu W, Nemesure B, et al: Diabetes in a Caribbean population: epidemiological profile and implications. International journal of epidemiology, 2002. 31(1): p. 234-239.

22. Bidulescu A, Ferguson TS, Hambleton I, et al: Educational health disparities in hypertension and diabetes mellitus among African descent populations in the Caribbean and the USA: a comparative analysis from the Spanish Town cohort (Jamaica) and the Jackson heart study (USA). Int J Epidemiol. 201;16 (1):33.

23. Institute for Health Metrics and Evaluation. Country Profiles: Guyana. Retrieved from http://www.healthdata.org/guyana. Accessed January 16, 2018. 
24. Griffith DM, Johnson JL, Zhang R, Neighbors HW, Jackson JS: Ethnicity, nativity, and the health of American blacks. J Health Care Poor Underserved. 2011;22(1):142-156.

25. Keane F, Tappen RM, Williams CL, Rosselli M: Comparison of African American and AfroCaribbean older adults' self-reported health status, function, and substance use. Journal of Black Psychology. 2009;35(1):44-62.

26. Read JG, Emerson MO, Tarlov A: Implications of black immigrant health for U.S. racial disparities in health. J Immigr Health. 2005;7(3):205-212.

27. Fang J, Madhavan S, Alderman MH: The association between birthplace and mortality from cardiovascular causes among black and white residents of New York City. N Engl J Med. 1996;335(21):1545-1551.

28. Carlisle SK: Nativity differences in chronic health conditions between nationally representative samples of Asian American, Latino American, and Afro-Caribbean American respondents. J Immigr Minor Health. 2012;14(6):903-911.

29. Bamimore A, Olafiranye O, Demede M, et al: High prevalence of hypertension and other cardiometabolic risk factors in US- and Caribbean-Born blacks with chest pain syndromes. Cardiorenal Medicine. 2012;2(3):163-167.

30. Mouzon DM, McLean JS: Internalized racism and mental health among African-Americans, USborn Caribbean blacks, and foreign-born Caribbean blacks. Ethn Health. 2017;22(1):36-48.

31. Jackson JS, Torres M, Caldwell CH, et al: The National Survey of American Life: a study of racial, ethnic and cultural influences on mental disorders and mental health. International Journal Of Methods In Psychiatric Research. 2004;13(4):196-207. 
32. Commodore-Mensah Y, Matthie N, Wells J, et al: African Americans, African Immigrants, and Afro-Caribbeans differ in social determinants of hypertension and diabetes: evidence from the National Health Interview Survey. Journal of Racial and Ethnic Health Disparities. 2017.

33. Hamilton TG, Hummer RA: Immigration and the health of U.S. black adults: does country of origin matter? Soc Sci Med. 2011;73(10):1551-1560.

34. Williams DR, Haile R, Gonzalez HM, Neighbors H, Baser R, Jackson JS. The mental health of Black Caribbean immigrants: results from the National Survey of American Life. Am J Public Health. 2007;97(1):52-59.

35. González HM, Tarraf W, Comorbid cardiovascular disease and major depression among ethnic and racial groups in the United States. Int Psychogeriatr, 2013. 25(5): p. 833-41.

36. Assari S: Race and ethnic differences in associations between cardiovascular diseases, anxiety and depression in the United States. International Hournal of Travel Medicine and Global Health, 2014. 2(2):p. 103-109.

37. Jackson JS, Neighbors HW, Nesse RM et al: Methodological innovations in the National Survey of American Life. Int J Methods Psychiatr Res, 2004. 13(4): p. 289-98.

38. Williams DR, Jackson JS. Race/ethnicity and the 2000 census: recommendations for African American and other black populations in the United States. Am J Public Health. 2000;90(11):1728-1730.

39. Davis EE, Huffman FG. Differences in coronary heart disease risk markers among apparently healthy individuals of African ancestry. Journal of National Medical Association. 2007;99(6):658-664.

40. Moss MC, McDowell JR. Rural Vincentians' (Caribbean) beliefs about the usage of nonprescribable medicines for treating Type 2 diabetes. Diabetic Medicine. 2005;22(11):1492-1496. 
41. Dagadu H, Christie-Mizell AC: Heart trouble and racial group identity: exploring ethnic heterogeneity among black Americans. Race and Social Problems, 2014. 6(2): p. 143-160.

42. Norton J, Sanderson M, Gupta L, et al: Methodology updates to the new york city community health survey. 2012. Available from URL: https://www1.nyc.gov/assets/doh/downloads/pdf/epi/epiresearch-chsmethods.pdf. Accessed November 10, 2017.

43. New York City Department of health and mental hygiene: NYC community health survey. Available from URL: https://www1.nyc.gov/site/doh/data/data-sets/community-healthsurvey.page. Accessed November 10, 2017.

44. SAS Enterprise Guide version 5.1: SAS Insititute Inc., Cary NC. USA.

45. Read JnG, Emerson MO: Racial context, black immigration and the US black/white health disparity. Social Forces. 2005;84(1):181-199.

46. Jass G, Massey DS. Immigrant health: Selectivity and acculturation. IFS Working Papers, Institute for Fiscal Studies (IFS).No. 04/23.

47. Batalova J, Schulz J: Haitian Immigrants in the United States. Available from: https://www.migrationpolicy.org/article/haitian-immigrants-united-states. Accessed January 12, 2018.

48. Francois F, Elysée G, Shah S, Gany F: Colon cancer knowledge and attitudes in an immigrant Haitian community. J Immigr Minor Health. 2009;11(4):319-325

49. Sangaramoorthy T, Guevara EM: Immigrant Health in Rural Maryland: A qualitative study of major barriers to health care access. J Immigr Minor Health. 2017;19(4):939-946. 
50. Lubetkin EI, Zabor EC, Isaac K, Brennessel D, Kemeny MM, Hay JL. Health literacy, information seeking, and trust in information in Haitians. Am J Health Behav. 2015;39(3):441450.

51. Allen JD, Mars DR, Tom L, et al: Health beliefs, attitudes and service utilization among Haitians. J Health Care Poor Underserved. 2013;24(1):106-119.

52. Gibson MA: Immigrant Adaptation and Patterns of Acculturation. Human Development. 2011;44(1):19-23.

53. Schwartz SJ, Unger JB, Zamboanga BL, Szapocznik J: Rethinking the concept of acculturation: implications for theory and research. Am Psychol. 2010;65(4):237-251 


\section{Chapter 5}

\section{Study 2 Manuscript}

Title: Length of Residence and Cardiovascular Health among AC immigrants in NYC

Author names and affiliations:

Sabena C. Thomas

West Virginia University School of Public Health

Department of Social and Behavioral Sciences

1 Medical Center Drive

Morgantown West Virginia 26506. U.S.A.

Tel: 681-285-7348

Amna Umer

West Virginia University School of Medicine

Department of Pediatrics

West Virginia University

1 Medical Center Drive

Morgantown West Virginia 26506. U.S.A.

amumer@hsc.wvu.edu

Tel: 304-293-1211

Yvonne Commodore-Mensah

Community-Public Health Nursing

John's Hopkins School of Nursing Room \#419

Baltimore, Maryland 21205

ycommod1@jhu.edu

Tel: 410-614-1519

Danielle Davidov

School of Medicine

Department of Emergency Medicine

West Virginia University

P.O. Box 9190

Morgantown, WV 26506. USA

Email: ddavidov@mix.wvu.edu

Tel: 304-293-4083

Corresponding author:

Christiaan G. Abildso

West Virginia University School of Public Health

Department of Social and Behavioral Sciences

1 Medical Center Drive

Morgantown West Virginia 26506. U.S.A

cgabildso@hsc.wvu.edu

Tel: 304-293-5374 


\begin{abstract}
Cardiovascular disease (CVD) disproportionately affects non-Hispanic blacks (NHB) in the United States (U.S.). Afro-Caribbean (AC) immigrants comprise over fifty percent of the immigrant black population and are critical in understanding the health trajectories of blacks in the U.S. We assessed the relationship between length of residence (proxy measure for acculturation) and cardiovascular health (CVH) based on American Heart Association's (AHA) seven ideal cardiovascular health components among AC immigrants in New York City (NYC). CVH scores were categorized into poor/intermediate CVH (0-3 components) or ideal CVH ( $\geq 4$ components). Multivariable logistic regression was used to examine the association between length of residence in the U.S. and poor/intermediate CVH. The odds of poor/intermediate CVH was significantly higher for Guyanese (OR = 3.51; 95\% CI: 1.03-11.95) and Haitian immigrants (OR =8.02; 95\% CI 1.88-34.12) residing in the U.S. for $\geq 10$ years than for those living in the U.S. for $<10$ years. Length of residence was not significantly associated with CVH among Jamaican immigrants. We found evidence of ethnic differences in the association between acculturation and CVH among AC immigrants in a major metropolitan city. Culturally tailored interventions are needed to improve the CVH of AC immigrants as they become integrated into the U.S., with special consideration of country of birth.
\end{abstract}

Keywords: cardiovascular health, Afro-Caribbean, immigrants, acculturation 


\section{Introduction}

Cardiovascular disease (CVD) remains the leading causes of death in the U.S. [1]. Through its strategic goals, the American Heart Association (AHA) conceptualized the cardiovascular health index (CVHI) to account for an individual's total cardiovascular health $(\mathrm{CVH})$ profile using seven health metrics [1]. The metrics include fasting plasma glucose, total cholesterol, blood pressure, body mass index (BMI), physical activity, diet and smoking status [1]. Each metric was assigned categories of value ranges labeled as "poor”, “intermediate” or "ideal” [1]. Further, the AHA placed special emphasis on the significance of addressing disparities among underserved minority groups in an effort to expand its preventative goals [1]. Blacks in the U.S. have a significantly higher prevalence of CVD and known risk factors than any other racial/ethnic minority group [2]. By 2035, it is projected that blacks will have the highest rates of CVDs in relation to other races [3]. Additionally, using the CVHI, it has been shown that ideal levels of all seven metrics are lower among black populations in the U.S. [4, 5].

Blacks in the U.S. are a heterogeneous group comprised of African and Afro-Caribbean immigrants [6]. Afro-Caribbean (AC) immigrants are people of Caribbean/West Indian origins from countries such as Guyana, Haiti and Jamaica [7]. There are approximately four million Caribbean immigrants in the U.S. and they make up more than half of the immigrant black population in the U.S. [8, 9]. Thus, it is critical to understand the health trajectory of this population to promote CVH. Few published studies have examined the risk of CVD among AC immigrants in the U.S. [10, 11] partly owing to AC immigrants being subsumed into the category of black/African American along with African immigrants [12]. The few published studies have identified a CVH advantage among AC immigrants in comparison to U.S. born blacks [13-15]. AC immigrants have been identified to have lower risk markers for coronary heart disease and lower rates of coronary artery disease mortality rates than U.S. born blacks $[11,15]$. However, as identified in other immigrant groups, this favorable health advantage may diminish with increased length of residence in the U.S. [16-18]. 
Length of residence has consistently been used as a proxy for acculturation [16, 19].

Acculturation refers to psychological and cultural changes that occur as a result of persistent and first hand contact with two or more cultural groups [20,21]. Increased residence in the U.S. may propel continuous contact with socio-cultural and environmental factors that negatively affect immigrants' health $[22,23]$. The proxy measure assumes greater length of residence is associated with greater acculturation, thus adopting a more "western” (and potentially unhealthy) lifestyle and loss of health behaviors associated with immigrants' home countries [17, 24]. Length of residence therefore, importantly denotes how social contexts and migration processes affect health.

Studies examining the impact of length of residence on the CVH of immigrants have found mixed results. For instance, a cross-sectional sample of West African immigrants residing $\geq 10$ years in the U.S. had higher odds of hypertension and obesity among females and males respectively compared to more recent immigrants [12]. Among Hispanic immigrants, increased residence in the U.S. has been shown to be both detrimental and beneficial to $\mathrm{CVH}$ [25-28]. Among Asian immigrants, increased length of residence has been found to be associated with increased smoking rates [26, 29], better dietary practices [30-32] and increased physical activity [33].

There are significant gaps in knowledge on the association between acculturation and CVH among ACs in the U.S. Additionally, the relatively few studies focusing on CVH and AC immigrants are limited by a lack of examination of country of birth (COB) differences among AC subgroups. AC immigrants are a diverse group with different languages, immigrant selectivity, socio-political and economic backgrounds that may influence different post-migration health outcomes [15, 34-36]. Further, AHA metrics have not been broadly studied or applied to the AC immigrant population. Hence, we sought to assess the relationship between length of residence in the U.S. and CVH for a population of AC immigrants. We hypothesized that ACs with greater length of residence ( $\geq 10$ years) will have a higher prevalence of poor/intermediate CVH than those who have resided in the U.S. for a shorter duration $(<10$ years). 


\section{Methods}

This study used data from the New York City (NYC) Department of Health and Mental Hygiene Community Healthy Survey (CHS) 2010-2014. The CHS is a cross-sectional telephone survey of approximately 9,000 randomly sampled NYC non-institutionalized residents $\geq 18$ years. Data from the random sample are weighted to properly represent the NYC population [37]. The CHS utilized a computer-assisted telephone interviewing system (CATI), and interviews were conducted in English, Spanish, Russian, Mandarin and Cantonese. The CHS captures neighborhood and citywide estimates of a variety of chronic diseases and behavioral risk factors of the NYC population. One adult is randomly selected from the household to complete the survey then consent information is received [38]. The 20102014 combined years’ analyses are weighted to the NYC adult residential population as per Census 2010 and the 2011-2013 American Community Survey. Detailed information of the CHS methodology is published elsewhere [37]. Institutional Review Board was not required for this study as the data were deidentified and provided under a data use agreement.

\section{Study Population and Sample}

The study population consisted of AC immigrant respondents who reported their race as nonHispanic Blacks (NHB) and place of birth as Guyana ( $n=369)$, Haiti $(n=291)$ or Jamaica $(n=1031)$ in the CHS. These three sub-groups provide the largest samples of AC-immigrants residing in NYC [39]. Respondents' place of birth was ascertained from the question "Where were you born? Please tell me the country” in the CHS.

\section{Calculation of Cardiovascular Health}

CVH was assessed from CHS self-report data using methodology adapted from previous studies [40, 41]. CVH incorporated seven metrics (fasting glucose, total cholesterol, blood pressure, body mass index (BMI), physical activity, diet and smoking status) as per AHA’s definition, but adapted based on 
CHS items. Diabetes, high cholesterol and high blood pressure were self-reported as "yes" or "no" on the CHS survey and were categorized as "not ideal" = 0 or "ideal” =1, respectively. The survey responses from the CHS did not capture information on "intermediate” category for each health factor. Hence, each behavioral factor and BMI were also categorized as "ideal” or "not ideal” as adapted from previous studies [40, 41]. BMI was categorized as not ideal (overweight/obese) and ideal (underweight/normal). For physical activity, “ideal” or “not ideal” was determined from a self-reported “yes” or “no” respectively on CHS survey question: “during the past 30 days, other than your regular job, did you participate in any physical activities or exercises such as running, calisthenics, golf, gardening, or walking for exercise?” Regarding diet, respondents who reported having consumed $\geq 5$ servings of fruit and or vegetable yesterday were classified were classified as “ideal”. Respondents who reported $<5$ servings were classified as “not ideal”. For smoking status, respondents who reported never having smoked at least 100 cigarettes in their lifetime were considered "ideal" and those who reported to be current or former smokers were considered "not ideal”. The seven metrics were summed together and could range from 0-7.

For the purpose of this study the overall CVH score was further grouped into three categories: "ideal" where the overall CVH score was $\geq 4$; "intermediate" where the overall CVH score ranged from 2-3; and "poor" where the overall CVH score ranged from 0-1 [42]. After conducting cross tabulations of length of stay and CVH as three categories (ideal, intermediate and poor), there was a paucity of individuals in the poor category. Therefore, intermediate and poor categories were combined into a single group for more stable estimates for each country of birth group. This CVH variable was analyzed as a dichotomous variable coded as 0 for “ideal” CVH and 1 for "poor/intermediate” CVH.

Independent Variables

Main Independent Variable: Length of residence in the U.S. 
Length of residence in the U.S. was determined from the question "how long have you lived in this country?” Responses were categorized as $<5$ years, $5-9$ years and $\geq 10$ years. This variable was dichotomized into $<10$ years and $\geq 10$ years based on prior literature among U.S. immigrants [43, 44].

\section{Covariates}

Covariates for this study included demographic information on the participant's age (18-44, 4564, 65+ years), sex (male, female), education (high school graduate or less education, some college or higher), employment status (employed, not in the labor force/unemployed), health insurance (insured, uninsured) and healthcare access. Healthcare access was determined from the question "Was there a time in the past 12 months when you needed medical care but did not get it?” Responses were dichotomized into yes or no. Responses were reversed coded to satisfy having healthcare access or not.

\section{Statistical Analysis}

Analyses were conducted in SAS 9.3[45] with $p$ values of $\leq 0.05$ considered significant for all analyses. To account for complex survey design each analysis included weights. We compared the crude prevalence of sample socio-demographic characteristics, CVH score metrics and CVH groups (ideal, intermediate/poor) by COB. Chi-square analysis were used to assess the relationship among sociodemographic characteristics and COB.

Multiple logistic regression analyses were used to determine the association between length of residence and CVH group (ideal vs poor/intermediate) for each COB. First, we performed univariable logistic regression models for each independent variable and CVH group. Second, multivariable models were assessed which included all covariates (age, sex, education, employment, insurance and healthcare access). These covariates were included in the model because of their theoretical significance and use in prior immigrant studies [16, 46]. Odds ratios and 95\% confidence intervals are reported. Analyses and coding were double checked for accuracy by the New York City Department of Mental Hygiene. 


\section{Results}

Sociodemographic Characteristics

Descriptive characteristics of the sample are described in table 1. The majority (76.4\%) of AC immigrants reported residing in the U.S. for $\geq 10$ years. Almost half of the sample was younger than 45 years old. Most AC immigrants in the sample reported being a high school graduate or having less education (53.9\%), employed (61.9\%) and insured (76.6\%). Among the subgroups, Haitian immigrants were more likely to have more than a high school degree (56.7\%) in comparison to Guyanese (42.9) and Jamaican $(44.0 \%)$ immigrants $, \chi^{2}(4,1688)=22.2, p=0.02$.

\section{CVH Score Metrics and CVH groups}

Table 1 also shows that among the AC immigrant subgroups, the greatest prevalence of achieving the "ideal” category of the behavioral risk factors was for smoking status (i.e., had not smoked at least 100 cigarettes in their lifetime; Guyana $=82.2 \%$, Haiti=87.1\% and Jamaica $=86.9 \%$ ). The prevalence of meeting “ideal” metabolic health factors was highest for diabetes (i.e., participant had never been told by a health professional they had diabetes) for all three subgroups (Guyana $=82.7 \%$, Haiti $=91.3 \%$ and Jamaica $=84.1 \%$ ). For all seven health metrics, AC immigrants were least likely to achieve ideal dietary health $\left(\right.$ Guyana $=5.9 \%{ }^{2}$, Haiti $=7.9 \%^{3}$ and Jamaica $\left.=9.2 \%\right)$. The prevalence of overall CVH group (ideal vs poor/intermediate) for each AC subgroup is shown in figure 1.

\section{Association between Length of Residence and CVH group by COB}

Table 2 shows univariable and multivariable analyses for the association between length of residence and CVH group by COB. In univariable analysis, Guyanese immigrants residing in the U.S.

\footnotetext{
${ }^{2,3}$ Estimate should be interpreted with caution Estimate's Relative Standard Error (a measure of estimate precision) is greater than 30\%, or the 95\% Confidence Interval half-width is greater than 10 or the sample size is too small, making the estimate potentially unreliable.
} 
$\geq 10$ vs. $<10$ years were more likely to have intermediate/poor $\mathrm{CVH}(\mathrm{OR}=4.88 ; 95 \% \mathrm{CI}: 1.69-14.11)$. In multivariable analysis, the association remained although reduced (OR = 3.51; 95\% CI: 1.03-11.95).

Results were similar for Haitian immigrants in both models. Haitian immigrants residing in the U.S. for $\geq$ 10 years were more likely to have poor/intermediate CVH than Haitian immigrants residing in the U.S. < 10 years $(\mathrm{OR}=10.17 ; 95 \% \mathrm{CI}$ 3.06-33.80). This association remained significant, although attenuated in the multivariable model adjusting for all known covariates (OR = 8.02; 95\% CI 1.88-34.12). In both adjusted and unadjusted analysis, the results for Jamaican immigrants showed that length of residence was not associated with CVH.

\section{Discussion}

Our analyses yield important insights regarding the association between CVH and length of residence in the U.S. among AC immigrants from Guyana, Jamaica and Haiti in a major metropolitan city. Firstly, we observed that greater length of residence was associated with poor/intermediate CVH but only among Guyanese and Haitian immigrants. This result is consistent with prior studies among Ghanaian and Nigerian immigrants that found increased length of residence in the U.S. to be associated with higher odds of having elevated CVD risk [44]. Similar results were also found among ethnically diverse immigrants using data from the National Health Interview Survey (NHIS), greater length of residence in the U.S. was associated with higher prevalence of cardiovascular risk factors [16, 46]. Previous studies have examined the relationship between length of residence and individual cardiovascular risk factors among immigrant groups [16, 47, 48]. However, the use of a CVH score gives a more salient representation of overall health in comparison to individual components of the score [49]. To our knowledge, this is the first study to examine the association between length of residence and CVH score using AHA metrics among AC immigrant subgroups.

In contrast, we did not find an association between length of residence and CVH among Jamaican immigrants. Similar results have been found in studies examining single cardiovascular risk factors. Bharmal and colleagues examined the association between length of residence and cardiovascular risk in 
Asian immigrants and found that length of residence was not associated with cardiovascular risk factors except overweight/obesity [30]. Likewise, another study among Asian immigrants found no association between length of residence and obesity; however, further ethnic subgroup analysis yielded significant associations for certain Asian ethnic subgroups [47]. This study develops on previous immigrant CVH studies by applying a comprehensive measure of CVH instead of individual risk factors. The results of the study also highlight the importance of sub-group investigation among regional groups that have very different genetic, social and cultural histories such as the Caribbean region.

In a broad context, the use of length of residence as a proxy measure for acculturation implies exposure to the psychosocial, cultural and environmental factors of U.S. society [50]. Cumulative exposure to these factors may influence psychosocial stressors [51]. Psychosocial stressors have been shown to be associated with adverse CVH outcomes and health behaviors [52-56]. In our sample, length of residence was associated with poor/intermediate cardiovascular health among Guyanese and Haitian immigrants, but not among Jamaican immigrants. One possible explanation for these differential outcomes is the varying experiences and social capital of black immigrants in the U.S. For example in our sample, Guyanese immigrants had significantly lower percentage of individuals reporting to have some form of college education or more. Haitian immigrants experience a double minority status of being nonnative English speakers and black [57]. Linguistic barriers may prevent healthcare utilization and uptake of health services $[58,59]$. Furthermore, a combination of stress and linguistic barriers may yield greater odds of adverse health outcomes in comparison to immigrants without a language barrier[59].

This study is limited in a number of ways. The cross-sectional nature of the data does not allow causal inferences or to assess temporal changes in immigrants' health. The prevalence of cardiovascular risk factors was self-reported; recall bias, cultural barriers or underestimation especially among the undiagnosed may limit accuracy of reports. Length of residence although conventionally used as a proxy for acculturation may not capture all the multidimensional facets of acculturation. The study may be underpowered because of the subgroup analyses that were conducted for the different COB categories and 
prevalence estimates for CV risk factors were unreliable for some sub-groups. The study has noteworthy strengths despite these limitations. A key strength is the use of the CHS data, which allows for COB stratification and analysis among three major AC immigrant groups in NYC. To our knowledge, this is the first examination of CVH using AHA metrics in the AC immigrant population. The study also highlights the importance of examining COB differences in an immigrant population that is usually grouped together with other racial/ethnic or regional groups.

Guyanese and Haitian immigrants could benefit from tailored strategies to address modifiable CVD risk factors. Longitudinal studies among Guyanese and Haitian subgroups are also needed to assess aspects of acculturation that may influence CVD risk such as changes in behavioral factors such as diet, physical activity and use of preventative services. Studies should also assess other social factors such as post-migration stress that may give rise to increased risk of CVD over time among AC immigrant subgroups. Additionally, emphasis should be placed on CVH disparities among understudied black immigrant populations that are often concealed under regional or racial groupings. 


\section{Manuscript 2: Tables and Figures}

Table 1. Descriptive Characteristics by Country of Birth among Afro-Caribbean Adult Immigrants, New York City Community Health Survey, 2010 -2014. Weighted \% (95\% CI)

\begin{tabular}{|c|c|c|c|c|}
\hline$(\%)$ & $\begin{array}{c}\text { Guyana } \\
(\mathrm{n}=369) 95 \% \mathrm{CI}\end{array}$ & $\begin{array}{c}\text { Haiti } \\
(n=291) 95 \% \text { CI }\end{array}$ & $\begin{array}{c}\text { Jamaica } \\
(\mathrm{n}=1031) 95 \% \mathrm{CI}\end{array}$ & $\begin{array}{c}\text { Total } \\
(n=1691) 95 \% \mathrm{CI}\end{array}$ \\
\hline \multicolumn{5}{|l|}{ Age Group } \\
\hline $18-44$ & $44.9(37.7,52.2)$ & $60.4(52.7,68.1)$ & $47.4(43.1,51.6)$ & $49.3(46.0,52.7)$ \\
\hline $45-64$ & $39.3(32.3,46.3)$ & $30.9(23.7,38.0)$ & $38.2(34.2,42.1)$ & $37.0(33.9,40.2)$ \\
\hline $65+$ & $15.8(10.7,20.8)$ & $8.7^{*}(4.8,12.6)$ & $14.4(11.7,17.2)$ & $13.6(11.5,15.7)$ \\
\hline$P$ value & & & & 0.02 \\
\hline Female & $56.6(49.4,63.7)$ & $55.6(47.4,63.8)$ & $61.5(57.4,65.6)$ & $59.2(56.0,62.5)$ \\
\hline$P$ value & & & & 0.30 \\
\hline \multicolumn{5}{|l|}{ Education } \\
\hline$\leq$ High School & $57.2(50.1,64.2)$ & $43.3(34.8,51.7)$ & $56.0(51.8,60.2)$ & $53.9(50.6,57.3)$ \\
\hline Tech School/College Grad & $42.9(35.8,49.9)$ & $56.7(48.3,65.2)$ & $44.0(39.8,48.2)$ & $46.1(42.7,49.4)$ \\
\hline$P$ value & & & & 0.02 \\
\hline \multicolumn{5}{|l|}{ Employment } \\
\hline Unemployed/Not in Labor Force & $38.2(31.2,45.2)$ & $42.4(34.0,50.7)$ & $36.6(32.5,40.7)$ & $38.1(34.8,41.4)$ \\
\hline P value & & & & 0.79 \\
\hline \multicolumn{5}{|l|}{ Insurance } \\
\hline Uninsured & $19.8(14.1-25.6)$ & $23.4(15.7,31.2)$ & $24.7(21.0,28.4)$ & $23.3(20.4,26.3)$ \\
\hline$P$ value & & & & 0.45 \\
\hline \multicolumn{5}{|l|}{ Healthcare Access } \\
\hline $\begin{array}{l}\text { No } \\
P \text { value }\end{array}$ & $8.1(4.1,12.2)$ & $16.7(10.3,23.2)$ & $10.0(7.5,12.5)$ & $\begin{array}{c}10.9(8.7,13.0) \\
0.03\end{array}$ \\
\hline \multicolumn{5}{|l|}{ Length of Residence } \\
\hline$<10$ years & $20.5(14.4,26.7)$ & $26.4(18.2,34.1)^{*}$ & $23.9(20.1,27.7)$ & $23.6(20.6,26.7)$ \\
\hline$\geq 10$ years & $79.5(73.3,85.6)$ & $73.6(65.3,81.8)$ & $76.1(72.3,79.9)$ & $76.4(73.3,79.4)$ \\
\hline P value & & & & 0.50 \\
\hline \multicolumn{5}{|c|}{ Cardiovascular Health Score Components } \\
\hline $\begin{array}{c}\text { Diabetes }^{\mathbf{a}} \\
\text { 0- Not Ideal } \\
\text { 1- Ideal }\end{array}$ & $\begin{array}{l}17.3(11.6,23.0) \\
82.7(77.0,88.4)\end{array}$ & $\begin{array}{c}8.7^{*}(4.7,12.7) \\
91.3(87.3,95.3)\end{array}$ & $\begin{array}{l}15.9(12.8,19.0) \\
84.1(81.0,87.2)\end{array}$ & $\begin{array}{l}14.9(12.5,17.2) \\
85.1(82.8,87.5)\end{array}$ \\
\hline $\begin{array}{c}\text { Cholesterol }^{\mathbf{b}} \\
\text { 0- Not Ideal } \\
\text { 1- Ideal }\end{array}$ & $\begin{array}{l}28.3(22.0,34.7) \\
71.7(65.3,78.0)\end{array}$ & $\begin{array}{l}23.3(16.4,30.1) \\
76.7(69.9,83.6)\end{array}$ & $\begin{array}{l}28.6(25.0,32.2) \\
71.4(67.8,75.0)\end{array}$ & $\begin{array}{l}27.5(24.7,30.4) \\
72.5(69.6,75.3)\end{array}$ \\
\hline $\begin{array}{c}\text { Blood pressure }^{c} \\
\text { 0- Not Ideal } \\
\text { 1- Ideal }\end{array}$ & $\begin{array}{l}38.2(31.3,45.1) \\
61.8(54.9,68.7)\end{array}$ & $\begin{array}{l}27.3(20.3,34.4) \\
72.7(65.6,79.7)\end{array}$ & $\begin{array}{l}38.9(34.9,42.9) \\
61.1(57.1,65.1)\end{array}$ & $\begin{array}{l}36.5(33.4,39.7) \\
63.5(60.3,66.6)\end{array}$ \\
\hline $\begin{array}{l}\text { BMI }^{\mathbf{d}} \\
\quad \text { 0- Not Ideal } \\
\\
\text { 1- Ideal }\end{array}$ & $\begin{array}{l}62.2(55.1,69.3) \\
37.8(30.7,44.9)\end{array}$ & $\begin{array}{l}73.8(66.6,80.9) \\
26.2(19.1,33.4)\end{array}$ & $\begin{array}{l}63.7(59.6,67.9) \\
36.3(32.1,40.4)\end{array}$ & $\begin{array}{l}65.3(62.1,68.5) \\
34.7(31.5,37.9)\end{array}$ \\
\hline $\begin{array}{c}\text { Physical Activity } \\
\text { 0- Not Ideal } \\
\text { 1- Ideal }\end{array}$ & $\begin{array}{l}27.7(21.0,34.4) \\
72.3(65.6,79.0)\end{array}$ & $\begin{array}{l}29.6(22.1,37.0) \\
70.4(63.0,77.9)\end{array}$ & $\begin{array}{l}21.7(18.2,25.3) \\
78.3(74.7,81.8)\end{array}$ & $\begin{array}{l}24.6(21.7,27.6) \\
75.4(72.4,78.3)\end{array}$ \\
\hline $\begin{array}{ll}\text { Diet }^{\mathbf{f}} & \\
& \text { 0- Not Ideal } \\
& \text { 1- Ideal }\end{array}$ & $\begin{array}{c}94.1(91.0,97.2) \\
5.9^{*}(2.8,9.0)\end{array}$ & $\begin{array}{c}92.1(86.8,97.3) \\
7.9^{*}(2.7,13.2)\end{array}$ & $\begin{array}{c}90.8(88.2,93.4) \\
9.2(6.6,11.8)\end{array}$ & $\begin{array}{c}91.8(88.2,93.4) \\
8.2(6.6,11.8)\end{array}$ \\
\hline $\begin{array}{c}\text { Smoking status }^{g} \\
\text { 0- Not Ideal } \\
\text { 1- Ideal }\end{array}$ & $\begin{array}{l}17.8(12.2,23.4) \\
82.2(76.6,87.8)\end{array}$ & $\begin{array}{c}12.9^{*}(7.5,18.3) \\
87.1(81.7,92.5)\end{array}$ & $\begin{array}{l}13.1(10.5,15.8) \\
86.9(84.2,89.5)\end{array}$ & $\begin{array}{l}14.2(11.9,16.4) \\
85.8(83.6,88.1)\end{array}$ \\
\hline
\end{tabular}

* Estimate should be interpreted with caution Estimate's Relative Standard Error (a measure of estimate precision) is greater than 30\%, or the 95\% Confidence Interval half-width is greater than 10 or the sample size is too small, making the estimate potentially unreliable.

a. Diabetes: Not Ideal: Participant was told by a health professional they had diabetes. Ideal: Participant had never been told by a health professional they had diabetes

b. Cholesterol: Not ideal: Participant was told by a health professional they had high cholesterol. Ideal: Participant had never been told by a health professional they had high cholesterol

c. Blood pressure: Not ideal: Participant was told by a health professional they had high blood pressure. Ideal: Participant had never been told by a health professional they had high blood pressure

d. BMI: Not ideal: Participant is overweight Ideal: Participant is underweight/normal weight

e. Physical Activity: Not Ideal: Participant did not participate in any physical activities or exercises such as running, calisthenics, golf, gardening, or walking for exercise during the past 30 days, other than their regular job Ideal: Participant did participate in physical activities or exercises such as running, calisthenics, golf, gardening, or walking for exercise during the past 30 days, other than their regular job

f. Diet: Not ideal: Participant consumed $<5$ servings of fruits and vegetables per day Ideal: Participant consumed $\geq$ five servings of fruit and vegetables per day

g. Smoking Status: Not ideal: Participant is a current/former smoker Ideal: Participant has never smoked at least 100 cigarettes in their lifetime 
Table 2: Logistic Regression Analyses of the Association between Length of Residence and Poor/ Cardiovascular Health, among Afro-Caribbean Adult Immigrants, New York City Community Health Survey, 2010-2014

\begin{tabular}{lllllll}
\hline \multicolumn{5}{c}{ Table 2: Logistic Regression Analyses of the Association between Length of Residence and Intermediate/Poor Cardiovascular Health, among Afro-Caribbean } \\
Adult Immigrants, New York City Community Health Survey, 2010-2014.
\end{tabular}

a. $\quad$ Length of residence (LOR): Model 1: unadjusted association between LOR and poor/intermediate cardiovascular health. Model 2: adjusted for sex, education, employment, insurance status, healthcare access. 
Figure 1: Prevalence of Ideal and Intermediate/Poor Cardiovascular Health Score by Country of Birth of Afro-Caribbean Adult Immigrants in New York City Community Health Survey, 2010-2014.

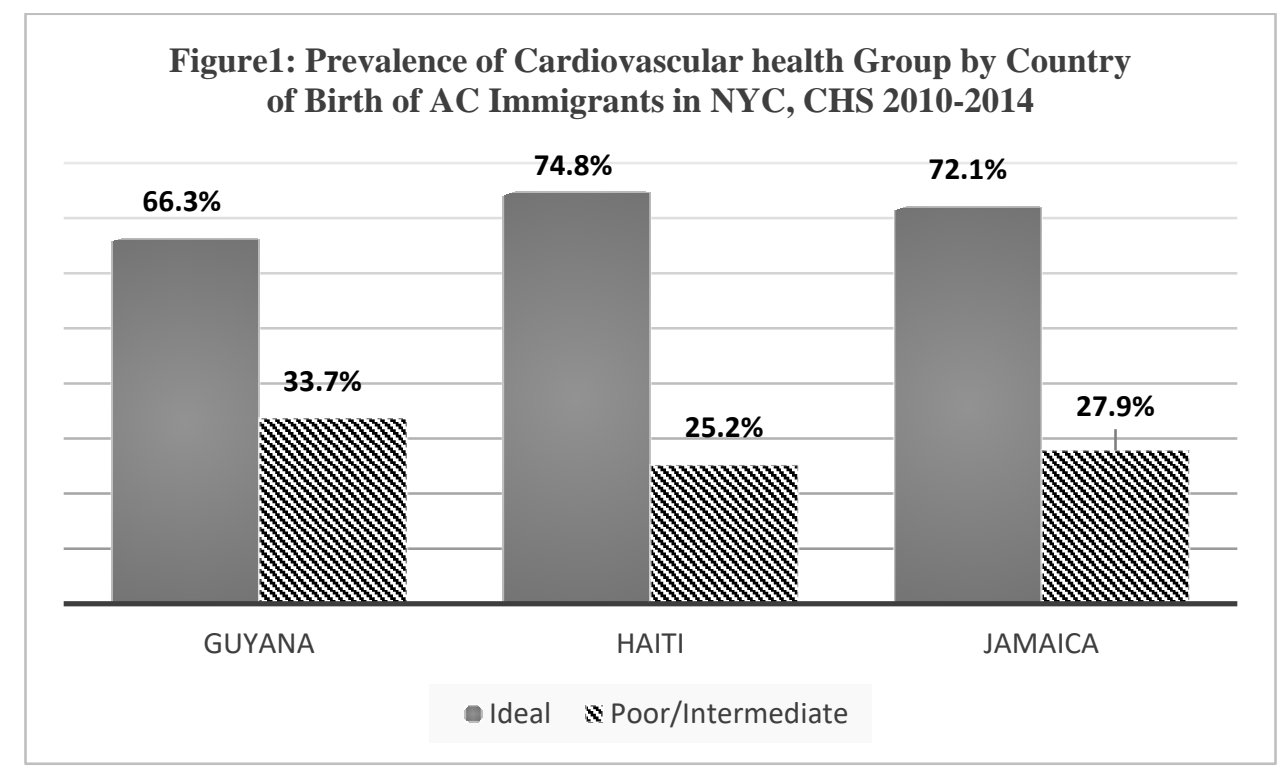




\section{References}

1. Lloyd-Jones DM, Hong Y, Labarthe D, et al. Defining and setting national goals for cardiovascular health promotion and disease reduction: the American Heart Association's strategic impact goal through 2020 and beyond. Circulation. 2010;121(4):586-613.

2. Benjamin EJ, Blaha MJ, Chiuve SE, et al. Heart disease and stroke statistics-2017 update: a report from the American Heart Association. Circulation. 2017;135(10): e146-e603.

3. American Heart Association. Cardiovascular disease: a costly burden for America: Projections throuh 2035. http://www.heart.org/idc/groups/heartpublic/@wcm/@adv/documents/downloadable/ucm_491543.pdf. Accessed 17 Mar 2018.

4. Folsom AR, Yatsuya H, Nettleton J A, et al. Community prevalence of ideal cardiovascular health, by the American Heart Association definition and relationship with cardiovascular disease incidence. J Am Coll Cardiol. 2011; 57(16): p. 1690-6.

5. Bambs C. Kip KE. Dinga A. Mulukutla SR Aiyer AN. and Reis SE. Low prevalence of "ideal cardiovascular health" in a community-based population: the heart strategies concentrating on risk evaluation (Heart SCORE) study. Circulation. 2011; 123(8): 850-7.

6. Rastogi SJ, Hoeffel E, Drewery MP: The black Population 2010. 2010 Census Briefs. Washington, DC: US Department of Commerce, Economics and Statistics Administration. U.S. Census Bureau, 2010. https://www.census.gov/prod/cen2010/briefs/c2010br-06.pdf. Accessed 30 Oct 2017.

7. Shaw-Taylor Y. The Other African Americans: Contemporary African and Caribbean Immigrants in the United States. Maryland: Rowman \& Littlefield; 2007.

8. Thomas KA. A demographic profile of black Caribbean Immigrants in the United States. Migration Policy Institute; 2012. Available at: https://www.migrationpolicy.org/research/CBIdemographic-profile-black-caribbean-immigrants. Accessed 27 Oct 2017. 
9. Zong J, Batalova J. Caribbean Immigrants in the United States. 2016. Available at https://www.migrationpolicy.org/article/caribbean-immigrants-united-states. Accessed 8 Jan 2018.

10. Griffith DM, Johnson JL, Zhang R, Neighbors HW, Jackson JS. Ethnicity, nativity, and the health of American blacks. J Health Care Poor Underserved. 2011;22(1):142-56

11. Fang J, Madhavan S, Alderman MH. The association between birthplace and mortality from cardiovascular causes among black and white residents of New York City. N Engl J Med. 1996;335(21):1545-51.

12. Commodore-Mensah, Y, Sampah M, Berko C. et al., The Afro-Cardiac Study: Cardiovascular Disease Risk and Acculturation in West African Immigrants in the United States: Rationale and Study Design. J Immigr Minor Health. 2016; 18(6): 1301-08.

13. Carlisle SK, Nativity differences in chronic health conditions between nationally representative samples of Asian American, Latino American, and Afro-Caribbean American respondents. J Immigr Minor Health. 2012;14(6): 903-11.

14. Davis EE, Huffman FG. Behavioral risk profiles for coronary heart disease among apparently healthy individuals of African ancestry. Ethn Dis. 2006;16(1):114-9.

15. Davis EE, Huffman FG. Differences in coronary heart disease risk markers among apparently healthy individuals of African ancestry. J Natl Med Assoc. 2007;99(6):658-64.

16. Commodore-Mensah Y, Ukonu N, Obisesan O, et al., Length of residence in the United States is associated with a higher prevalence of cardiometabolic risk factors in immigrants: a contemporary analysis of the national health interview survey. J Am Heart Assoc. 2016; 5(11).

17. Kaplan MS, Huguet N, Newsom JT. The association between length of residence and obesity among Hispanic immigrants. Am J Prev Med. 2004; 27(4): 323-6.

18. Barcenas CH, Wilkinson AV, Strom SS, et al. Birthplace, years of residence in the United States, and obesity among Mexican-American adults. Obesity. 2007;15(4):1043-52. 
19. Berry JW, Acculturation and adaptation in a new society. International Migration. 1992. 30(1): 69-85.

20. Berry JW. Immigration and Acculturation and Adaptation. Applied Psychology. 1997. 46(1): p. 5-34.

21. Thomson MD Hoffman-Goetz L. Defining and measuring acculturation: a systematic review of public health studies with Hispanic populations in the United States. Soc Sci Med. 2009. 69(7): p. 983-91.

22. Gibson MA. Immigrant Adaptation and Patterns of Acculturation. Human Development. 2011. 44(1): p. 19-23.

23. Schwartz SJ, Unger JB, Zamboanga BL, Szapocznik J. Rethinking the concept of acculturation: implications for theory and research. Am Psychol. 2010; 65(4): 237-51.

24. Zea MC, Asner-Self KK, Birman D, Buki LP. The abbreviated multidimensional acculturation scale: empirical validation with two Latino/Latina samples. Cultur Divers Ethnic Minor Psychol. 2003; 9(2):107-26.

25. Abraído-Lanza AF, Chao MT, Flórez KR. Do healthy behaviors decline with greater acculturation? Implications for the Latino mortality paradox. Soc Sci Med. 2005. 61(6): 1243-55.

26. Gorman BK, Lariscy JT, Kaushik C. Gender, acculturation, and smoking behavior among U.S. Asian and Latino immigrants. Soc Sci Med. 2014. 106: 110-8.

27. Lara M, Gamboa C, Kahramanian MI, Morales LS, Hayes Bautista DE. Acculturation and Latino health in the United States: a review of the literature and its sociopolitical context. Annu Rev Public Health. 2005. 26: 367-97.

28. Bermúdez OI, Falcón LM, Tucker KL. Intake and food sources of macronutrients among older Hispanic adults: association with ethnicity, acculturation, and length of residence in the United States. J Am Diet Assoc. 2000. 100(6): 665-73.

29. Jonnalagadda SS, Diwan S. Health behaviors, chronic disease prevalence and self-rated health of older Asian Indian immigrants in the U.S. J Immigr Health. 2005; 7(2):75-83. 
30. Bharmal N, Kaplan RM, Shapiro MF et al. The association of duration of residence in the United States with cardiovascular disease risk factors among South Asian immigrants. J Immigr Minor Health. 2015; 17(3): 781-90.

31. Wong SS, Dixon LB, Gilbride JA, Kwan TW, Stein RA. Measures of acculturation are associated with cardiovascular disease risk factors, dietary intakes, and physical activity in older Chinese Americans in New York City. J Immigr Minor Health. 2013; 15(3):560-8.

32. Ro A. The longer you stay, the worse your health? A critical review of the negative acculturation theory among Asian immigrants. Int J Environ Res Public Health. 2014; 11(8): 8038-57.

33. Taylor, V.M., et al., Heart disease prevention among Chinese immigrants. J Community Health, 2007. 32(5): p. 299-310.

34. Hamilton TG. Do country-of origin characteristics help explain variation in health among black immigrants in the United States. Social Science Quarterly. 2014; 95(3):817-834.

35. Hamilton TG. Hummer RA, Immigration and the health of U.S. black adults: does country of origin matter? Soc Sci Med. 2011; 73(10):1551-60.

36. Williams DR. Jackson JS. Race/ethnicity and the 2000 census: recommendations for African American and other black populations in the United States. Am J Public Health. 2000; 90(11):1728-30.

37. Norton J, Sanderson M, Gupta L, et al. Methodology updates to the new york city community health survey. 2012. https://www1.nyc.gov/assets/doh/downloads/pdf/epi/epiresearchchsmethods.pdf. Accessed 10 Nov 2017.

38. New York City Department of health and mental hygiene: NYC community health survey. Available from URL: https://www1.nyc.gov/site/doh/data/data-sets/community-healthsurvey.page. Accessed 10 Nov 2017

39. Lobo AP, Salvo JJ. The newest New Yorkers, 2000: immigrant New York in the new millenium . 2004: New York City Department of City Planning, Population Division. 
40. Pilkerton CS, Singh SS, Bias TK, Frisbee SJ. Changes in Cardiovascular Health in the United States, 2003-2011. J Am Heart Assoc. 2015; 4(9): p. e001650.

41. Yang Q, Cogswell ME, Flanders WD et al. Trends in cardiovascular health metrics and associations with all-cause and CVD mortality among US adults. JAMA. 2012. 307(12):1273-83.

42. Joseph JJ, Echouffo-Tcheugui JB, Carnethon MR. The association of ideal cardiovascular health with incident type 2 diabetes mellitus: the Multi-Ethnic Study of Atherosclerosis. Diabetologia. 2016; 59(9): 1893-903.

43. Kandula NR, Diez-Roux AV, Chan C et al. Association of acculturation levels and prevalence of diabetes in the multi-ethnic study of atherosclerosis (MESA). Diabetes Care. 2008; 31(8): p. 1621-8.

44. Commodore-Mensah Y, Ukonu N, Cooper LA et al. The Association Between Acculturation and Cardiovascular Disease Risk in Ghanaian and Nigerian-born African Immigrants in the United States: The Afro-Cardiac Study. J Immigr Minor Health. 2017; 1-10

45. SAS Enterprise Guide version 5.1: SAS Insititute Inc., Cary NC. USA.

46. Koya DL, Egede LE. Simi. J Gen Intern Med. 2007; 22(6): 841-6.

47. Nguyen HH, Smith C, Reynolds GL, Freshman B. The effect of acculturation on obesity among foreign-born Asians residing in the United States. J Immigr Minor Health. 2015; 17(2):389-99.

48. Kershaw KN, Giacinto RE, Gonzalez F et al. Relationships of nativity and length of residence in the U.S. with favorable cardiovascular health among Hispanics/Latinos: The Hispanic Community Health Study/Study of Latinos (HCHS/SOL). Prev Med. 2016; 89: 84-9.

49. Unger E, Diez-Roux AV, Lloyd-Jones DM et al. Association of neighborhood characteristics with cardiovascular health in the multi-ethnic study of atherosclerosis. Circ Cardiovasc Qual Outcomes. 2014; 7(4):524-31.

50. Afable A, Yeh MC, Trivedi T et al. Duration of US Residence and Obesity Risk in NYC Chinese Immigrants. J Immigr Minor Health. 2016; 18(3): 624-35. 
51. Landale NS, Oropesa RS, Llanes D, Gorman BK. Does Americanization have Adverse Effects on Health? Health Habits and Infant Health Outcomes among Puerto Ricans. Social Forces, 1999. 78(2): 613-641.

52. Krieger N, Smith K, Naishadham D et al. Experiences of discrimination: validity and reliability of a self-report measure for population health research on racism and health. Soc Sci Med, 2005. 61(7): 1576-96.

53. Thoits PA. Stress and health: major findings and policy implications. J Health Soc Behav. 2010; 51 Suppl: p. S41-53.

54. Adegbembo AO, Tomar SL, Logan HL. Perception of racism explains the difference between Blacks' and Whites' level of healthcare trust. Ethn Dis. 2006; 16(4):792-8.

55. Gee GC, Delva J, Takeuchi DT. Relationships between self-reported unfair treatment and prescription medication use, illicit drug use, and alcohol dependence among Filipino Americans. Am J Public Health. 2007; 97(5): 933-40.

56. Das S, O’Keefe JH. Behavioral cardiology: recognizing and addressing the profound impact of psychosocial stress on cardiovascular health. Curr Hypertens Rep. 2008; 10(5):374-81.

57. Strickman-Stein N, Gervais MD, Ludwig DA et al. Body mass index as a function of length of United States residency among Haitian immigrant children. Ethn Dis. 2010; 20(1): 22-8.

58. Allen JD, Mars DR, Tom L, et al. Health beliefs, attitudes and service utilization among Haitians. J Health Care Poor Underserved, 2013. 24(1):106-19.

59. Ding H, Hargraves L. Stress-associated poor health among adult immigrants with a language barrier in the United States. J Immigr Minor Health. 2009; 11(6): 446-52 


\section{Chapter 6}

\section{Study 3 Manuscript}

Title: Social Determinants of health among Afro-Caribbean Immigrants in New York City

Author names and affiliations:

Sabena C. Thomas

West Virginia University School of Public Health

Department of Social and Behavioral Sciences

1 Medical Center Drive

Morgantown West Virginia 26506. U.S.A.

Tel: 681-285-7348

Amna Umer

West Virginia University School of Medicine

Department of Pediatrics

West Virginia University

1 Medical Center Drive

Morgantown West Virginia 26506. U.S.A.

amumer@hsc.wvu.edu

Tel: 304-293-1211

Yvonne Commodore-Mensah

Community-Public Health Nursing

John's Hopkins School of Nursing Room \#419

Baltimore, Maryland 21205

ycommod1@jhu.edu

Tel: 410-614-1519

Danielle Davidov

School of Medicine

Department of Emergency Medicine

West Virginia University

P.O. Box 9190

Morgantown, WV 26506. USA

Email: ddavidov@mix.wvu.edu

Tel: 304-293-4083

Tom Bias

School of Public Health

Health Research Center

West Virginia University

P.O. Box 9190

Morgantown, WV 26506. USA

Email: tbias@mix.wvu.edu

Tel: 304-293-4083

Corresponding author: Christiaan G. Abildso

West Virginia University School of Public Health

Department of Social and Behavioral Sciences 
1 Medical Center Drive

Morgantown West Virginia 26506. U.S.A

cgabildso@hsc.wvu.edu

Tel: 304-293-5374 


\begin{abstract}
Cardiovascular diseases disproportionately affect Non-Hispanic blacks in comparison to any other ethnic group in the United States (U.S.). Despite their prominent presence in the U.S. as the largest black immigrant group, Afro-Caribbean (AC) immigrants are underrepresented in health research. Social determinants have been examined as a contributor to racial/ethnic disparities in cardiovascular health though not among AC immigrants. Using the American Heart Association’s (AHA) ideal metrics for $\mathrm{CVH}$, we examined the social determinants associated with poor/intermediate $\mathrm{CVH}$ among three AC immigrant sub-groups in NYC. Using logistic regression analysis, we examined the relationship between social determinants and CVH by country of birth for Jamaican, Haitian and Guyanese adult immigrants. Education and employment were significantly associated with poor/intermediate CVH among Jamaican immigrants in unadjusted models, but only education remained significant after adjusting for relevant covariates. Jamaicans with high school education or less were more likely to have poor/intermediate CVH than those with at least some college education (OR = 1.69; 95\% CI 1.10-2.60). Education, employment, health insurance and health care access were not significantly associated with CVH among Guyanese and Haitian immigrants. Since there are ethnic differences in social determinants of CVH among AC immigrants, future health research among AC immigrants should consider country of birth differences in order to identify and address health disparities among this population.
\end{abstract}

Keywords: cardiovascular health, Afro-Caribbean, immigrants, social determinants 


\section{Introduction}

Cardiovascular diseases (CVD) remain the number one cause of death worldwide despite a reduction in CVD mortality rates [1]. In the United States (U.S.) CVDs account for one in every three deaths annually and are significant contributors to racial/ethnic health disparities [1]. Non-Hispanic blacks (hereafter blacks) have the highest rates of cardiovascular and metabolic diseases compared to any other racial/ethnic group in the U.S. [1, 2]. Most notably, blacks have one of the lowest rates of individuals meeting recommended fruit and vegetable dietary intake, and highest rates of physical inactivity among all ethnic groups [1].

Social determinants of health are "the circumstances in which people are born, grow, live, work and age, and the systems put in place to deal with illness” [3]. Consistent findings show that social determinants such as education, employment, socioeconomic status and marital status may contribute to the development of CVDs [4-10], and may explain racial disparities in cardiovascular health (CVH) between different racial/ethnic groups [11]. Accordingly, the American Heart Association (AHA) emphasizes the importance of focusing on social determinants to achieve its goal of improving CVH among all Americans [2]. The AHA highlights socio-economic status (SES), race/ethnicity, social support, culture, access to medical care, residential environments as their foremost social determinants, and their relationship to cardiovascular outcomes [4].

In the U.S., research on cardiovascular health and risk factors among immigrants has been welldocumented [12-16]. A significant portion of this research focuses on acculturation and its impacts on cardiovascular health outcomes [17-20]. Less attention has been given to other social influences on CVH, particularly among black immigrants. There has been a consistent flow of black immigrants in the U.S. [21, 22] with Afro-Caribbean (AC) immigrants making up the majority of the black immigrant population in the U.S. [21]. Despite this, AC immigrants have been underrepresented in health research due to being traditionally classified as Black/African Americans along with other black immigrants [17]. Thus, it is important explore the CVH of AC immigrants in the U.S. 
The limited research shows that AC immigrants may have superior cardiovascular health than native-born black Americans [23-26]. However, with increased residence in the U.S. the health of immigrants deteriorate owing to social factors such as acculturation [12, 27, 28]. Other social determinants such as education, employment and healthcare access are underexplored among AC immigrants, who may be susceptible to negative experiences brought on by the migration process. For example, migration may induce additional stressors and barriers related to healthcare access [29-31]. AC immigrants may experience limited access to care based on immigration status and language proficiency [29]. These social experiences may also drive variation in CVD outcomes among AC sub-groups because there is considerable heterogeneity among the AC immigrant subgroups.

AC immigrant sub-groups differ relating to language, immigrant selectivity, socio-political and economic backgrounds [24, 25, 32, 33]. Previous studies highlight the importance of country of birth analysis in assessing the health of AC immigrants [25, 32]. However, most studies examine AC immigrants as one monolithic group. The limitation to this type of examination is in the failure to account for ethnic and social variations associated with country of birth. Given the study gaps highlighted above, the purpose of this study is to examine the social determinants of $\mathrm{CVH}$ among three AC immigrant sub-groups in New York City.

\section{Methods}

Data from this study were obtained from the New York City (NYC) Department of Health and Mental Hygiene Community Healthy Survey (CHS) 2010-2014. The CHS is a cross-sectional telephone survey administered annually among NYC non-institutionalized residents $\geq 18$ years. Roughly 9,000 residents are included in the survey and data from this random sample are weighted to represent the NYC population [34]. Interviews are conducted via a computer-aided telephone interviewing system (CATI) in five languages: English, Spanish, Russian, Mandarin and Cantonese. One adult is randomly selected from the household to participate in the survey. After informed consent, estimates on a variety of chronic diseases and behavioral risk factors are collected [35]. The 2010-2014 combined years' analyses are 
weighted to the NYC adult residential population as per Census 2010 and 2011-2013 American

Community Survey. Detailed information on CHS methodology is published elsewhere [34]. The study was exempt from Institutional Review Board as the data were de-identified and provided under a data use agreement.

\section{Study Population and Sample}

The study included AC immigrant respondents who reported their race as non-Hispanic Blacks (NHB) and country of birth (COB) as Guyana ( $n=369)$, Haiti $(n=291)$ or Jamaica $(n=1031)$ in the CHS. Country of birth of the respondents were determined from the question "Where were you born? Please tell me the country" in the CHS.

\section{Main Outcome: Cardiovascular Health (CVH)}

CVH was assessed from seven metrics (fasting plasma glucose, total cholesterol, blood pressure, body mass index (BMI), physical activity, diet and smoking status) based on AHA's definition. We adapted methodology from previous studies [36, 37] based on CHS items. Diabetes, high cholesterol and high blood pressure were self-reported as “yes” or "no” on the CHS survey and were categorized as "not ideal” $=0$ or "ideal” $=1$, respectively. BMI was categorized as not ideal (overweight/obese) and ideal (underweight/normal). Behavioral factors were also classified as “ideal” or “not ideal”. For physical activity, “ideal” or “not ideal” was determined from a self-reported “yes” or “no” respectively on CHS survey question: “during the past 30 days, other than your regular job, did you participate in any physical activities or exercises such as running, calisthenics, golf, gardening, or walking for exercise?’ Regarding diet, respondents who reported having consumed $\geq 5$ servings of fruit and or vegetable yesterday were classified as “ideal”. Respondents who reported $<5$ servings were classified as “not ideal”. For smoking status, respondents who reported never having smoked at least 100 cigarettes in their lifetime were considered “ideal” and those who reported to be current or former smokers were considered "not ideal”. 
The intermediate category was omitted because the CHS did not capture information to satisfy this category. All seven metrics were summed together and could range from 0-7.

The CVH score was then categorized as "ideal" where the overall CVH score was $\geq 4$; "intermediate" where the overall CVH score ranged from 2-3; or "poor" where the overall CVH score ranged from 0-1 [38]. After conducting cross tabulations for each country of birth and the three category variable (poor, intermediate and ideal), intermediate and poor categories were combined into a single group for more stable estimates for each country of birth group. The CVH variable was analyzed as 0 for “ideal” CVH and 1 for "poor/intermediate” CVH.

Social Determinants of Health (SDH)

Education: Education status was ascertained from the question "What is the highest grade or year of school you completed?” Responses were coded as < high school, high school graduate, some college, or college graduate. This variable was recoded as high school graduate or less education, or some college or higher.

Employment: The CHS categorized employment status as employed, unemployed, or not in labor force. This variable was recoded as employed versus unemployed/not in the labor force.

Health Insurance Status: Health insurance was assessed from the question "Do you have any kind of health insurance coverage?” Response categories were “yes”, “no”, “don’t know”, “refused” and “missing”. This variable was recoded as yes or no; other responses were coded as missing.

Healthcare Access: Healthcare access was derived from the question "Was there a time in the past 12 months when you needed medical care but did not get it?” Responses were dichotomized into yes or no. Responses were reversed coded to satisfy having healthcare access or not.

\section{Covariates}


Covariates for this study included participant's age (18-44, 45-64, 65+ years), sex (male, female) and length of residence in the U.S. ( $<10$ years, $\geq 10$ years).

\section{Statistical Analysis}

Analyses incorporated weights and were conducted in SAS 9.3[39]. We compared sample descriptive characteristics and prevalence of CVH groups (ideal, intermediate/poor) by COB (Table 1).

For each COB, we fitted unadjusted and adjusted logistic regression models to determine associations between SDH and CVH (ideal vs intermediate/poor). Adjusted models controlled for age, sex and length of residence in the U.S. Odds ratios and 95\% confidence intervals were reported; $p<0.05$ was considered statistically significant. Analyses and coding were double checked for accuracy by the New York City Department of Mental Health and Hygiene.

\section{Results}

\section{Participant Characteristics}

The characteristics of the participants are shown in Table 1 . The majority of the sample was female (59.2\%) and reported to be high school educated or less (53.9\%). Most Afro-Caribbean immigrants in this sample also reported to have ideal CVH (71.3\%) and living in the U.S. for 10 years or more (76.4\%) . Associations among SDH and intermediate/poor $\mathrm{CVH}$

\section{Education}

Table 2 shows the associations between social determinants and intermediate/poor CVH. Education was associated with intermediate/poor cardiovascular health among Jamaican immigrants only. Jamaican immigrants with high school education or less were more likely to have intermediate/poor cardiovascular 
health than those with at least some college education (OR = 1.87; 95\% CI: 1.30-2.68). This association was retained, although slightly attenuated after adjusting for age, sex and length of residence in the U.S. $(\mathrm{OR}=1.69 ; 95 \% \mathrm{CI}: 1.10-2.60)$.

\section{Employment}

Among Jamaican immigrants, those who were unemployed or not in the work force were more likely to have intermediate/poor $\mathrm{CVH}$ than those that were employed (OR $=1.75$; 95\% CI: 1.21-2.52). This association became insignificant after adjusting for age, sex and length of residence in the U.S. (OR $=1.47$; 95\% CI: 0.93-2.32).

\section{Health Insurance status}

Health insurance was not significantly associated with CVH among any of the AC immigrant sub-groups.

\section{Health Access}

Health access was not associated with CVH among any of the AC immigrant subgroups.

\section{Discussion}

This study indicates that social determinants vary in their association with CVH among Afro-Caribbean immigrant subgroups. Social determinants were significantly associated with CVH in unadjusted models only among Jamaican immigrants, but only the lack of health insurance remained when adjusting for covariates. The social determinants examined here were not associated with $\mathrm{CVH}$ among the other ethnic groups (Guyana and Haiti). To our knowledge, few studies have examined CVH among afro-Caribbean subgroups and this is the first study to examine social determinants of health among AC subgroups using the AHA metrics.

These findings support current evidence that social determinants influence CVH outcomes and contribute to health disparities [11, 40, 41]. Both education and employment have been used as proxies for SES in 
previous studies and have generally been found to have an inverse relationship with CVH [6, 7, 42, 43]. Evidence from this study lends support to the existing literature. Jamaican immigrants with lower education and those that were unemployed were more likely to have poor/intermediate CVH. However, for employment this relationship became insignificant after accounting for other covariates.

Surprisingly, uninsured AC immigrant sub-groups were less likely to have poor/intermediate CVH, although results were not statistically significant. This finding is contrary to other studies that found lack of health insurance to be associated with increased risk of poorer $\mathrm{CVH}[44,45]$. The conflicting findings may also be explained by differences in methodology; while previous studies examined individual cardiovascular risk factors, this study used a holistic measure for CVH. Also in this study, participants' responses were self-report based on being told by a health professional that they have the condition or not (i.e. CVD risk factors). In addition, research show uninsured individuals are less likely to receive screening and diagnosis for CVD metabolic risk factors [46, 47]. Therefore, it is plausible that their metabolic risk factors are unknown due to a lack of clinical testing. It has been shown that chronic illnesses including CVD risk factors are common among uninsured individuals in the U.S. [9]. The uninsured in this population may be unaware of their metabolic risk factors.

\section{Strengths and Limitations}

A unique strength of this study is the ability of the CHS data to provide population estimates of three of the most prominent AC immigrant groups in NYC. Additionally, this study employed AHA methodology to examine overall $\mathrm{CVH}$ rather than individual risk factors. To our knowledge, this is the first study to examine social determinants among AC immigrant sub-groups in the U.S. Despite the strengths of this study, there are some limitations. First, because of the cross-sectional nature of the study, causal inferences cannot be made between social determinants and CVH from the analysis. Secondly, the selfreported nature of the data may introduce recall bias or underestimation of prevalence rates of cardiovascular risk factors particularly among the undiagnosed. Third, small sample sizes particularly among the Haitian and Guyanese sub-groups may yield less than precise population estimates. Finally, 
data was not available on other relevant social determinants such as post-migration stress, racial discrimination and social support that may be pertinent to immigrant populations in the U.S.

\section{Conclusion}

These finding suggest that social determinants influencing CVH differ among AC immigrant sub-groups in NYC. Specifically, among Jamaican immigrants, education was the only SDH factor significantly associated with CVH after adjusting for covariates. It would be beneficial to research efforts if national surveillance would greater detail in determining country of origin and oversampling of racial/ethnic minority groups in order to correctly estimate their CVH outcomes. Future studies should incorporate analysis that takes into consideration country of birth differences among pan-regional immigrant groups usually examined together. Future research should also replicate this study among AC immigrants in other geographic areas and explore other social factors such as post-migration stress and social support that may influence CVH among black immigrants. 


\section{Manuscript 3 Tables}

Table 1: Descriptive characteristics of Afro-Caribbean Adult Immigrants by Country of Birth, New York City Community Health Survey, 20102014. Weighted\% (95\% CI).

\begin{tabular}{|c|c|c|c|c|}
\hline & Guyana $\mathrm{n}=369$ & Haiti $n=291$ & Jamaica $\mathrm{n}=1031$ & Total $n=1691$ \\
\hline \multicolumn{5}{|l|}{ Age Group } \\
\hline $18-44$ & $44.9(37.68-52.20)$ & $60.5(52.75-68.14)$ & $47.4(43.11-51.61)$ & $49.3(45.96-52.67)$ \\
\hline $45-64$ & $39.3(32.30-46.26)$ & $30.9(23.75-38.02)$ & $38.2(34.24-42.14)$ & $37.0(33.92-40.16)$ \\
\hline $65+$ & $15.8(10.71-20.84)$ & $8.7^{*}(4.76-12.58)$ & $14.4(11.74-17.15)$ & $13.6(11.55-15.74)$ \\
\hline Female & $56.6(49.44-63.73)$ & $55.6(36.18-52.65)$ & $61.5(57.44-65.60)$ & $59.2(55.96-62.54)$ \\
\hline \multicolumn{5}{|l|}{ Education } \\
\hline$\leq$ High School & $57.2(50.10-64.20)$ & $43.3(34.84-51.73)$ & $56.0(51.85-60.24)$ & $53.9(50.60-57.25)$ \\
\hline Tech School/College Grad & $42.9(35.80-49.90)$ & $56.7(48.27-65.16)$ & $44.0(39.76-48.15)$ & $46.1(42.75-49.40)$ \\
\hline $\begin{array}{l}\text { Employment } \\
\text { Unemployed/Not in Labor } \\
\text { Force }\end{array}$ & $38.2(31.21-45.22)$ & $42.4(34.01-50.71)$ & $36.6(32.52-40.68)$ & $38.1(34.79-41.37)$ \\
\hline \multicolumn{5}{|l|}{ Insurance } \\
\hline Uninsured & $19.8(14.09-25.56)$ & $23.4(15.65-31.25)$ & $24.7(21.01-28.42)$ & $23.3(20.42-26.28)$ \\
\hline \multicolumn{5}{|l|}{ Healthcare Access } \\
\hline No & $8.1^{*}(4.12-12.17)$ & $16.7^{*}(10.25-23.23)$ & $10.0(7.47-12.54)$ & 10.9 (8.71-12.99) \\
\hline \multicolumn{5}{|l|}{ Length of Residence } \\
\hline$<10$ years & $20.5(14.36-26.74)$ & $26.4^{*}(18.18-34.71)$ & $23.9(20.11-27.67)$ & $23.6(20.55-26.68)$ \\
\hline$\geq 10$ years & 79.5 (73.26-85.65) & $73.6(65.29-81.82)$ & 76.1 (72.33-79.89) & $76.4(73.32-79.45)$ \\
\hline \multicolumn{5}{|l|}{ Cardiovascular Health } \\
\hline Ideal & $66.3(59.51-73.17)$ & 74.8 (67.84-81.74) & $72.1(24.30-31.42)$ & $71.3(68.39-74.24)$ \\
\hline Intermediate/Poor & 33.7 (26.83-40.49) & $25.2(18.26-32.16)$ & $27.9(68.58-75.70)$ & $28.7(25.76-31.61)$ \\
\hline
\end{tabular}


Table 2: Association between Social Determinants of Health and Poor/Intermediate Cardiovascular Health by Country of Birth among AfroCaribbean Adult Immigrants, New York City Community Health Survey, 2010-2014 (n =1691)

\begin{tabular}{|c|c|c|c|c|c|c|}
\hline & & Guyana & & Haiti & & amaica \\
\hline & $\begin{array}{c}\text { Model } 1 \text { Unadjusted } \\
\text { OR(95\%CI) }\end{array}$ & $\begin{array}{c}\text { Model } 2 \\
\text { Adjusted } \\
\text { OR(95\%CI) }\end{array}$ & $\begin{array}{c}\text { Model } 1 \\
\text { Unadjusted } \\
\text { OR(95\%CI) }\end{array}$ & $\begin{array}{c}\text { Model } 2 \\
\text { Adjusted } \\
\text { OR(95\%CI) }\end{array}$ & $\begin{array}{c}\text { Model } 1 \\
\text { Unadjusted } \\
\text { OR(95\%CI) }\end{array}$ & $\begin{array}{c}\text { Model } 2 \\
\text { Adjusted } \\
\text { OR(95\%CI) }\end{array}$ \\
\hline \multicolumn{7}{|l|}{ Education } \\
\hline $\begin{array}{l}\text { Some college or } \\
\text { higher }\end{array}$ & Ref & Ref & Ref & Ref & Ref & Ref \\
\hline$\leq$ High school grad & $1.22(0.65-2.28)$ & $1.56(0.74-3.29)$ & $0.82(0.40-1.68)$ & $0.72(0.35-1.48)$ & $1.87(1.30-2.68)^{*}$ & $1.69(1.10-2.60)^{*}$ \\
\hline $\begin{array}{l}\text { Employment } \\
\text { employed } \\
\text { Unemployed/not in } \\
\text { labor force }\end{array}$ & $\begin{array}{c}\text { Ref } \\
1.39(0.75-2.59)\end{array}$ & $\begin{array}{c}\text { Ref } \\
1.02(0.51-2.01)\end{array}$ & $\begin{array}{c}\text { Ref } \\
1.82(0.86-3.87)\end{array}$ & $\begin{array}{c}\text { Ref } \\
1.93(0.71-5.24)\end{array}$ & $\begin{array}{c}\text { Ref } \\
1.75(1.21-2.52)^{*}\end{array}$ & $\begin{array}{c}\text { Ref } \\
1.47(0.93-2.32)\end{array}$ \\
\hline $\begin{array}{l}\text { Insurance status } \\
\text { insured } \\
\text { Uninsured }\end{array}$ & $\begin{array}{c}\text { Ref } \\
0.62(0.28-1.34)\end{array}$ & $\begin{array}{c}\text { Ref } \\
0.93(0.41-2.13)\end{array}$ & $\begin{array}{c}\text { Ref } \\
0.57(0.18-1.81)\end{array}$ & $\begin{array}{c}\text { Ref } \\
0.89(0.21-3.84)\end{array}$ & $\begin{array}{c}\text { Ref } \\
0.66(0.42-1.03)\end{array}$ & $\begin{array}{c}\text { Ref } \\
0.95(0.57-1.58)\end{array}$ \\
\hline $\begin{array}{l}\text { Healthcare access } \\
\text { yes } \\
\text { no }\end{array}$ & $\begin{array}{c}\text { Ref } \\
1.49(0.48-4.65)\end{array}$ & $\begin{array}{c}\text { Ref } \\
1.98(0.57-6.91)\end{array}$ & $\begin{array}{c}\text { Ref } \\
0.69(0.28-1.67)\end{array}$ & $\begin{array}{c}\text { Ref } \\
0.97(0.40-2.36)\end{array}$ & $\begin{array}{c}\text { Ref } \\
1.35(0.76-2.38)\end{array}$ & $\begin{array}{c}\text { Ref } \\
1.40(0.77-2.53)\end{array}$ \\
\hline
\end{tabular}

Model 2: Adjusted for Age, Sex and length of residence

${ }^{*} p<.05$ 


\section{References}

1. Benjamin EJ, Blaha MJ, Chiuve SE, et al. Heart disease and stroke statistics-2017 update: a report from the American Heart Association. Circulation. 2017;135(10): e146-e603.

2. Lloyd-Jones DM, Hong Y, Labarthe D, et al. Defining and setting national goals for cardiovascular health promotion and disease reduction: the American Heart Association's strategic impact goal through 2020 and beyond. Circulation. 2010;121(4):586-613

3. Marmot M, Closing the health gap in a generation: the work of the Commission on Social Determinants of Health and its recommendations. Glob Health Promot. 2009; Suppl 1: p. 23-7. doi: 10.1177/1757975909103742.

4. Havranek EP, Mujahid MS, Barr DA, et al. Social determinants of risk outcomes for cardiovascular disease: a scientific statement from the American Heart Association. Circulation. 132 (9):873-898

5. Kreatsoulas C, Anand SS, The impact of social determinants on cardiovascular disease. Can J Cardiol. 2010; 26 Suppl C:8C-13C.

6. Pollitt RA, Rose KM, and Kaufman JS, Evaluating the evidence for models of life course socioeconomic factors and cardiovascular outcomes: a systematic review. BMC Public Health. 2005; 5: 7.

7. Winkleby MA, Jatulis DE, Frank E et al. Socioeconomic status and health: how education, income, and occupation contribute to risk factors for cardiovascular disease. Am J Public Health. 1992; 82(6):816-20.

8. Chung ML Lennuie TA, Riegel B, Marital status as an independent predictor of event-free survival of patients with heart failure. Am J Crit Care. 2009; 18(6): 562-70. doi: 10.4037/ајсc2009388. 
9. Wilper AP, Woolhandler S, Lasser KE et al., A national study of chronic disease prevalence and access to care in uninsured U.S. adults. Ann Intern Med. 2008; 149(3):170-6.

10. Mensah, G.A. State of disparities in cardiovascular health in the United States. Circulation, 2005. 111(10): p. 1233-41.

11. Quarells RC, Liu J, Davis SK, Social determinants of cardiovascular disease risk factor presence among rural and urban Black and White men. J Mens Health. 2012; 9(2):120-126.

12. Commodore-Mensah Y. Ukonu N, Obisean O, et al. Length of Residence in the United States is Associated With a Higher Prevalence of Cardiometabolic Risk Factors in Immigrants: A Contemporary Analysis of the National Health Interview Survey. J Am Heart Assoc. 2016; 5(11).

13. Langellier BA, Garza JR, Glik D, et al. Immigration disparities in cardiovascular disease risk factor awareness. J Immigr Minor Health. 2012; 14(6): 918-25.

14. Salinas JJ Abdelbary B, Rentfro A, et al. Cardiovascular disease risk among the Mexican American population in the Texas-Mexico border region, by age and length of residence in United States. Prev Chronic Dis. 2014; 11: E58.

15. Daviglus ML, Talavera GA, Aviles-Santa ML, et al. Prevalence of major cardiovascular risk factors and cardiovascular diseases among Hispanic/Latino individuals of diverse backgrounds in the United States. JAMA. 2012; 308(17):1775-84.

16. Ton TG, Steinman L, Yip MP, et al. Knowledge of cardiovascular health among Chinese, Korean and Vietnamese immigrants to the U.S. J Immigr Minor Health. 2011; 13(1): 127-39.

17. Commodore-Mensah Y, Sampah M, Berko C, et al. The Afro-Cardiac Study: Cardiovascular Disease Risk and Acculturation in West African Immigrants in the United States: Rationale and Study Design. J Immigr Minor Health. 2016; 18(6):1301-1308.

18. Bharmal N, Kaplan RM, Shapiro MF et al. The association of duration of residence in the United States with cardiovascular disease risk factors among South Asian immigrants. J Immigr Minor Health. 2015; 17(3):781-90. 
19. Ro A. The longer you stay, the worse your health? A critical review of the negative acculturation theory among Asian immigrants. Int J Environ Res Public Health. 2014; 11(8):8038-57.

20. Wong SS, Dixon LB, Gilbride JA, et al. Measures of acculturation are associated with cardiovascular disease risk factors, dietary intakes, and physical activity in older Chinese Americans in New York City. J Immigr Minor Health. 2013; 15(3):560-8.

21. Zong J, Batalova J. Caribbean Immigrants in the United States. 2016. Available at https://www.migrationpolicy.org/article/caribbean-immigrants-united-states. Accessed January 8, 2018.

22. Pew research Center: Key facts about black immigrants in the U.S. 2018; Available from: http://www.pewresearch.org/fact-tank/2018/01/24/key-facts-about-black-immigrants-in-the-u-s/. Accessed March 5, 2018.

23. Griffith DM, Johnson JL, Zhang R, et al. Ethnicity, nativity, and the health of American Blacks. J Health Care Poor Underserved. 2011; 22(1):142-56.

24. Hamilton TG. Do country-of origin characteristics help explain variation in health among black immigrants in the United States. Social Science Quarterly. 2014; 95(3); 817-834.

25. Hamilton TG, Hummer RA, Immigration and the health of U.S. black adults: does country of origin matter? Soc Sci Med. 2011;73(10):1551-1560.

26. Read JnG, Emerson MO. Racial context, black immigration and the US black/white health disparity. Social Forces. 2005;84(1):181-199.

27. Kaplan MS., Haguet N, Newsom JT, at al. The association between length of residence and obesity among Hispanic immigrants. Am J Prev Med. 2004; 27(4):323-6.

28. Barcenas CH, Wilkinson AV, Strom SS, et al. Birthplace, years of residence in the United States, and obesity among Mexican-American adults. Obesity (Silver Spring), 2007; 15(4):1043-52.

29. Wafula EG, Snipes SA. Barriers to health care access faced by black immigrants in the US: theoretical considerations and recommendations. J Immigr Minor Health. 2014; 16(4):689-98. 
30. Williams, D.R., et al. The mental health of Black Caribbean immigrants: results from the National Survey of American Life. Am J Public Health, 2007. 97(1): p. 52-9.

31. Read, J.G., M.O. Emerson, and A. Tarlov, Implications of black immigrant health for U.S. racial disparities in health. J Immigr Health, 2005. 7(3): p. 205-12.

32. Davis EE, Huffman FG. Differences in coronary heart disease risk markers among apparently healthy individuals of African ancestry. Journal of National Medical Association. 2007;99(6):658-664.

33. Williams DR, Jackson JS. Race/ethnicity and the 2000 census: recommendations for African American and other black populations in the United States. Am J Public Health. 2000;90(11):1728-1730.

34. Norton J, Sanderson M, Gupta L, et al. Methodology updates to the new york city community health survey. 2012. Available from URL: https://www1.nyc.gov/assets/doh/downloads/pdf/epi/epiresearch-chsmethods.pdf. Accessed November 10, 2017.

35. New York City Department of health and mental hygiene: NYC community health survey. Available from URL: https://www1.nyc.gov/site/doh/data/data-sets/community-healthsurvey.page. Accessed November 10, 2017.

36. Pilkerton CS, Singh SS, Bias TK, et al. Changes in Cardiovascular Health in the United States, 2003-2011. J Am Heart Assoc. 2015; 4(9):e001650.

37. Yang Q, Cogswell ME, Flanders WD, et al. Trends in cardiovascular health metrics and associations with all-cause and CVD mortality among US adults. JAMA, 2012. 307(12):1273-83.

38. Joseph JJ, Echouffo-Tcheugui JB, Carnethon MR, et al. The association of ideal cardiovascular health with incident type 2 diabetes mellitus: the Multi-Ethnic Study of Atherosclerosis. Diabetologia. 2016; 59(9):1893-903.

39. SAS Enterprise Guide version 5.1: SAS Insititute Inc., Cary NC. USA. 
40. Commodore-Mensah Y, Matthie N, Wells J, et al. African Americans, African Immigrants, and Afro-Caribbeans Differ in Social Determinants of Hypertension and Diabetes: Evidence from the National Health Interview Survey. J Racial Ethn Health Disparities. 2017. doi: 10.1007/s40615017-0446-X

41. Clark AM, DesMeules M, Luo W, et al. Socioeconomic status and cardiovascular disease: risks and implications for care. Nat Rev Cardiol. 2009; 6(11):712-22.

42. Krieger N, William DR, Moss NE. Measuring social class in US public health research: concepts, methodologies, and guidelines. Annu Rev Public Health. 1997; 18:341-78.

43. Davila, EP, Kuklina EV, Valderama AL. Prevalence, management, and control of hypertension among US workers: does occupation matter? J Occup Environ Med, 2012. 54(9): p. 1150-6.

44. Fowler-Brown A, Corbie-Smith G, Garett J, et al. Risk of cardiovascular events and death--does insurance matter? J Gen Intern Med. 2007; 22(4):502-7.

45. Wadhera RK, and Joynt KE. Insurance and Cardiovascular Health: Time for Evidence to Trump Politics. Circulation. 2017; 135(21):1988-1990. doi: 10.1161/CIRCULATIONAHA.1

46. McWilliams JM. Health consequences of uninsurance among adults in the United States: recent evidence and implications. Milbank Q. 2009; 87(2):443-94. 


\section{Chapter 7}

\section{Discussion}

\section{Summary of Key Findings}

The main purpose of this dissertation project was to examine the $\mathrm{CVH}$ of three prominent $\mathrm{AC}$ immigrant groups (Guyanese, Haitian and Jamaican) disaggregated by country of birth. The project used crosssectional data from the NYC Department of Mental Health and Hygiene Community Health Survey (CHS) combined years 2010-2014. The main aims of this project were to 1) estimate and compare the prevalence of cardiovascular health factors among Guyanese, Haitian and Jamaican immigrants relative to U.S. born blacks, 2) assess the relationship between length of residence in the U.S. and CVH among the aforementioned AC immigrant groups and 3) examine the social determinants of CVH among the three AC immigrant subgroups.

The aim of the first study was to estimate the prevalence rates of cardiovascular risk factors (diabetes mellitus (DM), hyperlipidemia, hypertension, healthy body mass index (BMI)). Additionally, prevalence estimates were compared among Guyanese, Haitian and Jamaican immigrants relative to U.S. born blacks. The findings of this study showed an overall prevalence rate of $12.6 \%$ for diabetes among NHB. Both Guyanese (17.3\%) and Jamaican (15.9\%) immigrants had higher prevalence rates of DM compared to U.S. born blacks (11.7\%) and were 57\% and 42\% more likely to report having diabetes than U.S. born blacks. Hyperlipidemia and hypertension had an overall prevalence rates of $26.2 \%$ and $35.5 \%$ respectively among NHB. However for hyperlipidemia and hypertension there were no statistically significant differences in prevalence rates among the sub-groups. Overweight/obesity rates were 67.4\% overall for NHB in NYC. Guyanese and Jamaican immigrants were less likely to be overweight/obese compared to U.S. born blacks. Haitian immigrants had no significant differences in obesity/overweight prevalence rates from U.S. born blacks.

The second study (aim 2) assessed the relationship between length of residence in the U.S. (<10 years vs $\geq 10$ years) and CVH among Guyanese, Haitian and Jamaican NHB immigrants in NYC. For this study a 
CVH score categorized as ideal vs intermediate/poor $\mathrm{CVH}$ was used as the main outcome of interest rather than individual cardiovascular health risk factors. The analysis from this study revealed Guyanese and Haitian immigrants were more likely to report poor/intermediate health with greater length of residence in the U.S. However, for Jamaican immigrants length of residence was not associated with CVH in fully adjusted models.

The third study (aim 3) examined social determinants associated with CVH. Data limitations restricted analysis to education, employment, health insurance and healthcare access. The findings revealed that education and employment were associated with CVH among Jamaican immigrants only. Jamaican immigrants with lower levels of education (high school or less) and those who were unemployed/not in labor force were more likely to report intermediate/poor CVH. Unexpectedly, the results for insurance indicated being uninsured as a protective factor for all AC immigrant sub-groups although not statistically significant. For the other AC immigrant sub-groups in this sample, education, employment, health insurance and healthcare access were not significantly related to $\mathrm{CVH}$. A possible explanation for the lack of association was small sample sizes of participants from Guyana and Haiti.

\section{Contributions and Implications}

The overall findings from this dissertation project reveal that there is ethnic heterogeneity in CVH and associated risk factors among AC immigrants. For CVH factors Jamaican and Guyanese were more likely to have DM than U.S. born blacks. However, both the aforementioned sub-groups were less likely to be obese than U.S. born blacks. Haitian and Guyanese immigrants stood out from Jamaican immigrants has having intermediate/poor CVH with more years in the U.S. These findings suggests that country of birth may play a role in the immigrant health advantage previously identified among all AC immigrants [11, 18, 20]. Our findings show that it is therefore no longer correct to assume an overall health advantage among all AC immigrant sub-groups in comparison to U.S. born blacks. These findings also support other studies among other regional/ethnic groups that found a mixture of health advantages and disadvantages among immigrant groups usually examined together [83, 127]. 
Interpreted in the light of segmented assimilation theory, the results support the idea that social context and social capital of immigrants may explain diverging health outcomes. Acculturation (length of residence in the U.S.) was associated with intermediate/poor CVH among Guyanese and Haitian immigrants. Although length of residence does not represent a true measure of acculturation, it signifies that a prolonged exposure to the U.S. environment might contribute to adverse health outcomes [32]. The effects of acculturation (length of stay in the U.S.) on CVH may also vary among AC immigrant groups. As evidence by these findings, duration of stay in the U.S. had separate effects on AC immigrant subgroups possibly owing to their different social experiences prior to and after migration to the U.S.

Also, in keeping with the premise of segmented assimilation theory, social determinants such as education and employment were associated with CVH outcomes. As the U.S. becomes a more plural society, identifying socio-economic determinants that may contribute to health disparities among minority groups will become important. Policies addressing social factors such education and employment will be effective ways to address health disparities among AC immigrant groups. Unexpectedly, uninsured AC immigrants were less likely to have intermediate/poor CVH, however, these results were not significant. Possible explanations for this result may be attributed to the self-reported nature of the survey and it is also possible that the uninsured respondents are unaware of their cardiovascular health factors statuses.

\section{Study Strength and Limitations}

In addition, to the major contributions to the literature, a major strength of this project is the use of the NYC CHS. The CHS was able to provide disaggregated data by country of birth on the three immigrant groups of interest. Additionally, to my knowledge this project is the first to apply AHA cardiovascular health metrics among AC immigrant sub-groups. However, the findings should be interpreted in light of the following limitations. The cross-sectional nature of the data prevented any causal inferences or to examine temporal relationships. The health outcomes were self-reported, which may have resulted in underestimation of prevalence rates principally among undiagnosed respondents. Small sample sizes may have affected the precision of the estimates particularly among Guyanese and Haitian immigrants. Survey 
items used to determine cardiovascular health were not an exact representation of established AHA guidelines. The use of length of residence may not give an accurate representation of acculturation. Data limitations also prevented the exploration of other important social determinants of health among immigrants such as social support, post migration stress and perceived racism/discrimination.

\section{Future Research and Recommendations}

Future research among AC immigrants should include longitudinal studies examining the health of immigrants upon arrival in the U.S. and assessing their health outcomes overtime to obtain a more accurate picture of their health trajectories. As more AC immigrants migrate to the U.S., it would be beneficial to amplify national surveillance and data collection efforts of these groups in order to accurately estimate $\mathrm{CVH}$ outcomes. In addition to quantitative analysis, qualitative analysis is needed gain a deeper understanding of unique social issues that may contribute to adverse health outcomes among AC immigrants. It may also be beneficial to examine other social issues that are associated with the migration process or assimilating to a new environment.

Future research efforts should also consider other social determinants of health such as migratory stress, perceived racism/ discrimination which may have varying impact on immigrants from different country of origins. It may also be important to gain insights on the CV health outcomes different classes of AC immigrants such as undocumented immigrants or AC immigrants on employment or student visas. Acculturation is a multidimensional process involving several facets relating ethnic change [29]. Future studies should employ a more rounded measure of acculturation that more accurately captures the process. Lastly, this study should be replicated using nationally representative data sets or in other U.S. cities where AC immigrants are significantly represented. 


\section{References Chapters 1-3 \& 7}

1. Roth GA, Huffman MD, Moran AE, et al. Global and regional patterns in cardiovascular mortality from 1990 to 2013. Circulation, 2015. 132(17): p. 1667-78.

2. Benjamin EJ, Blaha MJ, Chiuve SE, et al. Heart Disease and Stroke Statistics-2017 Update: A Report From the American Heart Association. Circulation, 2017. 135(10): p. e146-e603.

3. Lloyd-Jones DM, Hong Y, Labarthe D, et al. Defining and setting national goals for cardiovascular health promotion and disease reduction: the American Heart Association's strategic Impact Goal through 2020 and beyond. Circulation, 2010. 121(4): p. 586-613.

4. Rastogi SJ, Hoeffel E, Drewery MP. The black Population 2010. 2010 Census Briefs. Washington, DC: US Department of Commerce, Economics and Statistics Administration. U.S. Census Bureau, 2010. Available at: https://www.census.gov/prod/cen2010/briefs/c2010br-06.pdf. Accessed October 30, 2017.

5. Shaw-Taylor Y, Tuch SA: The Other African Americans: Contemporary African and Caribbean Immigrants in the United States. Maryland: Rowman \& Littlefield; 2007.

6. Waters MC. Black Identities: West Indian Immigrant Dreams and American Realities. 2009: Harvard University Press.

7. Agyemang C, Bhopal R, and Bruijnzeels M. Negro, Black, Black African, African Caribbean, African American or what? Labelling African origin populations in the health arena in the 21st century. J Epidemiol Community Health, 2005. 59(12): p. 1014-8.

8. Williams DR, and Jackson JS. Race/ethnicity and the 2000 census: recommendations for African American and other black populations in the United States. Am J Public Health, 2000. 90(11): p. 1728-30.

9. Wafula EG, and Snipes SA. Barriers to health care access faced by black immigrants in the US: theoretical considerations and recommendations. J Immigr Minor Health, 2014. 16(4): p. 689-98.

10. Williams DR, Haile R, Gonzalez HM, Neighbors H, Baser R, Jackson JS. The mental health of Black Caribbean immigrants: results from the National Survey of American Life. Am J Public Health, 2007. 97(1): p. 52-9.

11. Read JG, Emerson MO, and Tarlov A. Implications of black immigrant health for U.S. racial disparities in health. J Immigr Health, 2005. 7(3): p. 205-12.

12. Archibald C. Cultural tailoring for an Afro-Caribbean community: A naturalisticapproach. Journal of cultural diversity. Journal of Cultural Diversity. 2011;18(4):114

13. Moss MC, and McDowell JR. Rural Vincentians' (Caribbean) beliefs about the usage of nonprescribable medicines for treating Type 2 diabetes. Diabet Med, 2005. 22(11): p. 1492-6.

14. Smith, CA. Living with sugar: influence of cultural beliefs on type 2 diabetes self-management of English-speaking Afro-Caribbean women. J Immigr Minor Health, 2012. 14(4): p. 640-7.

15. Gillespie-Johnson, M., HIV/AIDS prevention practices among recent-immigrant Jamaican women. Ethn Dis, 2008. 18(2 Suppl 2): p. S2-175-8.

16. Assari S: Race and ethnic differences in associations between cardiovascular diseases, anxiety and depression in the United States. International Hournal of Travel Medicine and Global Health, 2014. 2(2):p. 103-109.

17. González HM. and Tarraf W. Comorbid cardiovascular disease and major depression among ethnic and racial groups in the United States. Int Psychogeriatr, 2013. 25(5): p. 833-41.

18. Griffith DM. et al., Ethnicity, nativity, and the health of American Blacks. J Health Care Poor Underserved, 2011. 22(1): p. 142-56.

19. Keane F, Tappen RM, Williams CL, Rosselli M. Comparison of African American and AfroCaribbean older adults' self-reported health status, function, and substance use. Journal of Black Psychology, 2009. 35(1): p. 44-62. 
20. Fang J, Madhavan S, Alderman MH. The association between birthplace and mortality from cardiovascular causes among black and white residents of New York City. N Engl J Med, 1996. 335(21): p. 1545-51.

21. Thomas KA. A demographic profile of black Caribbean Immigrants in the United States. Migration Policy Institute; 2012. Available at: https://www.migrationpolicy.org/research/CBIdemographic-profile-black-caribbean-immigrants. Accessed 27 Oct 2017.

22. Hamilton TG, Hummer RA. Immigration and the health of U.S. black adults: does country of origin matter? Soc Sci Med, 2011. 73(10): p. 1551-60.

23. Davis EE, Huffman FG. Differences in coronary heart disease risk markers among apparently healthy individuals of African ancestry. J Natl Med Assoc, 2007. 99(6): p. 658-64.

24. Carlisle SK. Nativity differences in chronic health conditions between nationally representative samples of Asian American, Latino American, and Afro-Caribbean American respondents. J Immigr Minor Health, 2012. 14(6): p. 903-11

25. Dagadu H, Christie-Mizell AC. Heart trouble and racial group identity:Exploring ethnic heterogeneity among black Americans. Race and Social Problems, 2014. 6(2): p. 143-160.

26. Ferguson TS, Francis DK, Tulloch-Reid MK, Younger NO, McFarlane SR, Wilks RJ. An update on the burden of cardiovascular disease risk factors in Jamaica: findings from the Jamaica Health and Lifestyle Survey 2007-2008. West Indian Med J, 2011. 60(4): p. 422-8.

27. Institute for Health Metrics and Evaluation. Country Profiles: Guyana. Retrieved from http://www.healthdata.org/guyana. Accessed January 16, 2018.

28. Berry JW, Acculturation and adaptation: health consequences of culture contact among circumpolar peoples. Arctic Med Res, 1990. 49(3): p. 142-50.

29. Berry JW., Acculturation and adaptation in a new society. International Migration, 1992. 30(1): p. 69-85

30. Commodore-Mensah Y, Ukonu N, Obisesan O, et al. The association between acculturation and cardiovascular disease risk in Ghanaian and Nigerian-born African immigrants in the United States: The Afro-Cardiac Study. J Immigr Minor Health, 2017.

31. Bharmal N, Kaplan RM, Shapiro MF et al. The association of duration of residence in the United States with cardiovascular disease risk factors among South Asian immigrants. J Immigr Minor Health. 2015; 17(3): 781-90.

32. Kaplan MS, Huguet N, Newsom JT, McFarland BH. The association between length of residence and obesity among Hispanic immigrants. Am J Prev Med. 2004;27(4):323-326.

33. Ro, A. The longer you stay, the worse your health? A critical review of the negative acculturation theory among Asian immigrants. Int J Environ Res Public Health, 2014. 11(8): p. 8038-57.

34. Barcenas CH, Wilkinson AV, Strom SS, et al. Birthplace, years of residence in the United States, and obesity among Mexican-American adults. Obesity (Silver Spring). 2007;15(4):1043-1052.

35. Koya DL, Egede LE. Association between length of residence and cardiovascular disease risk factors among an ethnically diverse group of United States immigrants. J Gen Intern Med. 2007;22(6):841-846.

36. Abraído-Lanza AF, Echeverría SE, and Flórez KR. Latino Immigrants, acculturation, and health: promising new directions in research. Annu Rev Public Health, 2016. 37: p. 219-36.

37. Commodore-Mensah Y, Ukonu N, Cooper LA, Agyemang C, Himmelfarb CD. The association between acculturation and cardiovascular disease risk in Ghanaian and Nigerian-born African immigrants in the United States: The Afro-Cardiac Study. J Immigr Minor Health, 2017.

38. Agbemenu K. Acculturation and health behaviors of African immigrants living in the United States: an integrative review. ABNF Journal, 2016. 27(3).

39. Abraído-Lanza, AF, Echeverría SE, and Flórez KR, Latino Immigrants, Acculturation, and Health: Promising New Directions in Research. Annu Rev Public Health, 2016. 37: p. 219-36.

40. Wong SS, Dixon LB, Gilbride JA, Kwan TW, Stein RA. Measures of acculturation are associated with cardiovascular disease risk factors, dietary intakes, and physical activity in older Chinese Americans in New York City. J Immigr Minor Health, 2013. 15(3): p. 560-8. 
41. Kershaw KN, Giacinto RE, Gonzalez F et al. Relationships of nativity and length of residence in the U.S. with favorable cardiovascular health among Hispanics/Latinos: The Hispanic Community Health Study/Study of Latinos (HCHS/SOL). Prev Med, 2016. 89: p. 84-9.

42. Havranek EP, Mahasin MS, Barr DA, et al: Social determinants of risk and outcomes for cardiovascular disease: a scientific statement from the American Heart Association. Circulation, 2015. 132(9): p. 873-98

43. Jasso G. Massey DS. Rosenzweig MR. Smith JP. Immigration, health, and New York City: early results based on the US New Immigrant Cohort of 2003. FRBNY Economic Policy Review. 2005 Dec 1;11(2):127-51

44. Mendis S, Puska P, Norrving B. Global atlas on cardiovascular disease prevention and control. World Health Organization; 2011.

45. Association Heart Association \& American Stroke. Cardiovascular Disease: a costly burden for America. Projections through 2035. Available at http://www.heart.org/idc/groups/heartpublic/@wcm/@adv/documents/downloadable/ucm_491543.pdf. Accessed November 11, 2017.

46. Office of Minority Health. Profile: black/African Amerians. https://www.minorityhealth.hhs.gov/omh/browse.aspx?lvl=3\&lvlid=61 2017. Accessed November 3, 2017.

47. American Diabetes Association. Diagnosis and classification of diabetes mellitus. Diabetes Care. 2014;37 Suppl 1:S81-90.

48. Centers of Disease Control and Prevention. National diabetes statistics report: estimates of diabetes and its burden in the United States, 2017. Atlanta, GA: US Department of Health and Human Services. Available at https://www.cdc.gov/diabetes/pdfs/data/statistics/national-diabetesstatistics-report.pdf. Accessed November 24, 2017.

49. American Diabetes Association. Economic costs of diabetes in the US in 2012. Diabetes care. 2013;36(4):1033-1046.

50. Choi BG, Vilahur G, Yadegar D,Viles-Gonzalez JF, Badimon JJ. The role of high-density lipoprotein cholesterol in the prevention and possible treatment of cardiovascular diseases. Curr Mol Med. 2006;6(5):571-587.

51. Rao G, Powell-Wiley TM, Ancheta I, et al. Identification of obesity and cardiovascular risk in ethnically and racially diverse populations: a scientific statement from the American Heart Association. Circulation. 2015;132(5):457-472.

52. Must A, Spadano J, Coakley EH, Field AE, Colditz G, Dietz WH. The disease burden associated with overweight and obesity. JAMA. 1999;282(16):1523-1529.

53. Ogden CL, Carroll MD, Fryar CD, Flegal KM. Prevalence of obesity among adults and aouth: United States, 2011-2014. NCHS Data Brief. 2015(219):1-8.

54. Naish J. Medical Sciences E-Book. 2nd ed. London UK: Saunders Elsevier; 2014.

55. National Institute of Health. Data from Landmark NIH blood pressure study supports important part of new AHA/ACC hypertension guidelines., 2017. Available at https://www.nih.gov/newsevents/news-releases/data-landmark-nih-blood-pressure-study-supports-important-part-new-ahaacc-hypertension-guidelines. Accessed November 27, 2017.

56. National Center for Health Statistics. Health, United States, 2016: with chartbook on long-term trends in health. 2017: 57. Available at https://www.cdc.gov/nchs/data/hus/hus16.pdf. Accessed November 17, 2017.

57. Kochanek KD, Murphy SL, Xu J, Tejada-Vera B. Deaths: final data for 2014. National vital statistics reports: from the Centers for Disease Control and Prevention, National Center for Health Statistics, National Vital Statistics System,6(4), 1-122.2016.

58. Mozaffarian D, Benjamin EJ, Go AS, et al. Heart disease and stroke statistics--2015 update: a report from the American Heart Association. Circulation. 2015;131(4):e29-322.

59. Yoon SS, Carroll MD, Fryar CD. Hypertension prevalence and control among adults: United States, 2011-2014. NCHS Data Brief. 2015(220):1-8. 
60. World health Organization. Health Topics: Diet. http://www.who.int/topics/diet/en/. Published 2017. Accessed November 16, 2017.

61. Rehm CD, Peñalvo JL, Afshin A, Mozaffarian D. Dietary intake among US adults, 1999-2012. JAMA. 2016;315(23):2542-2553.

62. Bingham BA, Duong MT, Ricks M, et al. The association between stress measured by allostatic load score and physiologic dysregulation in African immigrants: the Africans in America Study. Front Public Health. 2016;4:265.

63. Jha P, Ramasundarahettige C, Landsman V, et al. 21st-century hazards of smoking and benefits of cessation in the United States. N Engl J Med. 2013;368(4):341-350..

64. Murray CJ, Atkinson C, Bhalla K, et al. The state of US health, 1990-2010: burden of diseases, injuries, and risk factors. JAMA. 2013;310(6):591-608.

65. US Department of Health and Human Services. The health consequences of smoking - 50 years of progress: a report of the Surgeon General. Atlanta, GA: US Department of Health and Human Services, CDC; 2014. Available at: http://www.surgeongeneral.gov/library/reports/50-years-ofprogress/full-report.pdf . Accessed November 3, 2017.

66. Kent M. Immigration and America's black population. Washington, DC: Population Reference Bureau; 2007. Available at: http://www.prb.org/pdf07/62.4immigration.pdf. Accessed November 25, 2017.

67. Barry H. A Concise History of the Caribbean. Cambridge University Press; 2010.

68. Fouron G. Haitian Immigrants in the US: Migration and Identity. In Realizing the Dream. Selected Conference Proceedings of the Annual Meeting of the New York State Teachers of English as a Second Language, Buffalo, New York, November 6-8, 1987. Available at https://files.eric.ed.gov/fulltext/ED314952.pdf. Accessed November 15, 2017.

69. Remy GM. Haitian immigrants and African-American relations: ethnic dilemmas in a raciallystratified society. Trotter Reveiw. 1996;10(1):5. Available at: http://scholarworks.umb.edu/trotter_review/vol10/iss1/5. Accessed November 19, 2017.

70. Chiswick BR. Are immigrants favorably self-selected? The American economic Reveiw. 1999;89(2):181-185.

71. Kennedy S, Kidd MP, McDonald JT, Biddle N. The healthy immigrant effect: patterns and evidence from Four Countries. International Migration \& Integration. 2014;16(2):317-332.

72. United States Census Bureau. American Factfinder. American Community Survey 1 Year Estimates 2016. Available at:

https://factfinder.census.gov/faces/tableservices/jsf/pages/productview.xhtml?fpt=table. Accessed November 24, 2017.

73. The City of New York Department of Youth and Community Development. 2017 Community needs assessment. Retrieved from https://www1.nyc.gov/assets/dycd/downloads/pdf/CNA/CNA_Report-4-19-17.pdf. Accessed June 18, 2018

74. New York Academy of Medicine. New York City health provider partnership Brooklyn needs assessment 2014. Available at https://www.health.ny.gov/health_care/medicaid/redesign/dsrip/pps applications/docs/maimonid es medical center/3.8 maimonides cna.pdf. Accessed June 19, 2018

75. Berry, J.W., Immigration and Acculturation and Adaptation. Applied Psychology, 1997. 46(1): p. 5-34.

76. Berry, J.W., Contexts of Acculturation.” In The Cambridge Handbook of Acculturation Psychology. 2006, New York, NY: Cambridge University Press. 27-42.

77. Commodore-Mensah Y, Ukonu N, Obisesan O, et al. Length of residence in the United States is associated with a higher prevalence of cardiometabolic risk factors in immigrants: A contemporary analysis of the National Health Interview Survey. J Am Heart Assoc. 2016;5(11). 
78. Hunter-Adams J, Cochran J, Laird L, Paasche-Orlow MK, Geltman PL. Acculturation and a potential relationship with oral health outcomes among Somali refugees in Massachusetts. Journal of Immigrant and Minority Health. 2017:1-9.

79. Thomson MD, Hoffman-Goetz L. Defining and measuring acculturation: a systematic review of public health studies with Hispanic populations in the United States. Soc Sci Med. 2009;69(7):983-991.

80. Celenk O, Van de Vijver FJ. Assessment of acculturation: Issues and overview of measures. Online Readings in Psychology and Culture. 2016;8(1):10.

81. Bennett GG, Wolin KY, Okechukwu CA, et al. Nativity and cigarette smoking among lower income blacks: results from the Healthy Directions Study. J Immigr Minor Health. 2008;10(4):305-311.

82. Oza-Frank R, Narayan KM. Overweight and diabetes prevalence among US immigrants. Am J Public Health. 2010;100(4):661-668.

83. Nguyen HH, Smith C, Reynolds GL, Freshman B. The effect of acculturation on obesity among foreign-born Asians residing in the United States. J Immigr Minor Health. 2015;17(2):389-399.

84. Marmot M, Closing the health gap in a generation: the work of the Commission on Social Determinants of Health and its recommendations. Glob Health Promot. 2009; Suppl 1: p. 23-7.

85. Krieger N, William DR, Moss NE. Measuring social class in US public health research: concepts, methodologies, and guidelines. Annu Rev Public Health. 1997; 18:341-78.

86. Galobardes B, Shaw M, Lawlor DA, Lynch JW, Davey Smith G. Indicators of socioeconomic position (part 1) J Epidemiol Community Health. 2006; 60 (1): 7-12. doi: 10.1136/jech. 2004.023531.

87. Pollitt RA, Rose KM, and Kaufman JS, Evaluating the evidence for models of life course socioeconomic factors and cardiovascular outcomes: a systematic review. BMC Public Health. 2005; 5: 7.

88. Winkleby MA, Jatulis DE, Frank E et al. Socioeconomic status and health: how education, income, and occupation contribute to risk factors for cardiovascular disease. Am J Public Health. 1992; 82(6):816-20.

89. Leigh JP and Du J. Hypertension and occupation among seniors. J Occup Environ Med, 2009. 51(6): p. 661-71.

90. Mensah GA. State of disparities in cardiovascular health in the United States. Circulation, 2005. 111(10): p. 1233-41.

91. Davila, EP, Kuklina EV, Valderama AL. Prevalence, management, and control of hypertension among US workers: does occupation matter? J Occup Environ Med, 2012. 54(9): p. 1150-6.

92. Lynch J, Kaplan GA, Salonen R, Salonen JT. Socioeconomic status and progression of carotid atherosclerosis: prospective evidence from the Kuopio Ischemic Heart Disease Risk Factor Study. Arteriosclerosis, thrombosis, and vascular biology. 1997 Mar 1;17(3):513-9. 92. Marmot, M.G., Socio-economic factors in cardiovascular disease. J Hypertens Suppl, 1996. 14(5): p. S201-5.

93. Marmot, M.G., Socio-economic factors in cardiovascular disease. J Hypertens Suppl, 1996. 14(5): p. S201-5.

94. Center for Immigration Studies. Immigrants in the United States: A Profile of america's Foreign Born Population using 2014and 2015 Census Bureau data. Available at https://cis.org/Report/Immigrants-United-States. Accessed June 14, 2018.

95. Hamilton, TG. Do country-of origin characteristics help explain variation in health among black immigrants in the United States. Social Science Quarterly, 2014. 95(3): p. 817-834.

96. Sangaramoorthy, T. and Guevara EM. Immigrant Health in Rural Maryland: A Qualitative Study of major barriers to health care access. J Immigr Minor Health, 2017. 19(4): p. 939-946.

97. Millman M, editor. Access to health care in America. National Academies Press; 1993.

98. National Healthcare Disparities Report. Access to Healthcare. 2011: Rockville, MD. Retrieved from https://www.ahrq.gov/research/findings/nhqrdr/index.html. Accessed April 23, 2018. 
99. Brooks, E.L., et al., Health insurance and cardiovascular disease risk factors. Am J Med, 2010. 123(8): p. 741-7.

100. Wilper AP, Woolhandler S, Lasser KE, McCormick D, Bor DH, Himmelstein DU. A national study of chronic disease prevalence and access to care in uninsured U.S. adults. Ann Intern Med, 2008. 149(3): p. 170-6.

101. Harris MI. Racial and ethnic differences in health care access and health outcomes for adults with type 2 diabetes. Diabetes Care, 2001. 24(3): p. 454-9.

102. Ku L. and Matani S. Left out: immigrants' access to health care and insurance. Health Aff (Millwood), 2001. 20(1): p. 247-56.

103. Francois F, Elysée G, Shah S, Gany F. Colon cancer knowledge and attitudes in an immigrant Haitian community. J Immigr Minor Health, 2009. 11(4): p. 319-25.

104. Alcalá HE, Albert SL, Roby DH, Beckerman J, Champagne P, Brookmeyer R, Prelip ML, Glik DC, Inkelas M, Garcia RE, Ortega AN. Access to care and cardiovascular disease prevention: a cross-sectional study in 2 Latino communities. Medicine. 2015 Aug;94(34)

105. Antecol H, Bedard K. Unhealthy assimilation: why do immigrants converge to American health status levels?. Demography. 2006 May 1;43(2):337-60.

106. Constant AF, García-Muñoz T, Neuman S, Neuman T. A "healthy immigrant effect” or a "sick immigrant effect”? Selection and policies matter. Eur J Health Econ. 2018 Jan 1;19(1):103-21.

107. Abraido-Lanza AF, Dohrenwend BP, Ng-Mak DS, Turner JB. The Latino mortality paradox: a test of the" salmon bias" and healthy migrant hypotheses. Am J Public Health, 1999. 89(10): p. 1543-8.

108. Palloni, A. and Arias E. Paradox lost: explaining the Hispanic adult mortality advantage. Demography, 2004. 41(3): p. 385-415.

109. Landale NS and RS. Oropesa, Migration, social support and perinatal health: an origindestination analysis of Puerto Rican women. J Health Soc Behav, 2001. 42(2): p. 166-83.

110. Akresh IR and Frank R. Health selection among new immigrants. Am J Public Health, 2008. 98(11): p. 2058-64.

111. Jass G. and Massey DS. Immigrant Health: selectivity and acculturation, I.f.F.S. (IFS), Editor. 2004.

112. Choi SH. Testing healthy immigrant effects among late life immigrants in the United States: using multiple indicators. J Aging Health, 2012. 24(3): p. 475-506.

113. O'Connor MY, Thoreson CK, Ricks M, Courville AB, Thomas F, Yao J, Katzmarzyk PT, Sumner AE. Worse cardiometabolic health in African immigrant men than African American men: reconsideration of the healthy immigrant effect. Metab Syndr Relat Disord, 2014. 12(6): p. 34753.

114. Portes A. and Zhou M. The New Second Generation: Segmented Assimilation and its Variants. The Annals of the American Academy of Political and Social Science, 1993. 530(1): p. 74-96.

115. Zhou M. Segmented Assimilation: Issues, Controversies, and Recent Research on the New Second Generation. The International Migration Review, 1997. 31(4): p. 975-1008.

116. James FJ. Romine JA, and Zwanzig PE. The Effects of Immigration on Urban Communities. Cityscape, 1998. 3(4): p. 171-192.

117. Osypuk TL, Galea S, McArdle N, Acevedo-Garcia D. Quantifying separate and unequal: racialethnic distributions of neighborhood poverty in metropolitan America. Urban Affairs Review. 2009 Sep;45(1):25-65.Urban Aff Rev Thousand Oaks Calif, 2009. 45(1): p. 25-65.

118. Krieger N. Racial and gender discrimination: risk factors for high blood pressure? Soc Sci Med, 1990. 30(12): p. 1273-81.

119. Mustillo S, Krieger N, Gunderson EP, Sidney S, McCreath H, Kiefe CI. Self-reported experiences of racial discrimination and Black-White differences in preterm and low-birthweight deliveries: the CARDIA Study.Am J Public Health, 2004. 94(12): p. 2125-31. 
120. Castro FG, Marsiglia FF, Kulis S, Kellison JG. Lifetime segmented assimilation trajectories and health outcomes in Latino and other community residents. Am J Public Health, 2010. 100(4): p. 669-76.

121. New York City Department of Health and Mental Hygiene. Community Health Survey (CHS) 2017. Available at: https://www1.nyc.gov/site/doh/data/data-sets/community-health-survey.page. Accessed November 13, 2017.

122. Norton J, Sanderson M, Gupta L, et al. MethodologyUpdates to the New York City Community Health Survey. 2012. Accessed at: https://www1.nyc.gov/assets/doh/downloads/pdf/epi/epiresearch-chsmethods.pdf. Accessed November 10, 2017.

123. Pilkerton CS, Singh SS, Bias TK, Frisbee SJ. Changes in Cardiovascular Health in the United States, 2003-2011. J Am Heart Assoc. 2015; 4(9): p. e001650.

124. Joseph JJ, Echouffo-Tcheugui JB, Carnethon MR. The association of ideal cardiovascular health with incident type 2 diabetes mellitus: the Multi-Ethnic Study of Atherosclerosis. Diabetologia. 2016; 59(9): 1893-903.

125. Yang Q, Cogswell ME, Flanders WD et al. Trends in cardiovascular health metrics and associations with all-cause and CVD mortality among US adults. JAMA. 2012. 307(12):1273-83.

126. Kandula NR, Diez-Roux AV, Chan C et al. Association of acculturation levels and prevalence of diabetes in the multi-ethnic study of atherosclerosis (MESA). Diabetes Care. 2008; 31(8): p. 1621-8.

127. Zsembik, BA, and Fennell D. Ethnic variation in health and the determinants of health among Latinos. Soc Sci Med, 2005. 61(1): p. 53-63. 